\title{
New Pyridazinium-based Ionic Liquids: An Eco-friendly Ultrasound-assisted Synthesis, Characterization and Biological Activity
}

\author{
Mouslim Messali, ${ }^{\mathrm{a}, \star}$, Mohammed N. Almtiri ${ }^{\mathrm{a}}$, Bousskri Abderrahman ${ }^{\mathrm{b}}$, Rachid Salghi ${ }^{\mathrm{b}}$, \\ Mohamed R. Aouad ${ }^{\mathrm{a}, \mathrm{c}}$, Solhe F. Alshahateet ${ }^{\mathrm{d}}$ and Adeeb A-S. Ali ${ }^{\mathrm{a}}$ \\ ${ }^{a}$ Department of Chemistry, Taibah University, 30002, Al-Madina Al-Mounawara, Saudi Arabia. \\ ${ }^{b}$ Laboratory of Environmental Engineering and Biotechnology, ENSA, Ibn Zohr University, Box 1136, 80000 Agadir, Morocco. \\ ${ }^{c}$ Department of Chemistry, (LCECM) USTO-MB, University of Sciences and Technology Mohamed Boudiaf, BP 1505 Oran, El M'nouar, Algeria. \\ ${ }^{d}$ Department of Chemistry, Mutah University, Mutah 61710, Karak-Jordan.
}

Received 21 May 2015, revised 25 June 2015, accepted 26 June 2015.

\begin{abstract}
An eco-friendly ultrasound-assisted procedure was developed for the preparation of a series of novel pyridazinium ionic liquids (ILs) 1-8. The structures of the novel ILs were established based on their FT-IR, ${ }^{1} \mathrm{H},{ }^{13} \mathrm{C}$ NMR and mass spectra. Furthermore, the antimicrobial and anticancer activities of ILs 1-8 have been also investigated. The results of these screening experiments revealed that the ILs exhibited good to moderate antibacterial activity, such as IL 7, compared with standard drugs. Some of the newly synthesized ILs were also tested in vitro against human hepatocellular carcinoma (HEPG2), human breast adenocarcinoma (MCF7) and human colon carcinoma (HCT116) cell lines. Among the synthesized ILs, IL 8 was found to exhibit promising antiproliferative effects and produced the lowest $\mathrm{IC}_{50}$ values among the tested ILs.
\end{abstract}

KEYWORDS

Eco-friendly procedure, ionic liquid, ultrasound irradiation, antibacterial, antifungal and anticancer activity.

\section{Introduction}

The level of research interest directed towards ionic liquids (ILs) has grown considerably during the past two decades because of their many outstanding properties, including their negligible vapour pressure, great thermal stability, nonflammability, good electrical conductivity, moderate viscosity and excellent solubility towards organic and inorganic compounds. ${ }^{1-2}$ Based on their attractive properties, ILs were extensively employed as an alternative green solvent to the common organic solvents. ${ }^{3}$ Furthermore, ILs have been used in a broad range of applications in a variety of different fields, including the electrodeposition of metals ${ }^{4}$ and the development of corrosion inhibitors, ${ }^{5-7}$ as well as numerous applications in polymer science and catalysis. ${ }^{8-9}$

On the basis of these findings, a series of novel functionalized pyridazinium-based ILs 1-7 is communicated using an efficient green ultrasound-assisted reaction. Our group recently reported the synthesis of another interesting IL known as 1-(2-(4-nitrophenyl)-2-oxoethyl)pyridazinium bromide, which will be referred to hereafter as IL $8 .^{7}$ The antimicrobial and antitumor activities of ILs 1-8 were evaluated in the current study and the results of these experiments have been discussed in detail.

\section{Results and Discussion}

\subsection{Chemistry}

Numerous reports have recently been published pertaining to the use of ultrasonic irradiation to promote a variety of organic transformations. ${ }^{10-11}$ With this in mind, ultrasonic irradiation was used in the current study as an eco-friendly approach for

* To whom correspondence should be addressed. E-mail: mouslim@mail.be the successful construction of new pyridazinium-based ILs 1-8. Briefly, a solution of pyridazine was treated with several different alkyl halides under ultrasonic irradiation in a closed system (Scheme 1).

Conventional $\mathrm{N}$-alkylation conditions generally require long reaction times and provide moderate to low yields of the desired products. However, the use of ultrasound technology can lead to a significant decrease in the reaction time $(5 \mathrm{~h})$ required for an $\mathrm{N}$-alkylation reaction compared with conventional conditions. ${ }^{12}$ The yields obtained in the current study for the synthesis of ILs 1-8 under ultrasonic irradiation are shown in Table 1.

The newly synthesized ILs 1-8 were characterized by ${ }^{1} \mathrm{H}$ NMR, ${ }^{13} \mathrm{C}$ NMR, FT-IR and LCMS analyses. The characterization of IL 2 was discussed in detail as the most representative compound of this new family of ILs.

The $N$-alkylation of pyridazine with methyl 6-bromohexanoate afforded 2, which result in the appearance of a singlet at $3.59 \mathrm{ppm}$ due to the methyl protons of $\mathrm{OCH}_{3}$ group. The five methylene protons of the IL2 appeared respectively as a triplet at $4.88 \mathrm{ppm}$ for $\mathrm{NCH}_{2} \mathrm{CH}_{2}$, a triplet at $2.32 \mathrm{ppm}$ for $\mathrm{COCH}_{2} \mathrm{CH}_{2}$, a quintet at $2.03 \mathrm{ppm}$ for $\mathrm{COCH}_{2} \mathrm{CH}_{2}$, a sextet at $1.58 \mathrm{ppm}$ for $\mathrm{CH}_{2} \mathrm{CH}_{2} \mathrm{CH}_{2}$ and as a quintet at 2.03 for $\mathrm{NCH}_{2} \mathrm{CH}_{2}$. The ${ }^{1} \mathrm{H}$ NMR spectrum for 2 displays also two type of signals related to the pyridazinium protons. Two doublets at 9.70 and $10.16 \mathrm{ppm}$ represent $\mathrm{CHN}=\mathrm{NCH}$ and two doublets of doublet at 8.69 and 8.80 originate from $\mathrm{NCHCHCHCHN}$.

The ${ }^{13} \mathrm{C}$ NMR spectra of ILs 2 contained signal is consistent with the presence of a carbonyl group (O) at $173.2 \mathrm{ppm}$. The signals of the five $\mathrm{CH}_{2}$ groups and $\mathrm{CH}_{3}$ group appeared respectively at $64.2 \mathrm{ppm}$ for $\left(\mathrm{NCH}_{2}\right), 51.2 \mathrm{ppm}$ for $\left(\mathrm{OCH}_{3}\right), 32.9 \mathrm{ppm}$ for $\left(\mathrm{CO} \underline{\mathrm{CH}_{2}}\right)$, and 23.7, 24.7, 29.0 ppm for $\underline{\mathrm{C}} \mathrm{H}_{2} \mathrm{CH}_{2} \mathrm{CH}_{2}$. The ${ }^{13} \mathrm{C}$ NMR 


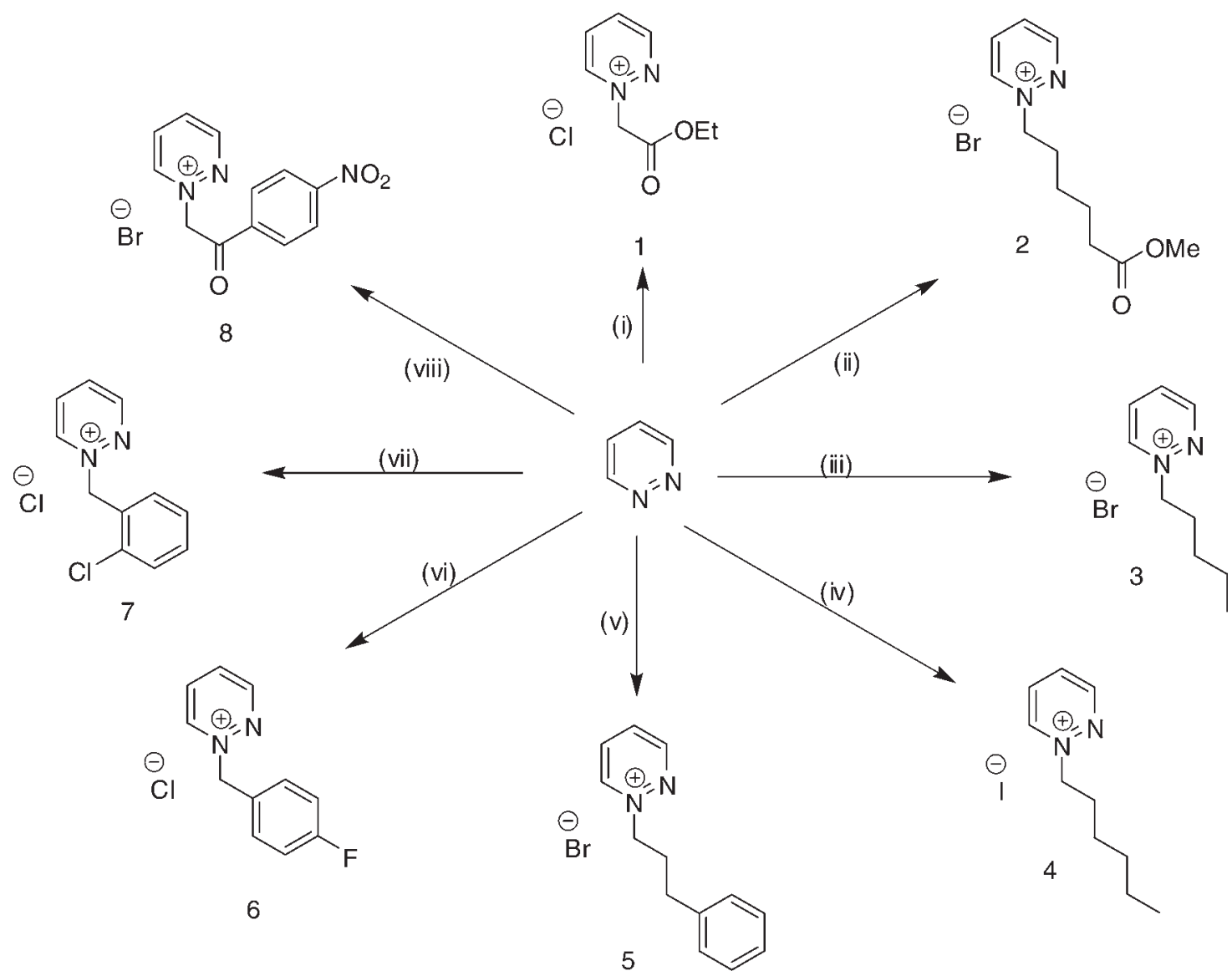

Scheme 1

$\mathrm{N}$-alkylation of pyridazine under ultrasonic irradiation (US) conditions. (i) $\mathrm{RX} /$ toluene, $70{ }^{\circ} \mathrm{C}, 5 \mathrm{~h}$. (i) $\mathrm{R}=-\mathrm{CH}_{2} \mathrm{CO}_{2} \mathrm{Et}$ for 1 ; (ii) $-\left(\mathrm{CH}_{2}\right)_{5} \mathrm{CO}_{2} \mathrm{Me}$ for 2; (iii) $-\left(\mathrm{CH}_{2}\right)_{4} \mathrm{CH}_{3}$ for 3; (iv) $-\left(\mathrm{CH}_{2}\right)_{5} \mathrm{CH}_{3}$ for 4; (v) $-\left(\mathrm{CH}_{2}\right)_{3} \mathrm{Ph}$ for 5; (vi) $4-\mathrm{FC}_{6} \mathrm{H}_{4} \mathrm{CH}_{2}-$ for 6; (vii) $2-\mathrm{ClC}_{6} \mathrm{H}_{4} \mathrm{CH}_{2}-$ for 7 ; (viii) $4-\mathrm{NO}_{2} \mathrm{C}_{6} \mathrm{H}_{4} \mathrm{CH}_{2}-$ for 8; $\mathrm{X}=\mathrm{Cl}, \mathrm{Br}$, I.

Table 1 Synthesis of pyridazinium-based ILs 18 under ultrasonic irradiation conditions.

\begin{tabular}{clc}
\hline Ionic liquid & $\mathrm{RX}$ & Yield $/ \%$ \\
\hline $\mathbf{1}$ & $\mathrm{EtO}_{2} \mathrm{C}\left(\mathrm{CH}_{2}\right) \mathrm{Cl}$ & 84 \\
$\mathbf{2}$ & $\mathrm{MeO}_{2} \mathrm{C}\left(\mathrm{CH}_{2}\right)_{5} \mathrm{Br}$ & 86 \\
$\mathbf{3}$ & $\mathrm{CH}_{3}\left(\mathrm{CH}_{2}\right)_{4} \mathrm{Br}$ & 89 \\
$\mathbf{4}$ & $\mathrm{CH}_{3}\left(\mathrm{CH}_{2}\right)_{5} \mathrm{I}$ & 87 \\
$\mathbf{5}$ & $\mathrm{Ph}^{\mathrm{I}}\left(\mathrm{CH}_{2}\right)_{3} \mathrm{Br}$ & 87 \\
$\mathbf{6}$ & $4-\mathrm{FC}_{6} \mathrm{H}_{4} \mathrm{CH}_{2} \mathrm{Cl}$ & 88 \\
7 & $2-\mathrm{ClC}_{6} \mathrm{H}_{4} \mathrm{CH}_{2} \mathrm{Cl}$ & 89 \\
$\mathbf{8}$ & $4-\mathrm{NO}_{2} \mathrm{C}_{6} \mathrm{H}_{4} \mathrm{CH}_{2} \mathrm{Br}$ & 80 \\
\hline
\end{tabular}

a US: time $5 \mathrm{~h}$, temperature $70^{\circ} \mathrm{C}$.

spectra also displayed the signals of the four tertiary carbons which appeared, respectively, at 150.0 and $154.4 \mathrm{ppm}$ for the $\underline{\mathrm{C}} \mathrm{HN}=\mathrm{N} \underline{\mathrm{CH}}, 136.0$ and $136.5 \mathrm{ppm}$ for the NCH$\underline{\mathrm{CH}} \underline{\mathrm{C} H C H N}$ groups.

The structure of IL 2 was also confirmed by the FT-IR spectra in which an absorption band at $1731 \mathrm{~cm}^{-1}$ indicated clearly the presence of a carbonyl group $(\mathrm{C}=\mathrm{O})$ belonging to an ester. And finally, LCMS spectra of ILs 2 contained a peak at 209.3 ppm related the desired mass ions $[\mathrm{M}-\mathrm{Br}]^{+}$.

Generally, the ${ }^{1} \mathrm{H}$ NMR spectra of ILs $\mathbf{1}$ and 3-8 all contained signals in the range of 8.4-10.0 ppm, which were attributed to the pyridazinium protons. The phenyl protons of the pendent aromatic rings in ILs 5-8 were observed at 7.3-8.1 ppm. The characteristic ethyl ester protons of IL 1 appeared as a triplet and quartet at 1.25 and $4.25 \mathrm{ppm}$, respectively.
The ${ }^{13} \mathrm{C}$ NMR spectra of ILs 1 and $\mathbf{8}$ contained signals consistent with the presence of a carbonyl group at $\delta_{\mathrm{C}} 165.7$ and $189.7 \mathrm{ppm}$, respectively. The ${ }^{13} \mathrm{C}$ NMR spectra of ILs $\mathbf{1}$ and $\mathbf{3}-\mathbf{8}$ all contained signals corresponding to aromatic carbons, including those of the pyridazinium ring, in the range of $\delta_{\mathrm{C}} 116-162 \mathrm{ppm}$. Furthermore, the ${ }^{13} \mathrm{C}$ NMR spectra of ILs $\mathbf{1}$ and 3-8 contained carbon signals corresponding to $\mathrm{CH}_{2}$ and $\mathrm{CH}_{3}$ groups with the usual chemical shifts.

The success of this new strategy for the $N$-alkylation of pyridazine was also confirmed by the FT-IR spectra of ILs 1 and 3-8. The FT-IR spectra of IL 1 contained an absorption band at $1730 \mathrm{~cm}^{-1}$, which indicated the presence of a carbonyl group $(\mathrm{C}=\mathrm{O})$ belonging to an ester. Furthermore, the FT-IR spectrum of IL 8 contained a peak at $1637 \mathrm{~cm}^{-1}$, which was consistent with the presence of a carbonyl group $(\mathrm{C}=\mathrm{O})$ belonging to a ketone. Finally, the LCMS spectra of ILs 1 and 3-8 contained peaks consistent with the desired mass ions $[\mathrm{M}-\mathrm{X}]^{+}$.

\subsection{Antimicrobial Properties}

Several recent reports showed that ILs possess promising biological activities. ${ }^{13-15}$ Encouraged by these results, we proceeded to evaluate the antimicrobial activities of ILs 1-8 against four strains of bacteria, including two Gram-positive and two Gram-negative strains, and four strains of fungi.

\subsubsection{Antifungal Properties}

In recent years, extensive research appeared in literature regarding the design of new families of antifungal agents presumably due to the increasing resistance of fungi towards 
existing antifungal agents. The antifungal activities of ILs 1-8 were screened in vitro against Aspergillus fumigatus, Penicillium italicum, Candida albicans and Geotrichum candidum. The antifungal activities were measured using the agar diffusion method with Sabouraud's agar medium. The results of these experiments are summarized in Table 2 and represented graphically in Fig. 1.

As shown in Table 2, the zones of inhibition fluctuated from $21.3 \mathrm{~mm}$ for IL 7 to $13.1 \mathrm{~mm}$ for IL 3, and were therefore comparable to those observed of the antibiotic Amphotericin B, which was used as a positive control.

\subsubsection{Antibacterial Properties}

The antibacterial activities of ILs 1-8 were tested in vitro against two Gram-positive (Staphylococcus aureus and Bacillus subtilis) and to Gram-negative (Pseudomonas aeruginosa and Escherichia coli) bacteria. The antibacterial activities of ILs 1-8 were determined using the agar diffusion method with Mueller-Hinton agar medium.

The results of these experiments are displayed in Table 3 and represented graphically in Fig. 2, and show that ILs 1-8 exhibited similar levels of antibacterial activity towards S. aureus, B. subtilis, $P$. aeruginosa and E. coli to both Ampicillin and Gentamicin.
Furthermore, IL 7 exhibited the highest activity towards all of the microorganisms tested in the current study at a concentration of $30 \mu \mathrm{g} \mathrm{mL}^{-1}$. The higher activity of IL 7 was attributed to its 2-chlorobenzyl group.

\subsubsection{Minimum Inhibitory Concentration (MIC)}

Since ILs 2-3 and 5-8 showed good Inhibition zone, they were selected in order to test the in vitro Minimum Inhibitory Concentration (MIC) and the obtained results are summarized in Table 4.

The MIC of the tested ILs showed good to moderate activity against eight types of human pathogens comparing with drugs standard and the range of MIC levels varied from $0.99 \mu \mathrm{M}$ to more than $260 \mu \mathrm{M}$.

\subsubsection{Cytotoxic Activity of Compounds 1, 2 and $\mathbf{8}$ against Tumor Cell Lines}

ILs 1, 2 and $\mathbf{8}$ were selected for further evaluation based on their in vitro activities, and their cytotoxic activities were evaluated towards a series of human cancer cell lines, including HEPG2 (human hepatocellular carcinoma), MCF-7 (human breast adenocarcinoma) and HCT116 (colon carcinoma) cells. Cell growth and cell viability measurements were recorded

Table 2 Antifungal activity of ILs 1-8 against four fungi. (The concentration used in the antimicrobial test was $1 \mathrm{mg} \mathrm{mL}^{-1}$.)

\begin{tabular}{|c|c|c|c|c|}
\hline \multirow[t]{2}{*}{ Compound } & \multicolumn{4}{|c|}{ Inhibition zone $\mathrm{a} / \mathrm{mm}$} \\
\hline & A. fumigatus & P. italicum & C. albicans & G. candidum \\
\hline 1 & - & - & - & - \\
\hline 2 & $19.3 \pm 0.63$ & $17.8 \pm 0.44$ & - & $21.4 \pm 0.43$ \\
\hline 3 & $18.3 \pm 0.73$ & $16.4 \pm 0.52$ & - & $20.1 \pm 0.76$ \\
\hline 4 & $13.1 \pm 0.66$ & $15.0 \pm 0.25$ & - & $15.9 \pm 0.36$ \\
\hline 5 & $15.8 \pm 0.25$ & $16.3 \pm 0.17$ & - & $18.3 \pm 0.35$ \\
\hline 6 & $19.3 \pm 0.43$ & $17.4 \pm 0.66$ & - & $19.2 \pm 0.52$ \\
\hline 7 & $20.1 \pm 0.29$ & $18.1 \pm 0.24$ & - & $21.3 \pm 0.38$ \\
\hline 8 & $18.1 \pm 0.33$ & $16.3 \pm 0.54$ & - & $19.3 \pm 0.66$ \\
\hline Amphotericin B & $23.7 \pm 0.10$ & $21.9 \pm 0.12$ & $19.8 \pm 0.20$ & $28.7 \pm 0.22$ \\
\hline
\end{tabular}

${ }^{a}$ Results are the mean of three repetitions.

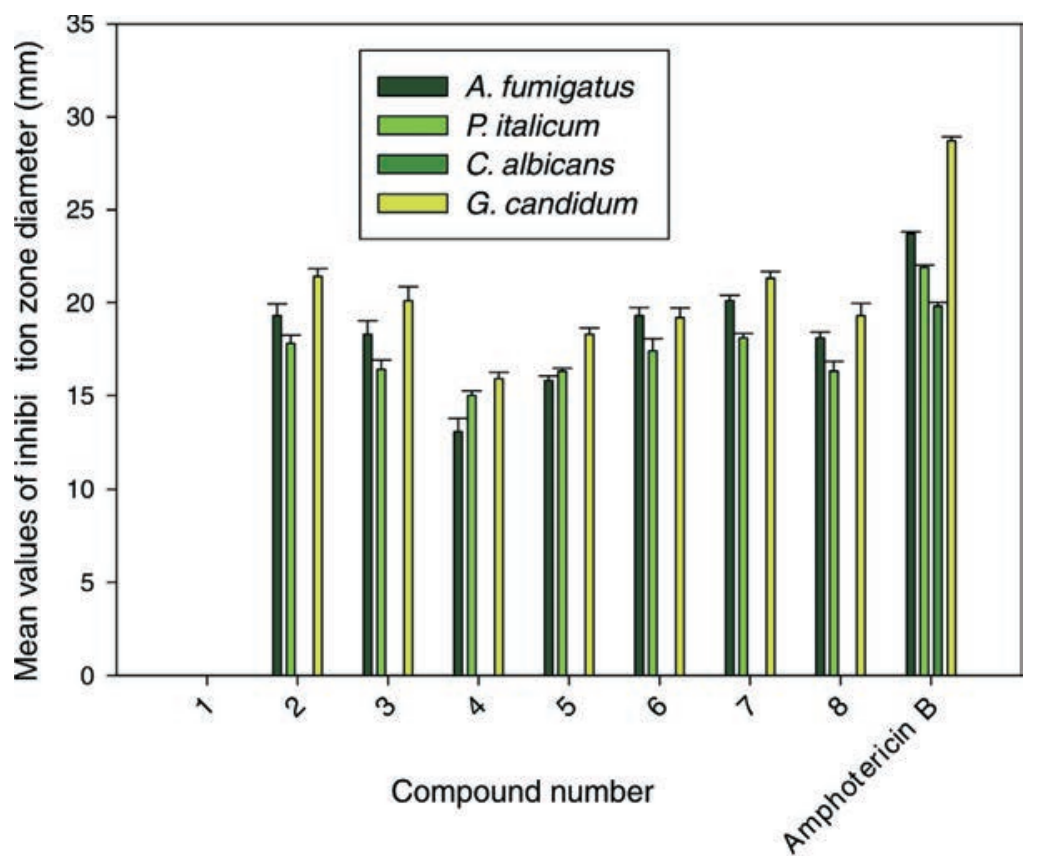

Figure 1 Antifungal activity of ILs 1-8 against Aspergillus fumigatus, Penicillium italicum, Candida albicans and Geotrichum candidum. (The concentration used in the antimicrobial test was $1 \mathrm{mg} \mathrm{mL}^{-1}$.) 
Table 3 Antibacterial activity of ILs 1-8 against four bacteria. (The concentration used in the antimicrobial test was $1 \mathrm{mg} \mathrm{mL}^{-1}$.)

\begin{tabular}{|c|c|c|c|c|}
\hline \multirow[t]{2}{*}{ Compound } & \multicolumn{4}{|c|}{ Inhibition zone $/ \mathrm{mm}$} \\
\hline & S. aureus & S. aureus & S. aureus & S. aureus \\
\hline 1 & $11.7 \pm 0.36$ & $12.4 \pm 0.64$ & - & $9.8 \pm 0.58$ \\
\hline 2 & $21.3 \pm 0.36$ & $22.2 \pm 0.46$ & - & $18.2 \pm 0.54$ \\
\hline 3 & $19.3 \pm 0.42$ & $20.2 \pm 0.28$ & - & $19.2 \pm 0.36$ \\
\hline 4 & $12.6 \pm 0.43$ & $13.9 \pm 0.62$ & - & $10.0 \pm 0.36$ \\
\hline 5 & $19.2 \pm 0.31$ & $20.4 \pm 0.37$ & - & $17.1 \pm 0.43$ \\
\hline 6 & $21.7 \pm 0.64$ & $22.6 \pm 0.44$ & - & $20.1 \pm 0.64$ \\
\hline 7 & $22.4 \pm 0.55$ & $23.0 \pm 0.43$ & $12.6 \pm 0.58$ & $20.2 \pm 0.29$ \\
\hline 8 & $19.6 \pm 0.58$ & $20.4 \pm 0.48$ & - & $17.3 \pm 0.58$ \\
\hline Ampicillin & $27.4 \pm 0.18$ & $32.4 \pm 0.10$ & - & - \\
\hline Gentamicin & - & - & $17.3 \pm 0.15$ & $22.3 \pm 0.18$ \\
\hline
\end{tabular}

${ }^{\text {a }}$ Results are the mean of three repetitions.

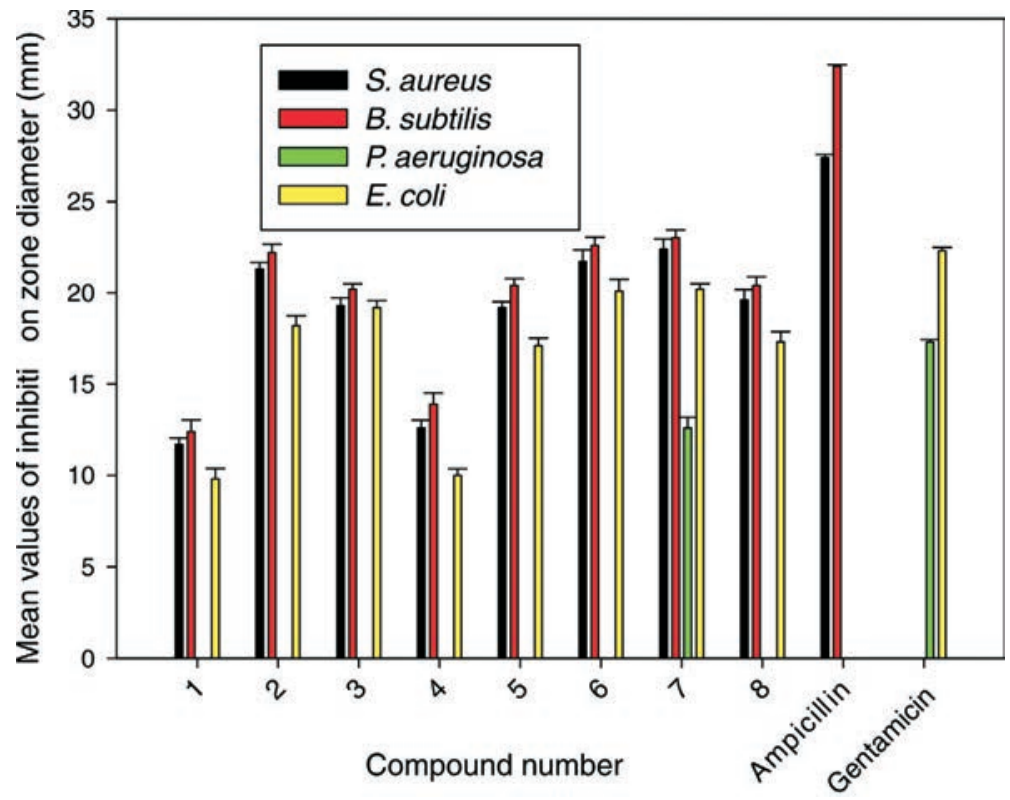

Figure 2 Antibacterial activity of ILs 1-8 against Gram-negative and Gram-positive bacteria. (The concentration used in the antimicrobial test was $1 \mathrm{mg} \mathrm{mL}^{-1}$.)

according to a previously reported procedure. ${ }^{16}$ Cytotoxicity was evaluated using various viability assays (HCT cytotoxicity Assay and MTT Metabolic impairment Assay), which were performed by the Regional Center for Mycology \& Biotechnology at Al-Azhar University, Egypt. The results of these assays are displayed in Figs. 3-5. The used concentrations are the same for all tested ILs and are expressed in $\mathrm{mg} \mathrm{mL}^{-1}$ and he results are the mean of three repetitions.
The results of the cytotoxicity assays showed that ILs 1,2 and 8 exhibited dose-dependent activities towards all three cell lines, with increases in the dose leading to a reduction in survival. However, the dose responses were less pronounced for concentrations in the range of $25-50 \mathrm{mg} \mathrm{mL}^{-1}$, but IL 8 was found to exhibit the higher antiproliferative activity in the range of 5 to 25

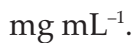

The $\mathrm{IC}_{50}$ values of ILs 1, 2 and $\mathbf{8}$ were found to be in the range of

Table 4 Antimicrobial activity expressed as $\mathrm{MIC} / \mathrm{mM}^{\mathrm{a}}$.

\begin{tabular}{|c|c|c|c|c|c|c|c|c|}
\hline \multirow[t]{2}{*}{ Compound } & \multicolumn{4}{|c|}{ Antifungal activity } & \multicolumn{4}{|c|}{ Antibacterial activity } \\
\hline & A. fumigatus & P. italicum & C. albicans & G. candidum & S.aureus & B. subtilis & P. aeruginosa & E.coli \\
\hline 2 & 13.5 & 27 & - & 3.38 & 3.38 & 1.69 & - & 27 \\
\hline 3 & 33.8 & 13.5 & - & 8.43 & 16.8 & 8.43 & - & 16.8 \\
\hline 5 & 111 & 111 & - & 27.9 & 13.9 & 6.98 & - & 55.9 \\
\hline 6 & 17222.3 & 6.95 & - & 17.3 & 2.18 & 1.07 & - & 8.67 \\
\hline 7 & 8.08 & 64.8 & - & 4.06 & 2.03 & 0.99 & 259.1 & 8.1 \\
\hline 8 & 48.2 & 96.4 & - & 12.03 & 6.01 & 6.01 & - & 48.2 \\
\hline Amphotericin B & 0.13 & 0.53 & 2.11 & 0.032 & - & - & - & - \\
\hline Ampicillin & - & - & - & - & 0.17 & 0.04 & - & - \\
\hline Gentamicin & - & - & - & - & - & - & 32.7 & 1.02 \\
\hline
\end{tabular}

${ }^{\text {a }}$ Results are the mean of three repetitions. 


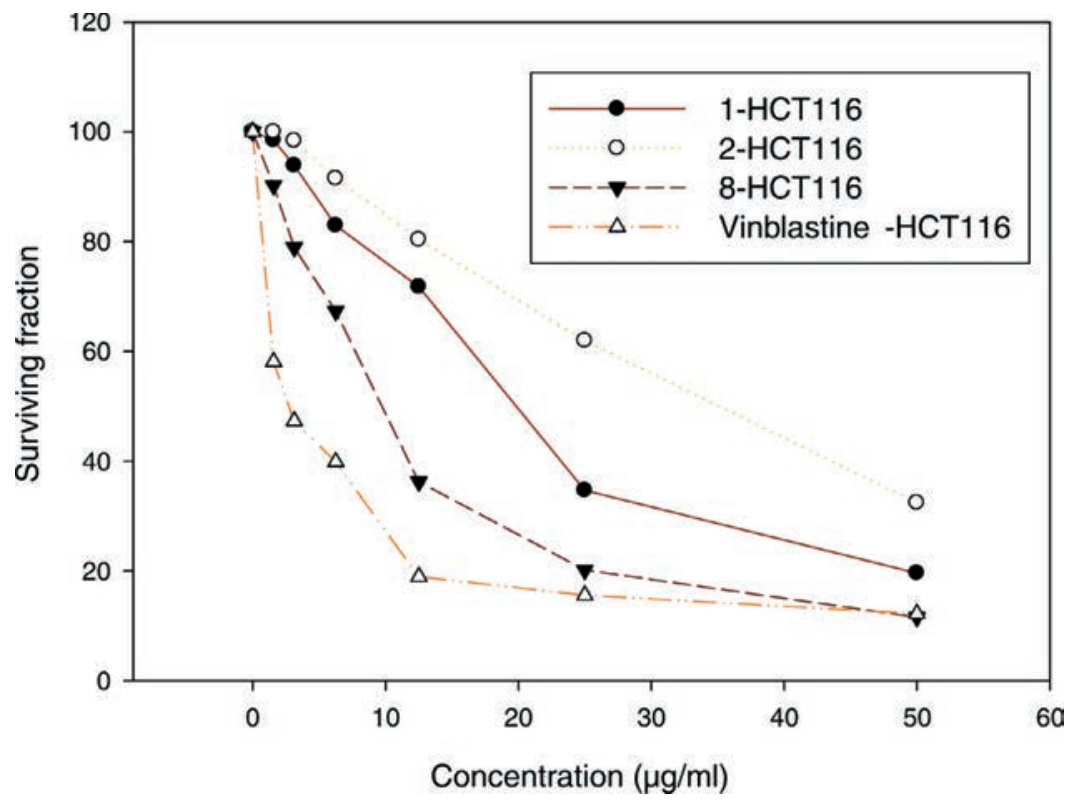

Figure 3 Cytotoxic activities of ILs 1, 2 and 8 against HCT116 cells.

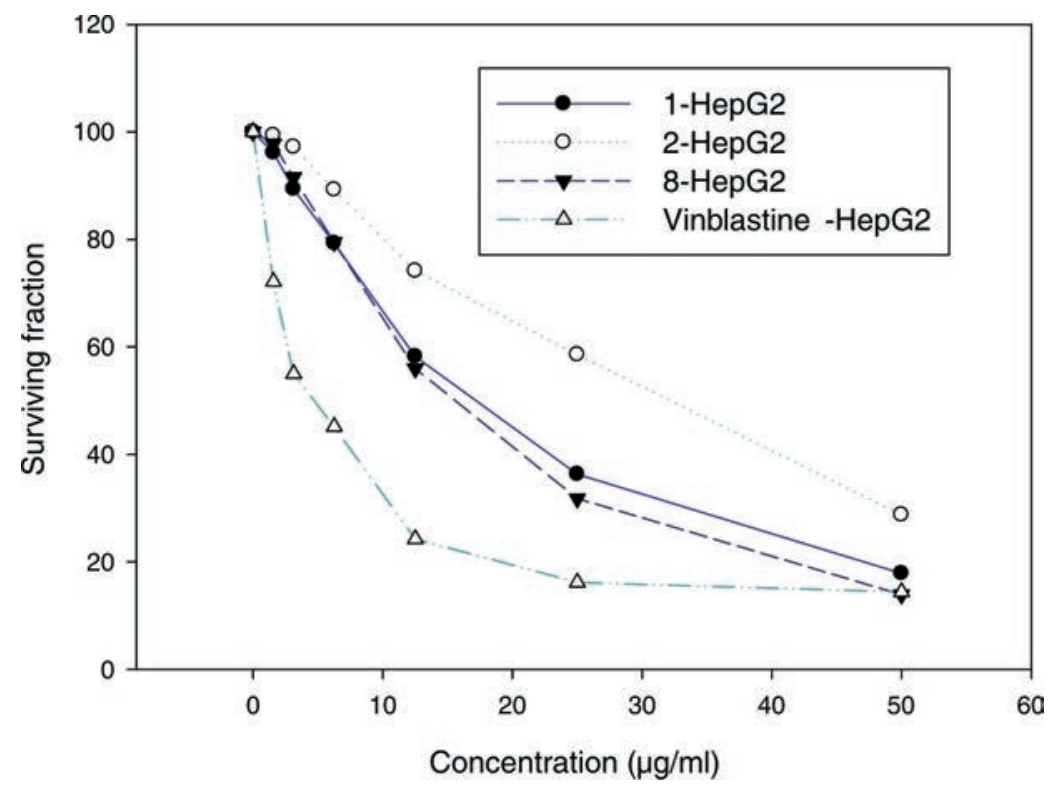

Figure 4 Cytotoxic activities of ILs 1, 2 and 8 against HepG2 cells.

30 to $140 \mu \mathrm{M}$, with IL 2 showing the weakest activity of the three different compounds (Table 5). Notably, IL 8 showed the highest activities of the three ILs tested towards all three cell lines, with $\mathrm{IC}_{50}$ values in the range of 30 to $51 \mu \mathrm{M}$, although the activities of this compound was less than those of Vinblastine, which was used as a positive control.

\section{Experimental}

All new compounds were characterized by ${ }^{1} \mathrm{H}$ NMR, ${ }^{13} \mathrm{C}$ NMR and IR spectroscopy and LCMS. ${ }^{1} \mathrm{H}$ NMR $(400 \mathrm{MHz})$ and ${ }^{13} \mathrm{C}$ NMR (100 MHz) spectra were measured in DMSO and $\mathrm{D}_{2} \mathrm{O}$ at room temperature. Chemical shifts $(\delta)$ were reported in ppm, with tetramethylsilane (TMS) as an internal standard. The Liquid chromatography-mass spectrometry LCMS (spectra were measured with a Micromass LCT (Liquid Chromatography Tandem) mass spectrometer (Model: Micromass LCT Classic, Agilent Technologies, Germany). IR spectra were recorded on a $\mathrm{KBr}$ disc with a Shimadzu 8201 PC FT-IR spectrophotometer $\left(v_{\max }\right.$ in $\mathrm{cm}^{-1}$ ). Ultrasound-assisted reactions were performed with a high-intensity ultrasonic processor SUB Aqua 5 Plus-Grant with a temperature controller $(750 \mathrm{~W})$, microprocessor controlled2004. The ultrasonic frequency of the cleaning bath used is $25 \mathrm{KHz}$

\subsection{Synthesis}

3.1.1. General Procedure for the Synthesis of N-alkylpyridazinium Halides 1-8 with Ultrasonic Irradiation

Pyridazine (1.0 eq.) and an alkyl halide (1.1 eq.) were added to toluene $(15 \mathrm{~mL})$ and placed in a closed vessel and exposed to irradiation for $5 \mathrm{~h}$ at $70{ }^{\circ} \mathrm{C}$ in a sonicator until a precipitate was formed. The obtained solid was filtered and washed with ethylacetate to afford the desired pyridazinium IL

\subsection{Characterization}

3.2.1. 1-(2-Ethoxy-2-oxoethyl)pyridazinium Chloride $\mathbf{1}$

This compound was obtained as brown solid; Mp 120-122 ${ }^{\circ} \mathrm{C}$; 


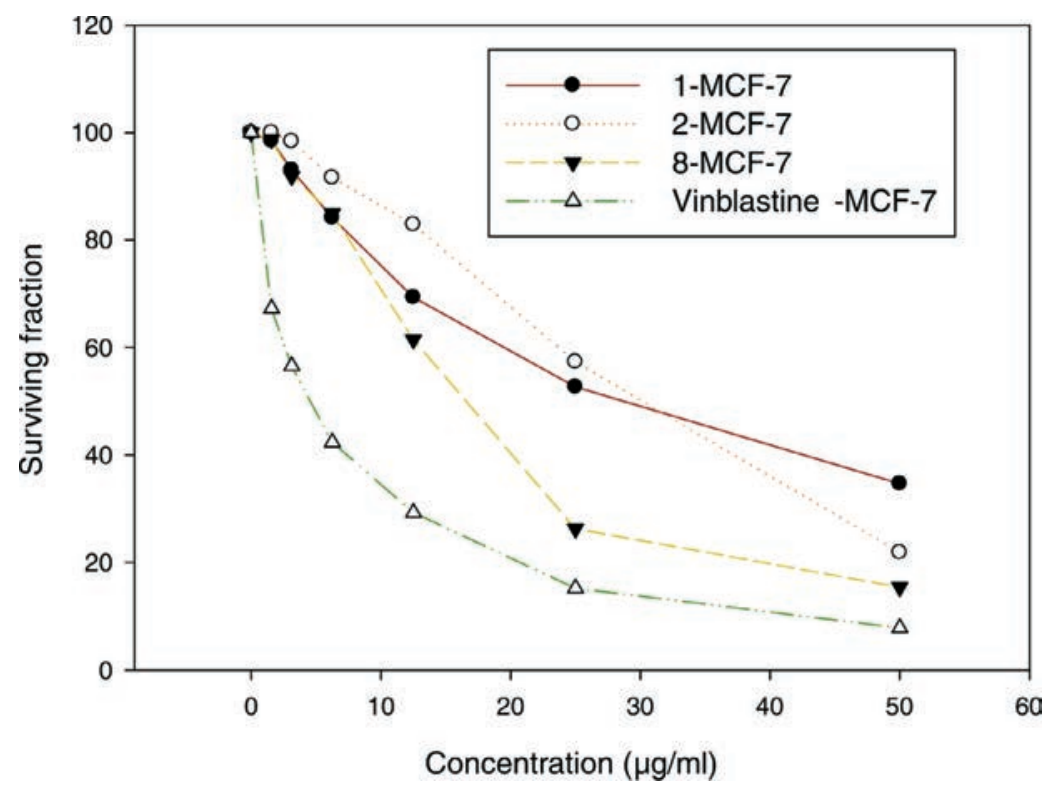

Figure 5 Cytotoxic activities of ILs 1, 2 and 8 against MCF7 cells.

Table $5 \mathrm{IC}_{50}\left(\mathrm{mg} \mathrm{mL}^{-1}(\mathrm{mM})\right)$ values of compounds $\mathbf{1}, \mathbf{2}$ and 8 towards HCT116, HEPG2 and MCF7 cells.

\begin{tabular}{lcccc}
\hline Cell line & \multicolumn{1}{c}{} & $\mathbf{2}$ & $\mathbf{8}$ & Vinblastine \\
\hline HCT116 & $19.8(\mathbf{9 7 )}$ & $35.1 \mathbf{( 1 2 0 )}$ & $9.73(\mathbf{3 0 )}$ & $2.38(\mathbf{2 . 9 3 )}$ \\
HEPG2 & $17.2 \mathbf{( 8 5 )}$ & $32.2(\mathbf{1 1 0 )}$ & $15.6(\mathbf{4 8 )}$ & $4.6(\mathbf{5 . 6 7 )}$ \\
MCF7 & $28.7 \mathbf{( 1 4 0 )}$ & $30.2(\mathbf{1 0 0 )}$ & $16.6(\mathbf{5 1})$ & $4.6(5.67)$ \\
\hline
\end{tabular}

yield $84 \% ; \delta_{\mathrm{H}}\left(\mathrm{DMSO}-\mathrm{d}_{6}, 400 \mathrm{MHz}\right): 1.25(\mathrm{t}, J=7.2 \mathrm{~Hz}, 3 \mathrm{H}), 4.26$ $(\mathrm{q}, J=7.2 \mathrm{~Hz}, 2 \mathrm{H}), 6.17(\mathrm{~s}, 2 \mathrm{H}), 8.82-8.98(2 \mathrm{Ar}-\mathrm{H}), 9.82(\mathrm{~d}, 1 \mathrm{Ar}-\mathrm{H})$, $10.42(1 \mathrm{Ar}-\mathrm{H}) ; \delta_{\mathrm{C}}\left(\mathrm{DMSO}_{6}, 100 \mathrm{MHz}\right): 13.8\left(\mathrm{CH}_{3}\right), 62.5\left(\mathrm{CH}_{2}\right)$, $64.2\left(\mathrm{CH}_{2}\right), 136.0(\mathrm{CH}), 137.8(\mathrm{CH}), 151.9(\mathrm{CH}), 154.7(\mathrm{CH}), 165.7$ (CO); IR $\left(v_{\max } \mathrm{cm}^{-1}\right) 3000(\mathrm{C}-\mathrm{H} \mathrm{Ar}), 1748(\mathrm{C}=\mathrm{O}), 1572-1446(\mathrm{C}=\mathrm{C})$, 1240 (C-N), 1027 (C-O) cm ${ }^{-1}$; LCMS (M-Cl) 167 found for $\mathrm{C}_{8} \mathrm{H}_{11} \mathrm{~N}_{2} \mathrm{O}_{2}{ }^{+}$. (Found: C, 47.35; H, 5.50; N, $13.76 \%$. Calc. for $\mathrm{C}_{8} \mathrm{H}_{11} \mathrm{ClN}_{2} \mathrm{O}_{2}$ (202.64); C, 47.42; $\mathrm{H}, 5.47 ; \mathrm{N}, 13.82 \%$ ).

\subsubsection{1-(6-Methoxy-6-oxohexyl)pyridazinium Bromide 2}

This compound was obtained as dark semi-solid; yield $86 \%$; $\delta_{\mathrm{H}}\left(\mathrm{DMSO}-\mathrm{d}_{6}, 400 \mathrm{MHz}\right.$ ): 1.34 (quint, $J=7.2 \mathrm{~Hz}, 2 \mathrm{H}$ ), 1.58 (sextet, $\mathrm{J}=7.2 \mathrm{~Hz}, 2 \mathrm{H}), 2.03$ (quint, $J=7.2 \mathrm{~Hz}, 2 \mathrm{H}), 2.32(\mathrm{t}, J=7.2 \mathrm{~Hz}$, $2 \mathrm{H}), 3.59(\mathrm{~s}, 3 \mathrm{H}), 4.88(\mathrm{t}, J=7.2 \mathrm{~Hz}, 2 \mathrm{H}), 8.69(1 \mathrm{Ar}-\mathrm{H}), 8.80$ (1Ar-H), $9.70(1 \mathrm{Ar}-\mathrm{H}), 10.16(1 \mathrm{Ar}-\mathrm{H}) ; \delta_{\mathrm{C}}(\mathrm{DMSO}, 100 \mathrm{MHz}): 23.7$ $\left(\mathrm{CH}_{2}\right), 24.7\left(\mathrm{CH}_{2}\right), 29.0\left(\mathrm{CH}_{2}\right), 32.9\left(\mathrm{CH}_{2}\right), 51.2\left(\mathrm{CH}_{3}\right), 64.2\left(\mathrm{CH}_{2}\right)$, $136.0(\mathrm{CH}), 136.5(\mathrm{CH}), 150.0(\mathrm{CH}), 154.5(\mathrm{CH}), 173.2(\mathrm{CO})$; IR $\left(v_{\max } \mathrm{cm}^{-1}\right) 2997$ (C-H Ar), $1747(\mathrm{C}=\mathrm{O}), 1595-1445(\mathrm{C}=\mathrm{C}), 1195$ (C-N), 998 (C-O) cm $\mathrm{cm}^{-1}$, LCMS (M-Br) 209 found for $\mathrm{C}_{11} \mathrm{H}_{17} \mathrm{~N}_{2} \mathrm{O}_{2}{ }^{+}$. (Found: C, 45.60; H, 6.02; N, $9.74 \%$. Calc. for $\mathrm{C}_{11} \mathrm{H}_{17} \mathrm{BrN}_{2} \mathrm{O}_{2}$ (289.17); C, 45.69; H, 5.93; N, $9.69 \%)$.

\subsubsection{1-Pentylpyridazinium Bromide 3}

This compound was obtained as brown solid; Mp 118-120 ${ }^{\circ} \mathrm{C}$; yield $89 \% ; \delta_{\mathrm{H}}(400 \mathrm{MHz}, \mathrm{DMSO}): 0.87(\mathrm{t}, 3 \mathrm{H}), 1.13(\mathrm{~m}, 4 \mathrm{H}), 2.03$ (quint, 2H), 4.89 (t, 2H), 8.68 (dd, $1 \mathrm{Ar}-\mathrm{H}), 8.83(\mathrm{dd}, 1 \mathrm{Ar}-\mathrm{H}), 9.71$ $(\mathrm{d}, 1 \mathrm{Ar}-\mathrm{H}), 10.20(\mathrm{~d}, 1 \mathrm{Ar}-\mathrm{H}) ; \delta_{\mathrm{C}}(100 \mathrm{MHz}, \mathrm{DMSO}): 13.6\left(\mathrm{CH}_{3}\right), 21.5$ $\left(\mathrm{CH}_{2}\right), 27.4\left(\mathrm{CH}_{2}\right), 29.1\left(\mathrm{CH}_{2}\right), 64.4\left(\mathrm{CH}_{2}\right), 136.0(\mathrm{CH}), 136.5(\mathrm{CH})$, $149.8(\mathrm{CH}), 154.5(\mathrm{CH})$. IR $\left(v_{\max } \mathrm{cm}^{-1}\right) 3032\left(\mathrm{C}-\mathrm{H}, \mathrm{sp}^{2}\right), 1570-1471$ $(\mathrm{C}=\mathrm{C})$, 1165(C-N); LCMS (M-Br) 151 found for $\mathrm{C}_{9} \mathrm{H}_{15} \mathrm{~N}_{2}{ }^{+}$. (Found: $\mathrm{C}, 46.70 ; \mathrm{H}, 6.48 ; \mathrm{N}, 12.16 \%$. Calc. for $\mathrm{C}_{9} \mathrm{H}_{15} \mathrm{BrN}_{2}$ (231.13); C, 46.77; H, 6.54; N, $12.12 \%$ ).

\subsubsection{1-Hexylpyridazinium Iodide $\mathbf{4}$}

This compound was obtained as greenish brown solid; $\mathrm{Mp}$ 62-64 ${ }^{\circ} \mathrm{C}$; yield $87 \%$; $\delta_{\mathrm{H}}\left(400 \mathrm{MHz}, \mathrm{DMSO}-\mathrm{d}_{6}\right): 0.85(\mathrm{t}, 3 \mathrm{H}), 1.30$ $(\mathrm{m}, 6 \mathrm{H}), 2.02$ (quint, $2 \mathrm{H}), 4.84(\mathrm{t}, 2 \mathrm{H}), 8.64(1 \mathrm{Ar}-\mathrm{H}), 8.77(1 \mathrm{Ar}-\mathrm{H})$, $9.68(1 \mathrm{Ar}-\mathrm{H}), 10.04(1 \mathrm{Ar}-\mathrm{H}) ; \delta_{\mathrm{C}}\left(100 \mathrm{MHz}, \mathrm{DMSO}-\mathrm{d}_{6}\right): 13.8\left(\mathrm{CH}_{3}\right)$, $21.8\left(\mathrm{CH}_{2}\right), 25.0\left(\mathrm{CH}_{2}\right), 29.3\left(\mathrm{CH}_{2}\right), 30.5\left(\mathrm{CH}_{2}\right), 64.5\left(\mathrm{CH}_{2}\right), 136.0$ $(\mathrm{CH}), 136.5(\mathrm{CH}), 149.8(\mathrm{CH}), 154.5(\mathrm{CH}) . \mathrm{IR}\left(v_{\max } \mathrm{cm}^{-1}\right) 3028(\mathrm{C}-\mathrm{H}$, $\left.\mathrm{sp}^{2}\right)$, 1567-1441 (C=C), 1143(C-N); LCMS (M-I) 165 found for $\mathrm{C}_{10} \mathrm{H}_{17} \mathrm{~N}_{2}^{+}$. (Found: $\mathrm{C}, 41.05 ; \mathrm{H}, 5.92 ; \mathrm{N}, 9.53 \%$. Calc. for $\mathrm{C}_{1} \mathrm{H}_{17} \mathrm{IN}_{2}$ (292.16); C, 41.11; H, 5.86; N, $9.59 \%$ ).

\subsubsection{1-(3-Phenylpropyl)pyridazinium Bromide $\mathbf{5}$}

This compound was obtained as brown solid; Mp 100-102 ${ }^{\circ} \mathrm{C}$; yield $87 \% ; \delta_{\mathrm{H}}\left(400 \mathrm{MHz}, \mathrm{DMSO}-\mathrm{d}_{6}\right)$ : 2.35 (quint, $\left.2 \mathrm{H}\right), 2.72(\mathrm{t}, 3 \mathrm{H})$, $4.91(\mathrm{t}, 2 \mathrm{H}), 7.19-7.31(\mathrm{~m}, 5 \mathrm{H}), 8.67(1 \mathrm{Ar}-\mathrm{H}), 8.77$ (1Ar-H), 9.68 (1Ar-H), $10.04(1 \mathrm{Ar}-\mathrm{H}) ; \delta_{\mathrm{H}}\left(100 \mathrm{MHz}, \mathrm{DMSO}-\mathrm{d}_{6}\right): 30.9\left(\mathrm{CH}_{2}\right), 31.5$ $\left(\mathrm{CH}_{2}\right), 64.2\left(\mathrm{CH}_{2}\right), 126.1(\mathrm{CH}), 128.3(\mathrm{CH}), 128.4(\mathrm{CH}), 136.0(\mathrm{CH})$, $136.5(\mathrm{CH}), 140.3(\mathrm{C}), 150.0(\mathrm{CH}), 154.4(\mathrm{CH}) ; \mathrm{IR}\left(v_{\max } \mathrm{cm}^{-1}\right) 2997$ (C-H, sp 2 ), 1587-1473 (C=C), 1162(C-N); LCMS (M-Br) 199 found for $\mathrm{C}_{13} \mathrm{H}_{15} \mathrm{~N}_{2}^{+}$. (Found: $\mathrm{C}, 55.82 ; \mathrm{H}, 5.49 ; \mathrm{N}, 9.99 \%$. Calc. for $\mathrm{C}_{13} \mathrm{H}_{15} \mathrm{BrN}_{2}$ (279.18); C, 55.93; H, 5.42; N, $10.08 \%$ ).

\subsubsection{1-(4-Fluorobenzyl)pyridazinium Chloride 6}

This compound was obtained as beige solid; $\mathrm{Mp} 200-202{ }^{\circ} \mathrm{C}$; yield $88 \% ; \delta_{\mathrm{H}}\left(400 \mathrm{MHz}, \mathrm{D}_{2} \mathrm{O}\right): 5.96(\mathrm{~s}, 2 \mathrm{H}), 7.75(\mathrm{Ar}-\mathrm{H}), 8.13$ (2Ar-H), $8.82(1 \mathrm{Ar}-\mathrm{H}), 8.94(1 \mathrm{Ar}-\mathrm{H}), 9.78(1 \mathrm{Ar}-\mathrm{H}), 10.05(1 \mathrm{Ar}-\mathrm{H})$; $\delta_{\mathrm{C}}\left(100 \mathrm{MHz}, \mathrm{D}_{2} \mathrm{O}\right): 67.9\left(\mathrm{CH}_{2}\right), 116.1(\mathrm{CH}), 116.3(\mathrm{CH}), 132.0(\mathrm{CH})$, $132.1(\mathrm{CH}), 136.1(\mathrm{CH}), 137.0(\mathrm{CH}), 149.2(\mathrm{CH}), 154.7(\mathrm{CH}), 162.0$ (C); IR $\left(v_{\max } \mathrm{cm}^{-1}\right) 3038\left(\mathrm{C}-\mathrm{H}, \mathrm{sp}^{2}\right), 1588-1470(\mathrm{C}=\mathrm{C}), 1188(\mathrm{C}-\mathrm{N})$; LCMS (M-Cl) 189 found for $\mathrm{C}_{11} \mathrm{H}_{10} \mathrm{FN}_{2}{ }^{+}$. (Found: C, 58.72; H, 4.55; $\mathrm{N}, 12.40 \%$. Calc. for $\mathrm{C}_{11} \mathrm{H}_{10} \mathrm{Cl}_{\mathrm{F}} \mathrm{N}_{2}(224.66) ; \mathrm{C}, 58.81 ; \mathrm{H}, 4.49$; $\mathrm{N}, 12.47 \%$ ).

\subsubsection{1-(2-Chlorobenzyl)pyridazinium Chloride 7}

This compound was obtained as beige solid; Mp $176-178^{\circ} \mathrm{C}$; yield $89 \% ; \delta_{\mathrm{H}}\left(400 \mathrm{MHz}, \mathrm{D}_{2} \mathrm{O}\right): 6.09(\mathrm{~s}, 2 \mathrm{H}), 7.35-7.45(\mathrm{~m}, 3 \mathrm{Ar}-\mathrm{H})$, $7.58(1 \mathrm{Ar}-\mathrm{H}), 8.47(1 \mathrm{Ar}-\mathrm{H}), 8.53(1 \mathrm{Ar}-\mathrm{H}), 9.37(1 \mathrm{Ar}-\mathrm{H}), 9.71$ $(1 \mathrm{Ar}-\mathrm{H}) ; \delta_{\mathrm{C}}\left(100 \mathrm{MHz}, \mathrm{D}_{2} \mathrm{O}\right): 66.3\left(\mathrm{CH}_{2}\right), 128.0(\mathrm{CH}), 129.1(\mathrm{C})$, $130.2(\mathrm{CH}), 132.1(\mathrm{CH}), 134.7(\mathrm{C}), 136.0(\mathrm{CH}), 137.1(\mathrm{CH}), 133.2$ (C), $149.6(\mathrm{CH}), 154.7(\mathrm{CH})$; IR $\left(v_{\max } \mathrm{cm}^{-1}\right) 3043\left(\mathrm{C}-\mathrm{H}, \mathrm{sp}^{2}\right)$, 1572-1474 (C=C), 1167 (C-N); LCMS (M-Cl) 205 found for 
$\mathrm{C}_{11} \mathrm{H}_{10} \mathrm{ClN}_{2}^{+}$; (Found: C, 54.71; H, 4.26; N, $11.59 \%$. Calc. for $\mathrm{C}_{11} \mathrm{H}_{10} \mathrm{Cl}_{2} \mathrm{~N}_{2} \mathrm{O}_{2}$ (241.12); $\mathrm{C}, 54.79 ; \mathrm{H}, 4.18 ; \mathrm{N}, 11.62 \%$ ).

\subsubsection{1-(2-(4-Nitrophenyl)-2-oxoethyl)pyridazinium Bromide 8}

This compound was obtained as beige solid; $\mathrm{Mp} 225-227^{\circ} \mathrm{C}$; yield $80 \% ; \delta_{\mathrm{H}}(400 \mathrm{MHz}, \mathrm{DMSO}): 6.87(\mathrm{~s}, 2 \mathrm{H}), 7.75(2 \mathrm{Ar}-\mathrm{H}), 8.13$ (dd, 2Ar-H), 8.82 (1Ar-H), 8.94 (1Ar-H), 9.78 (1Ar-H), 10.05 $(1 \mathrm{Ar}-\mathrm{H}) ; \delta_{\mathrm{C}}(100 \mathrm{MHz}, \mathrm{DMSO}): 70.5\left(\mathrm{CH}_{2}\right), 124.1(\mathrm{CH}), 129.9(\mathrm{CH})$, $136.0(\mathrm{CH}), 137.6(\mathrm{CH}), 137.9(\mathrm{C}), 151.8(\mathrm{CH}), 154.7(\mathrm{CH}), 150.7$ (C), $189.7(\mathrm{CO})$; IR $\left(v_{\max } \mathrm{cm}^{-1}\right) 3112\left(\mathrm{C}-\mathrm{H}, \mathrm{sp}^{2}\right), 1721(\mathrm{C}=\mathrm{O})$, 1591-1448 (C=C), 1112(C-N); LCMS (M-Br) 244 found for $\mathrm{C}_{12} \mathrm{H}_{10} \mathrm{~N}_{3} \mathrm{O}_{3}{ }^{+}$; (Found: C, 44.39; $\mathrm{H}, 3.19 ; \mathrm{N}, 12.93 \%$. Calc. for $\mathrm{C}_{12} \mathrm{H}_{10} \mathrm{BrN}_{3} \mathrm{O}_{3}$ (324.13); C, 44.47; $\mathrm{H}, 3.11 ; \mathrm{N}, 12.96 \%$ ).

\subsection{Determination of IZ and MIC}

The antimicrobial potential was estimated in terms of inhibition zone (IZ) measurements by agar disc diffusion method. The test was performed by transferring $24 \mathrm{~h}$ fresh bacterial cultures onto the surface of Muller-Hinton agar plates to yield confluent growth. The antibacterial potential was assayed using filter paper discs (6 mm i.d.) loaded with $10 \mu \mathrm{g}$ of tested ILs. Loaded discs were transferred onto the centre of inoculated Petri-plates which were then maintained for $2 \mathrm{~h}$ in a refrigerator at $4 \mathrm{C}$ to allow for the diffusion of the bioactive compound. The diameter of the inhibition zone was measured (in $\mathrm{mm}$ ) after $24 \mathrm{~h}$ incubation at $37^{\circ} \mathrm{C}$. Sterile distilled water was used as a control. Clinical samples of Escherichia coli, Enterobacter sp., Pseudomonas aeruginosa, Staphylococcus aureus, Staphylococcus epidermidis, Bacillus cereus and Acinetobacter baumannii were used as test strains.

The minimum inhibitory concentration (MIC) of tested ionic liquids were determined by CLSI microdilution-based method. ${ }^{17}$ Test compound was dissolved in sterile, distilled water and diluted to a final concentration of $256 \mu \mathrm{g} \mathrm{mL}^{-1}$ in Mueller-Hinton broth (Becton Dickinson, USA). ${ }^{18}$ Two-fold serial dilutions were prepared in a 96-well microtitre plate. Bacterial suspension containing approximately $1 \times 10^{8} \mathrm{CFU} \mathrm{mL}^{-1}$ were prepared from $24 \mathrm{~h}$ agar plates with Mueller Hinton broth. Aliquots of $100 \mu \mathrm{L}$ of each bacterial suspension was mixed with $100 \mu \mathrm{L}$ serially diluted tested compound in microtitre plate..$^{19}$ Uninoculated wells were prepared as control samples. Plates were incubated at $37^{\circ} \mathrm{C}$ for $24 \mathrm{~h}$. The MIC was defined as the lowest concentration of test compound producing no visible growth. All experiments were performed in triplicate.

\section{Conclusion}

A novel series of functionalized pyridazinium-based ILs has been successfully synthesized under ultrasonic irradiation conditions. The structures of these compounds were fully characterized by FT-IR, ${ }^{1} \mathrm{H}-\mathrm{NMR},{ }^{13} \mathrm{C}-\mathrm{NMR}$ and mass spectrometry. Compared with standard antibiotics, the results of several antimicrobial screening experiments showed that our newly synthesized ILs exhibited good to moderate antimicrobial and antifungal activities. Furthermore, the cytotoxic activities of three of these new ILs were tested in vitro against three different human carcinoma cell lines. The results revealed that IL 8 could be considered as a promising antiproliferative agent with low $\mathrm{IC}_{50}$ values against all three cell lines.

\section{Supplementary Data}

Supplementary data $\left({ }^{1} \mathrm{H}\right.$ NMR, ${ }^{13} \mathrm{C}$ NMR, Dept NMR, IR and mass spectra) associated with this article are available in the online supplement.

\section{References}

1 H. Olivier-Bourbigou, L. Magna and D. Morvan, Ionic liquids and catalysis: recent progress from knowledge to applications, Appl. Catal. A, 2010, 373, 1-56.

2 R.P. Swatloski, S. K. Spear, J.D. Holbrey and R.D. Rogers, Dissolution of cellulose with ionic liquids, J. Am. Chem. Soc., 2002, 124, 4974-4975.

3 R.A. Sheldon, R.M. Lau, M. J. Sorgedrager, F. van Rantwijk and K.R. Seddon, Biocatalysis in ionic liquids, Green Chem., 2002, 4, 147-151.

4 F. Endres, Ionic liquids: solvents for the electrodeposition of metals and semiconductors, Port. Electrochim. Acta, 2011, 29, 375-389.

5 Ibrahim M.A.M. Ibrahim, M. Messali, Z. Moussa, A.Y. Alzahrani, S.N. Alamry and B. Hammouti, Corrosion inhibition of carbon steel by imidazolium and pyridinium cations ionic liquids in acidic environment, Port. Electrochim. Acta, 2011, 29, 375-389.

6 M. Messali, A green microwave-assisted synthesis, characterization and comparative study of new pyridazinium-based ionic liquids derivatives towards corrosion of mild steel in acidic environment, J. Mater. Environ. Sci., 2011, 2, 174-185.

7 M. Messali, A. Bousskri, A. Anejjar, R. Salghi and B. Hammouti, Electrochemical studies of new pyridazinium-based ionic liquid, (1-4-nitro phenyl-1-ethanone) pyridazinium bromide, on carbon steel corrosion in hydrochloric acid medium, Int. J. Electrochem. Sci., 2015, 10, 4532-4551.

8 P. Kubisa, Application of ionic liquids as solvents for polymerization processes, Prog. Polym. Sci., 2004, 29, 3-12.

9 R.G. Kalkhambkar, S.N. Waters and K.K. Laali, Highly efficient synthesis of amides via Ritter chemistry with ionic liquids, Tetrahedron Lett., 2011, 52, 867-871.

10 J.D. Oxley, T. Prozorov and K.S. Suslick, Sonochemistry and sonoluminescence of room-temperature ionic liquids, J. Am. Chem. Soc., 2003, 125, 11138-11139.

11 S. Zhao, E. Zhao, P. Shen, M. Zhao and J. Sun, An atom-efficient and practical synthesis of new pyridinium ionic liquids and application in Morita-Baylis-Hillman reaction, Ultrason. Sonochem., 2008, 15, 955-959.

$12 \mathrm{M}$. Messali, An efficient and green sonochemical synthesis of some new eco-friendly functionalized ionic liquids, Arab. J. Chem., 2014, 7, 63-70.

13 M. Messali, Z. Moussa, A.Y. Alzahrani, M.Y. El Naggar, A.S. El Douhaibi and B. Hammouti, Synthesis, characterization, antimicrobial activity of new green-chemistry-friendly ionic liquids, Chemosphere, 2013, 91, 1627-1634.

14 M. Messali, M. R. Aouad, W.S. El sayed, A.A-S. Ali, T. Ben Hadda and B. Hammouti, New eco-friendly 1-alkyl-3-(4-phenoxybutyl) imidazolium-based ionic liquids derivatives: a green ultrasoundassisted synthesis, characterization, antimicrobial activity and POM analyses, Molecules, 2014, 19, 11741-11759.

15 M. Messali, M.R. Aouad, A.A-S. Ali, N. Rezki, T. Ben Hadda and B. Hammouti, Synthesis, characterization, and POM analyses of novel bioactive imidazolium-based ionic liquids, Med. Chem. Res., 2015, 24, 1387-1395.

16 M.I. Atta-Ur-Rahman, W.J. Thomsen and W.J. Thomsen, Bioassay Techniques for Drug Development, Harwood Academic Publishers, Netherlands, 2001, p. 22.

17 Clinical and Laboratory Standards Institute (CLSI), Document M26-A, Methods of determining bactericidal activity of antimicrobial agents for dilution antimicrobial susceptibility tests for bacteria that grow aerobically. Approved Guideline, Wayne, PA, 1999.

18 H. Nomura, Y. Isshiki, K. Sakuda, K. Sakuma and S. Kondo, The antibacterial activity of compounds isolated from oakmoss against Legionella pneumophila and other Legionella spp., Biol. Pharm. Bull., $2012,35,1560-1567$.

19 Clinical and Laboratory Standards Institute (CLSI), Document M7-A5, Methods for antibacterial susceptibility test for bacteria that grow aerobically. Approved Standard, 5th edn., Wayne, PA, 2000. 


\title{
Supporting Information
}

\section{New pyridazinium based ionic liquids: An eco-friendly ultrasound-assisted} synthesis, characterization and biological activity

\author{
Mouslim Messali,,${ }^{[a] *}$ Mohammed N. Almtiri, ${ }^{[a]}$ Bousskri Abderrahman, ${ }^{[b]}$ Rachid \\ Salghi, ${ }^{[b]}$ Mohamed R. Aouad, ${ }^{[a, c]}$ Solhe F. Alshahateet ${ }^{[\mathrm{d}]}$ and Adeeb A-S Ali ${ }^{[\mathrm{a}]}$ \\ ${ }^{a}$ Department of Chemistry, Taibah University, 30002, Al-Madina Al-Mounawara, Saudi \\ Arabia. \\ ${ }^{b}$ Laboratory of Environmental Engineering and Biotechnology, ENSA, Ibn Zohr University, \\ Box 1136, 80000 Agadir, Morocco \\ ${ }^{c}$ Department of Chemistry, (LCECM) USTO-MB, University of Sciences and Technology \\ Mohamed Boudiaf, BP 1505 Oran, El M`nouar, Algeria. \\ ${ }^{d}$ Department of Chemistry, Mutah University, Mutah 61710, Karak-Jordan.
}

*E-mail: $\underline{\text { mouslim@mail.be }}$

The following spectra are included:

S1: ${ }^{1} \mathrm{H}$ NMR, ${ }^{13} \mathrm{C}$ NMR, Dept135 NMR, mass and IR spectra of IL 1

S2: ${ }^{1} \mathrm{H}$ NMR, ${ }^{13} \mathrm{C}$ NMR, Dept135 NMR, mass and IR spectra of IL 2

S3: ${ }^{1} \mathrm{H}$ NMR, ${ }^{13} \mathrm{C}$ NMR, Dept135 NMR, mass and IR spectra of IL 3

S4: ${ }^{1} \mathrm{H}$ NMR, ${ }^{13} \mathrm{C}$ NMR, Dept135 NMR, mass and IR spectra of IL 4

S5: ${ }^{1} \mathrm{H}$ NMR, ${ }^{13} \mathrm{C}$ NMR, Dept135 NMR, mass and IR spectra of IL 5

S6: ${ }^{1} \mathrm{H}$ NMR, ${ }^{13} \mathrm{C}$ NMR, Dept135 NMR, mass and IR spectra of IL 6

S7: ${ }^{1} \mathrm{H}$ NMR, ${ }^{13} \mathrm{C}$ NMR, Dept135 NMR, mass and IR spectra of IL 7

S8: ${ }^{1} \mathrm{H}$ NMR, ${ }^{13} \mathrm{C}$ NMR, Dept135 NMR, mass and IR spectra of IL 8 


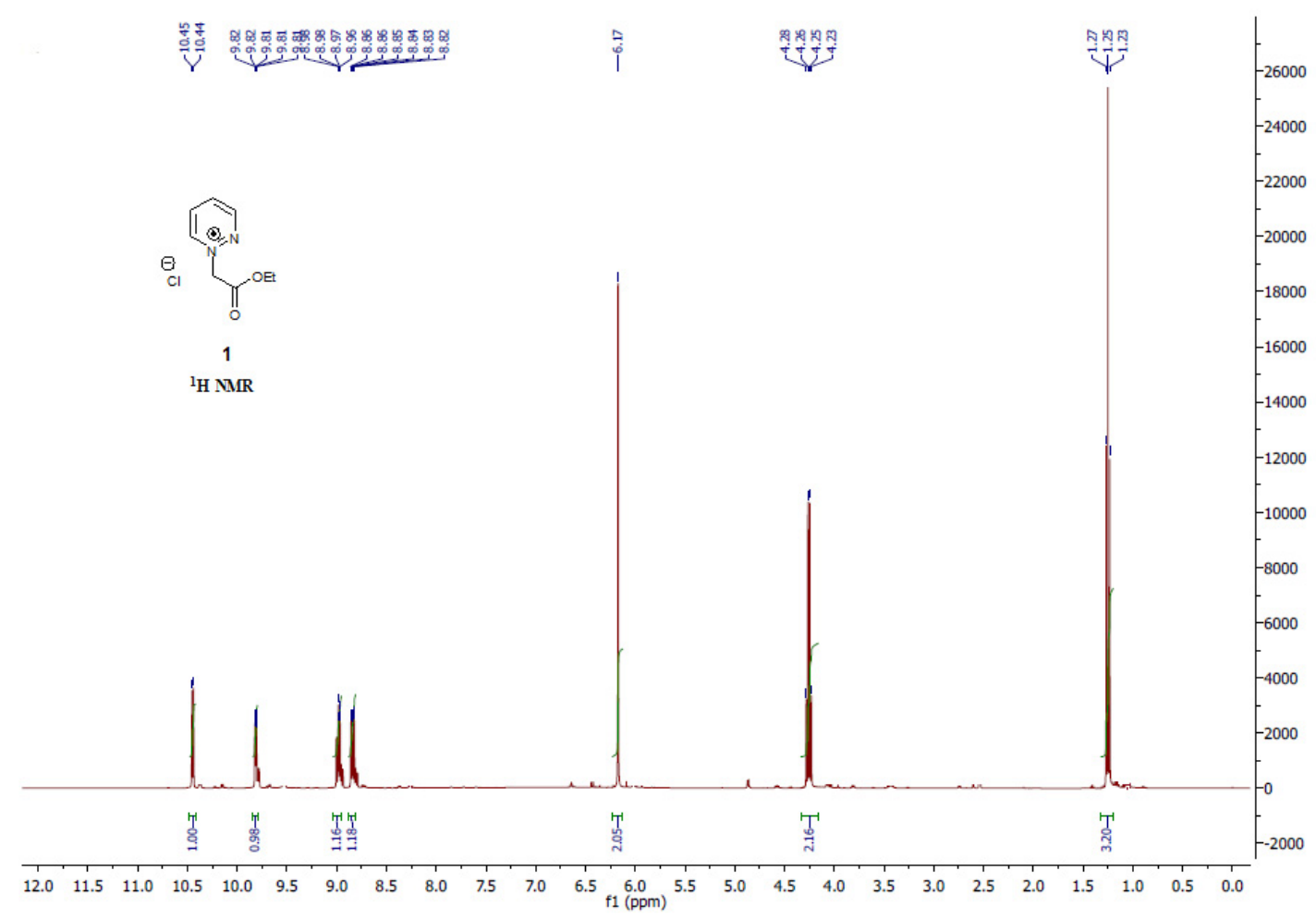

S1: ${ }^{1} \mathrm{H}$ NMR spectrum of IL 1 in DMSO (400 MHz)

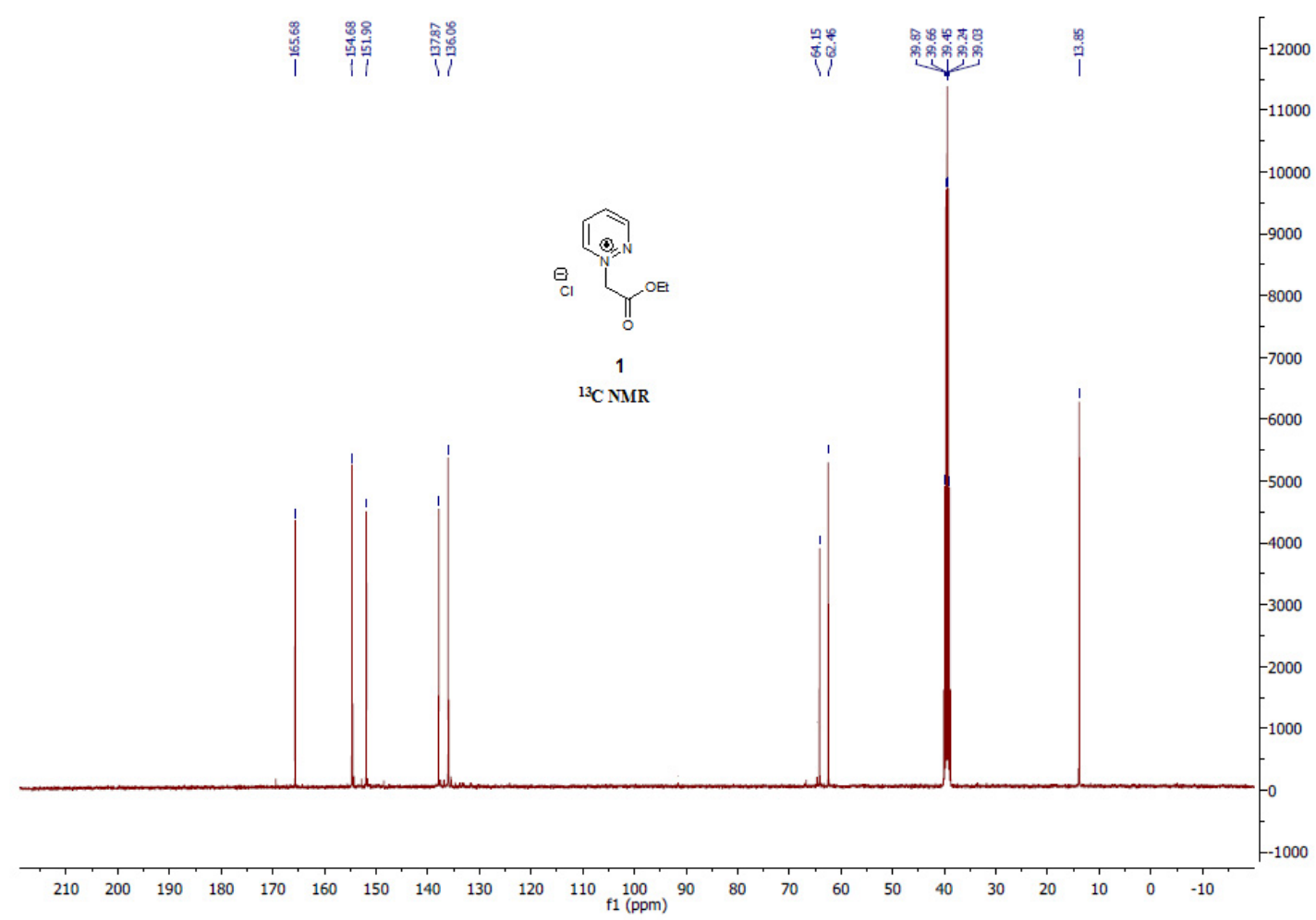

S1: ${ }^{13} \mathrm{C}$ NMR spectrum of IL 1 in DMSO (100 MHz) 


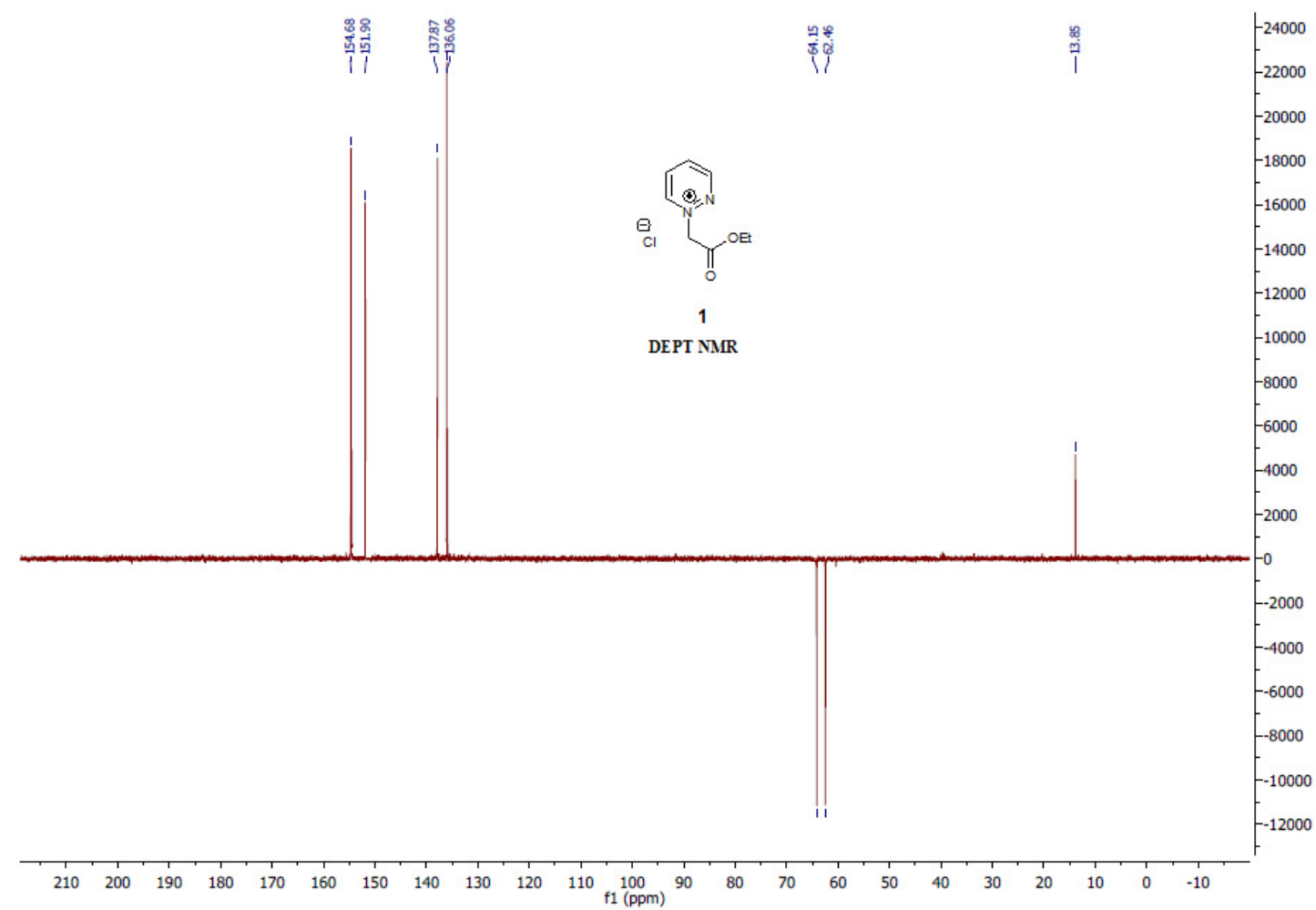

S1: DEPT- 135 NMR spectrum of IL 1 in DMSO (100 MHz)

$\begin{array}{ll}\text { Scan \# }: 4 & \\ \text { Mass Peak \# : } 40 \text { Ret. Time : } 0.067\end{array}$

Base Peak : 80.10 ( 123189 )

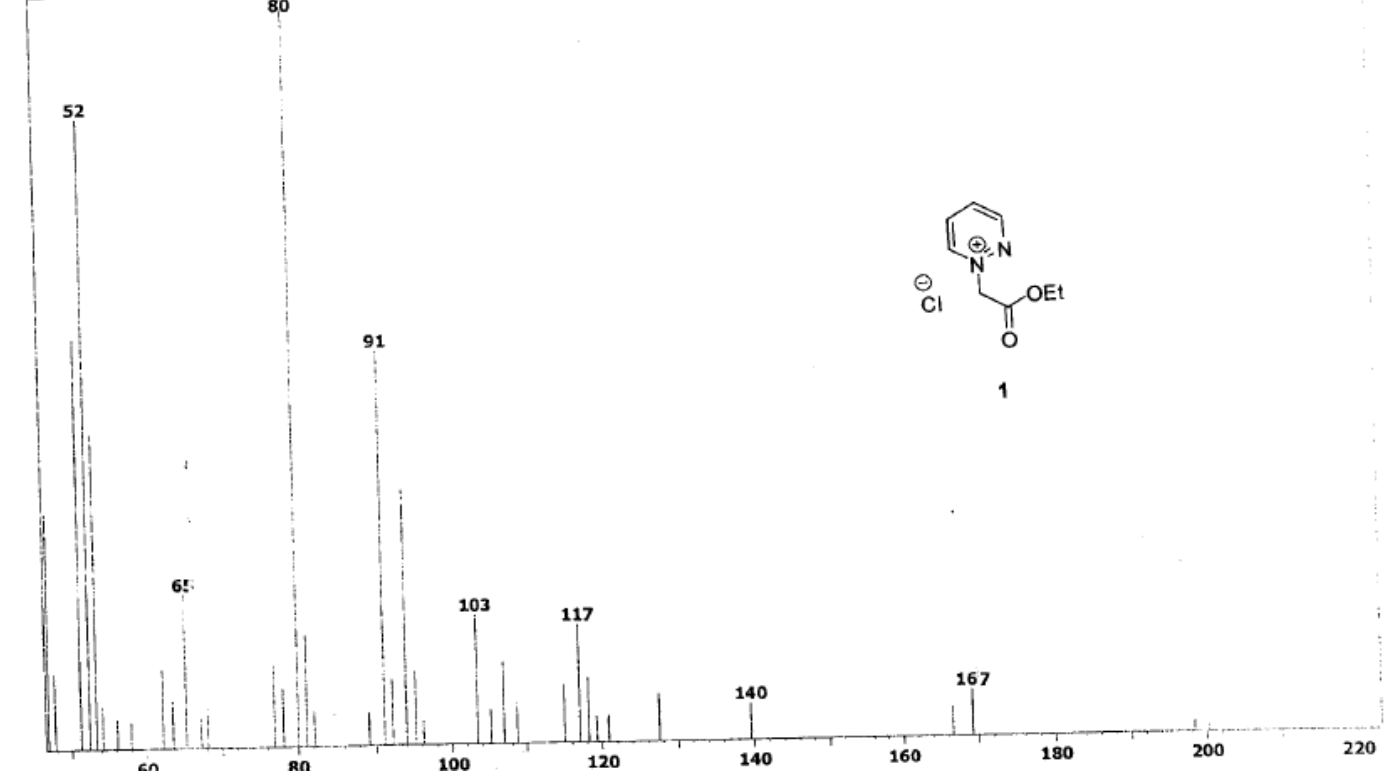

S1: (LCMS) Mass spectrum of IL 1 


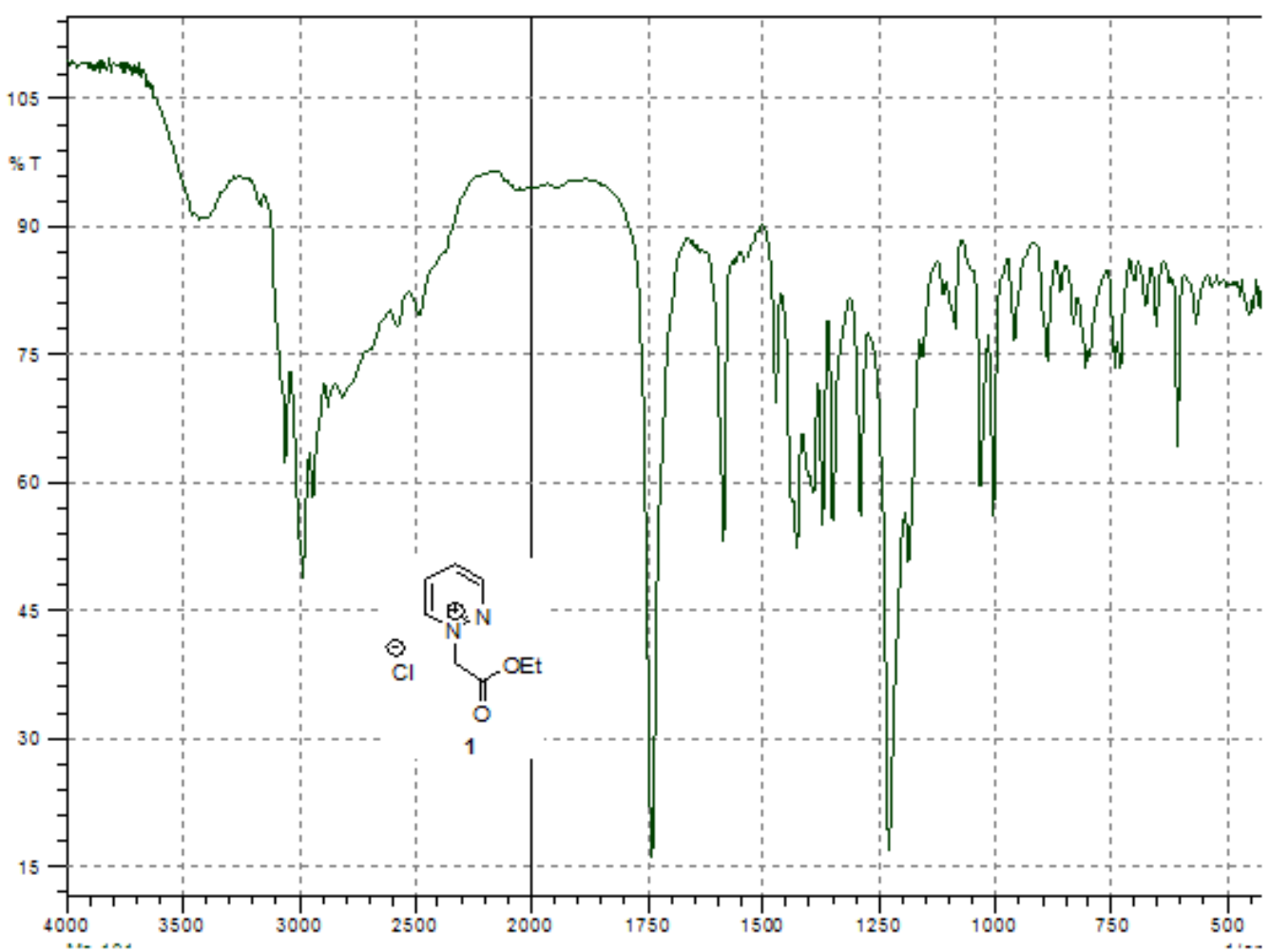

S1: IR spectrum of IL 1

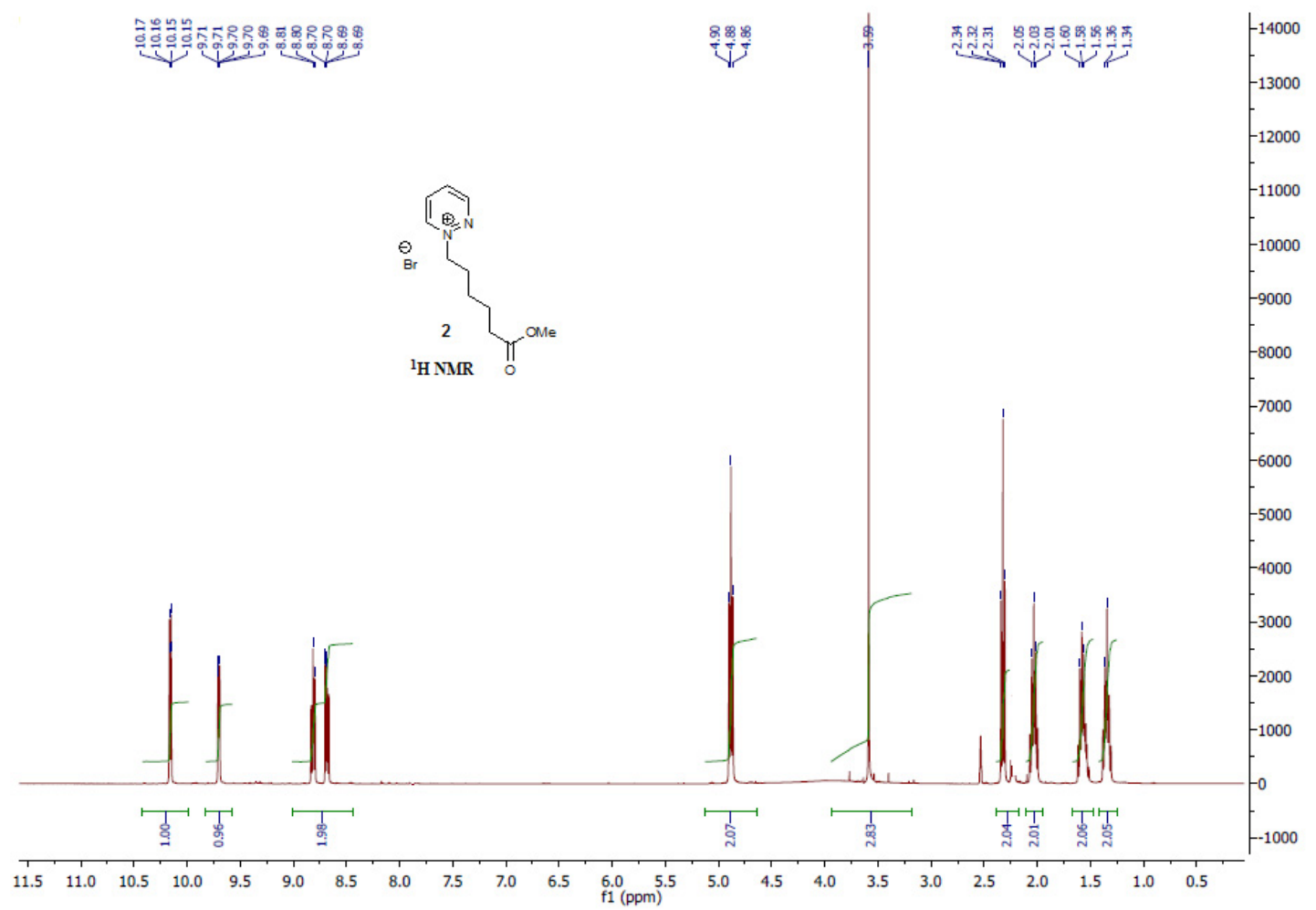

S2: ${ }^{1} \mathrm{H}$ NMR spectrum of IL 2 in DMSO (400 MHz) 


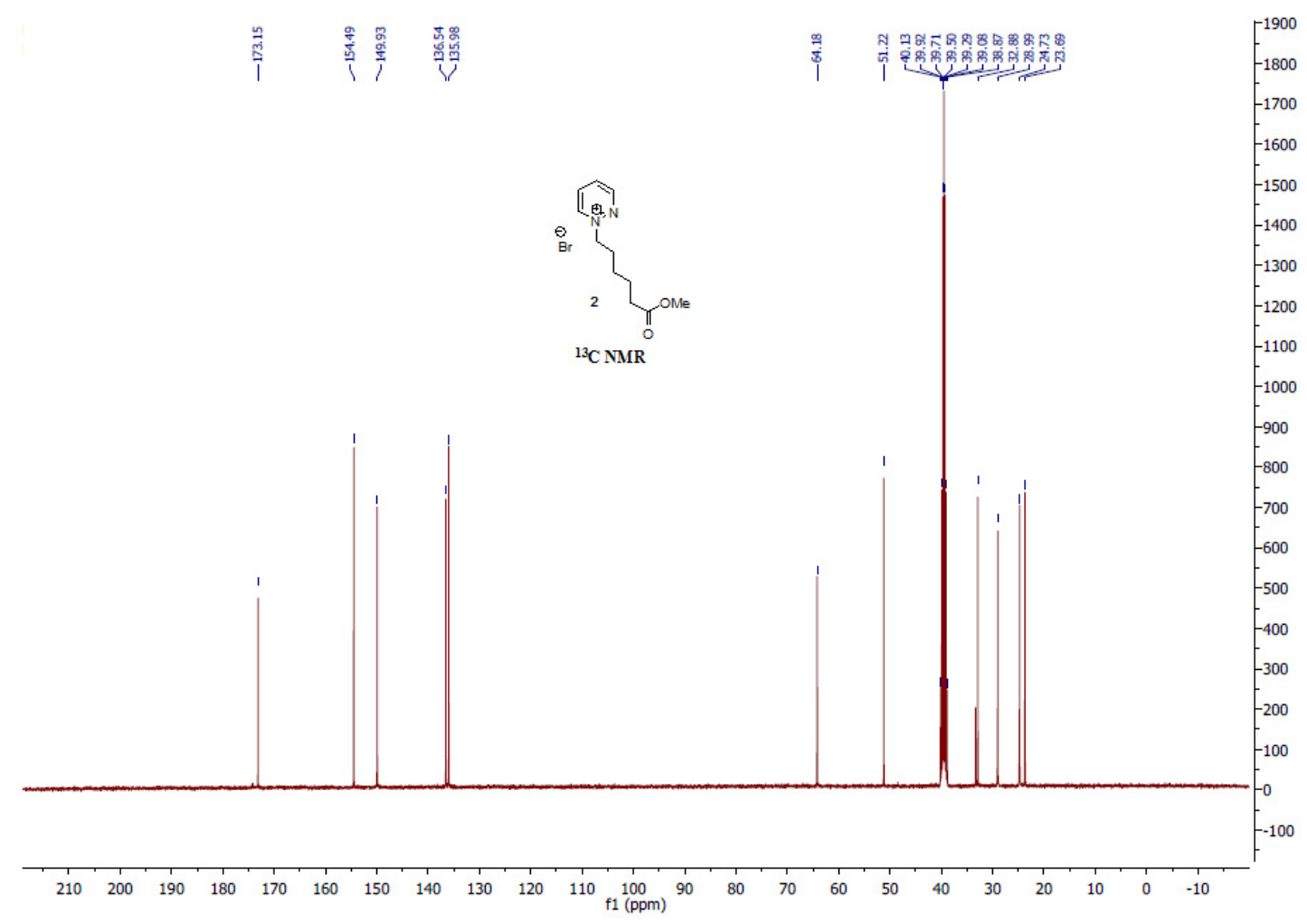

S2: ${ }^{13} \mathrm{C}$ NMR spectrum of IL 2 in DMSO (100 MHz)

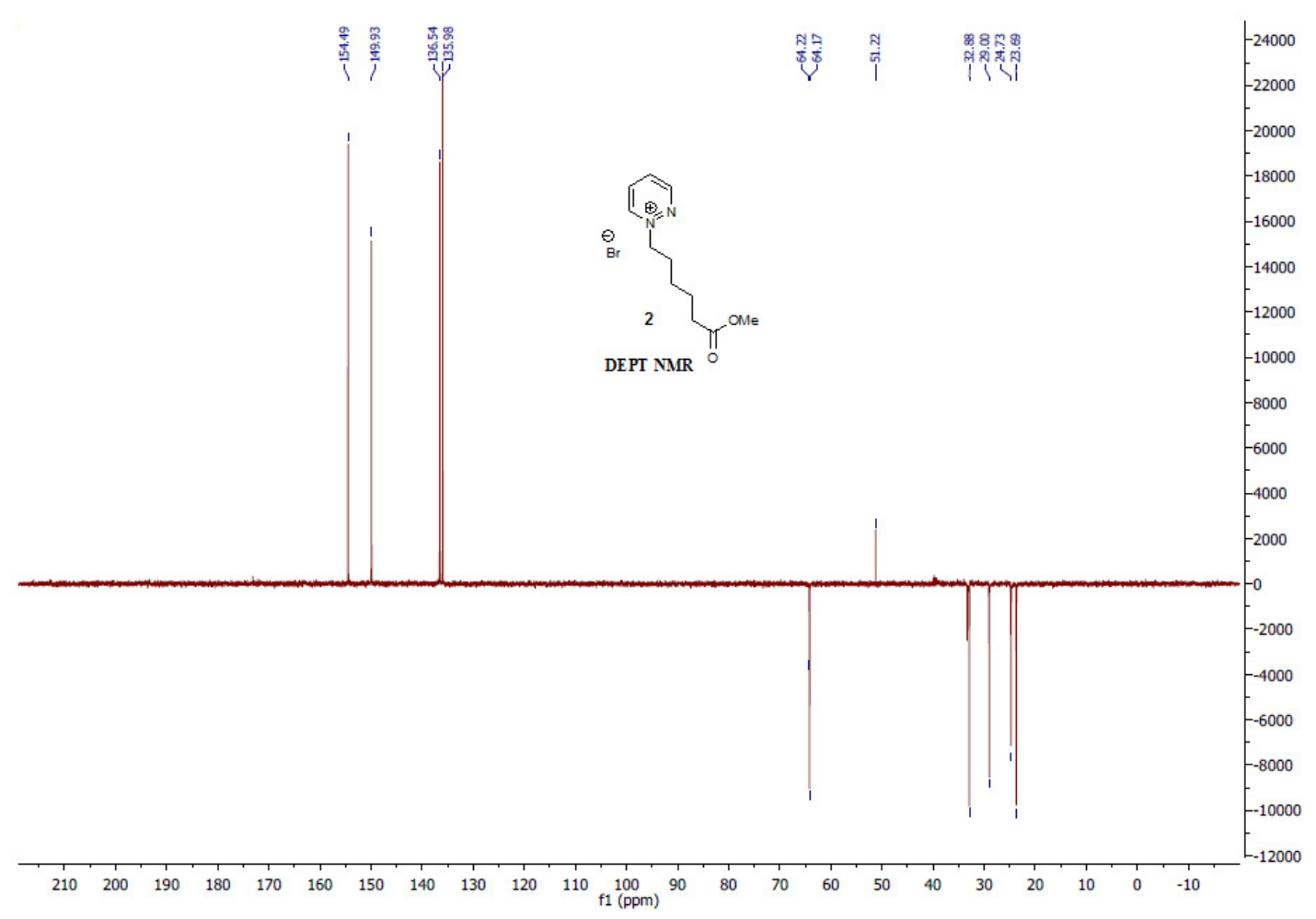

S2: DEPT- 135 NMR spectrum of IL 2 in DMSO (100 MHz) 


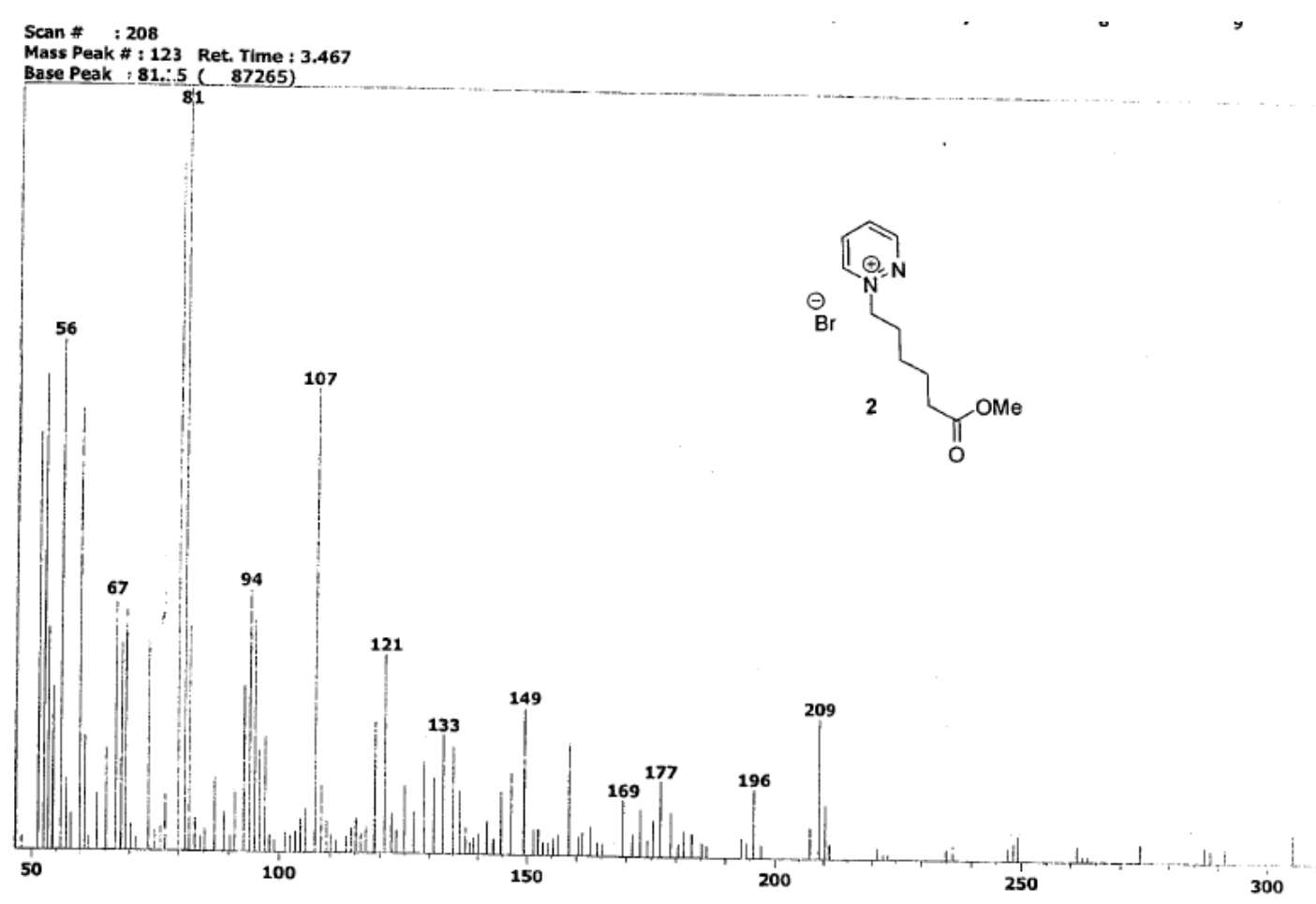

S2: (LCMS) Mass spectrum of IL 2

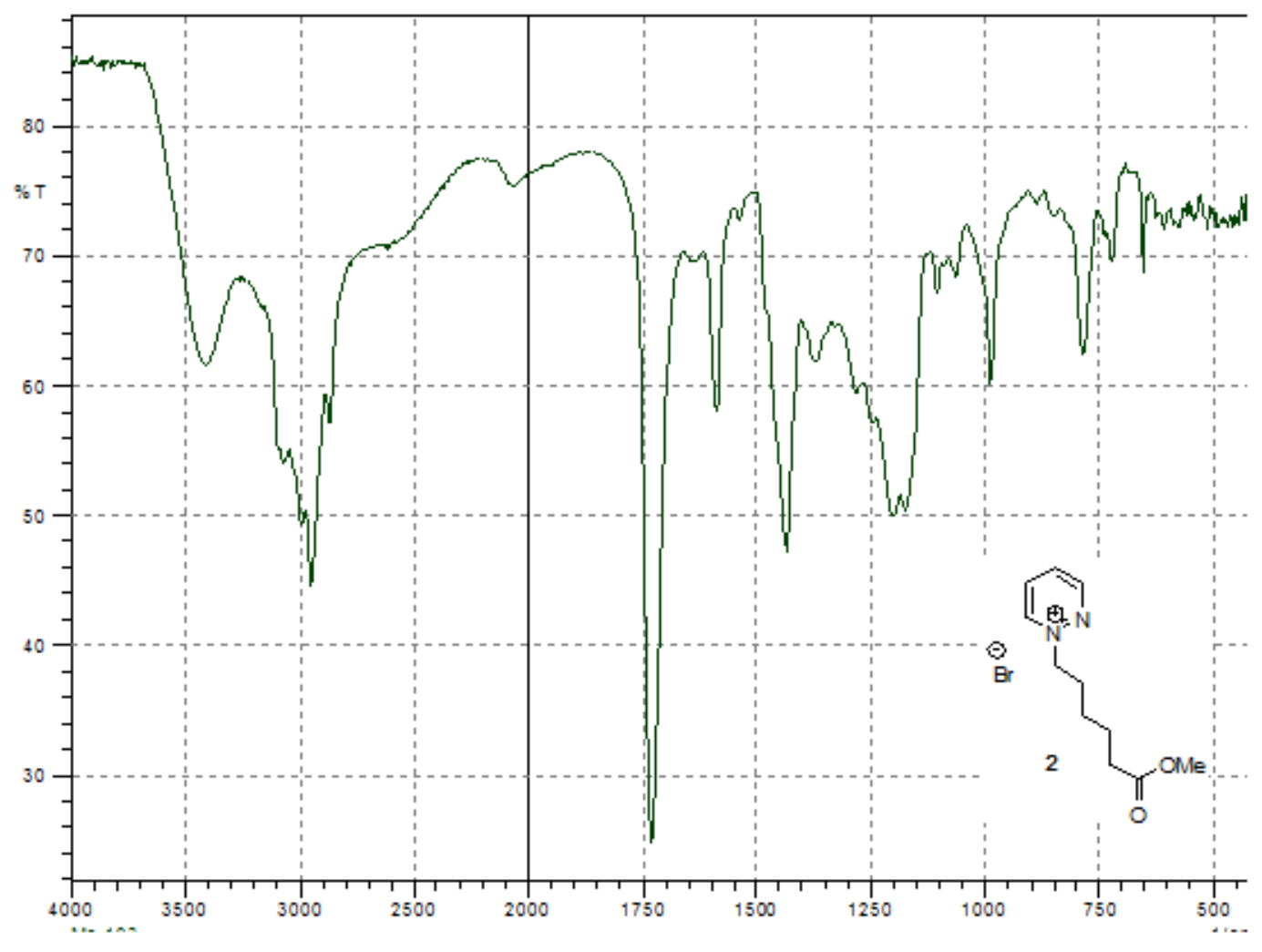

S2: IR spectrum of IL 2 


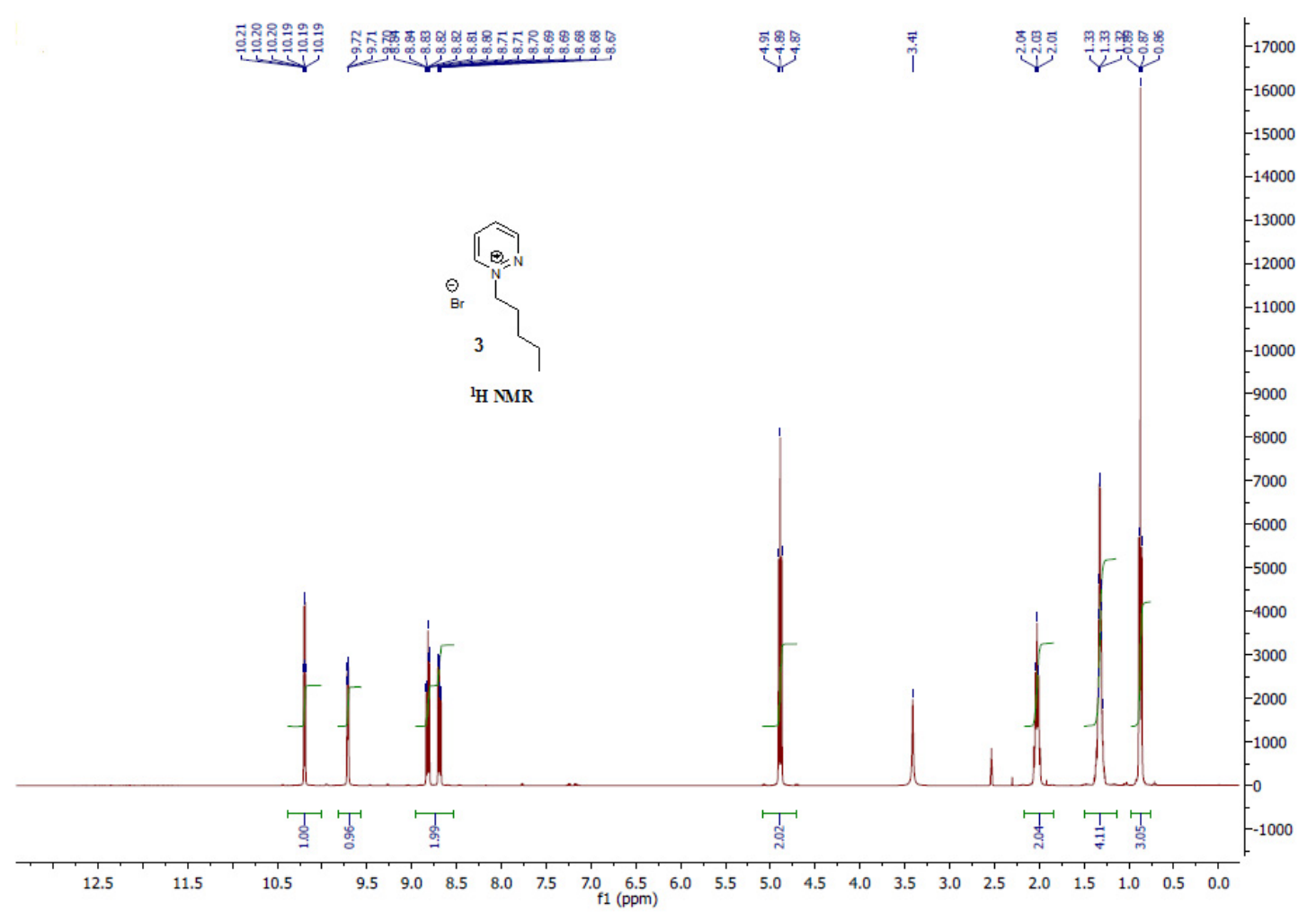

S3: ${ }^{1} \mathrm{H}$ NMR spectrum of IL 3 in DMSO (400 MHz)

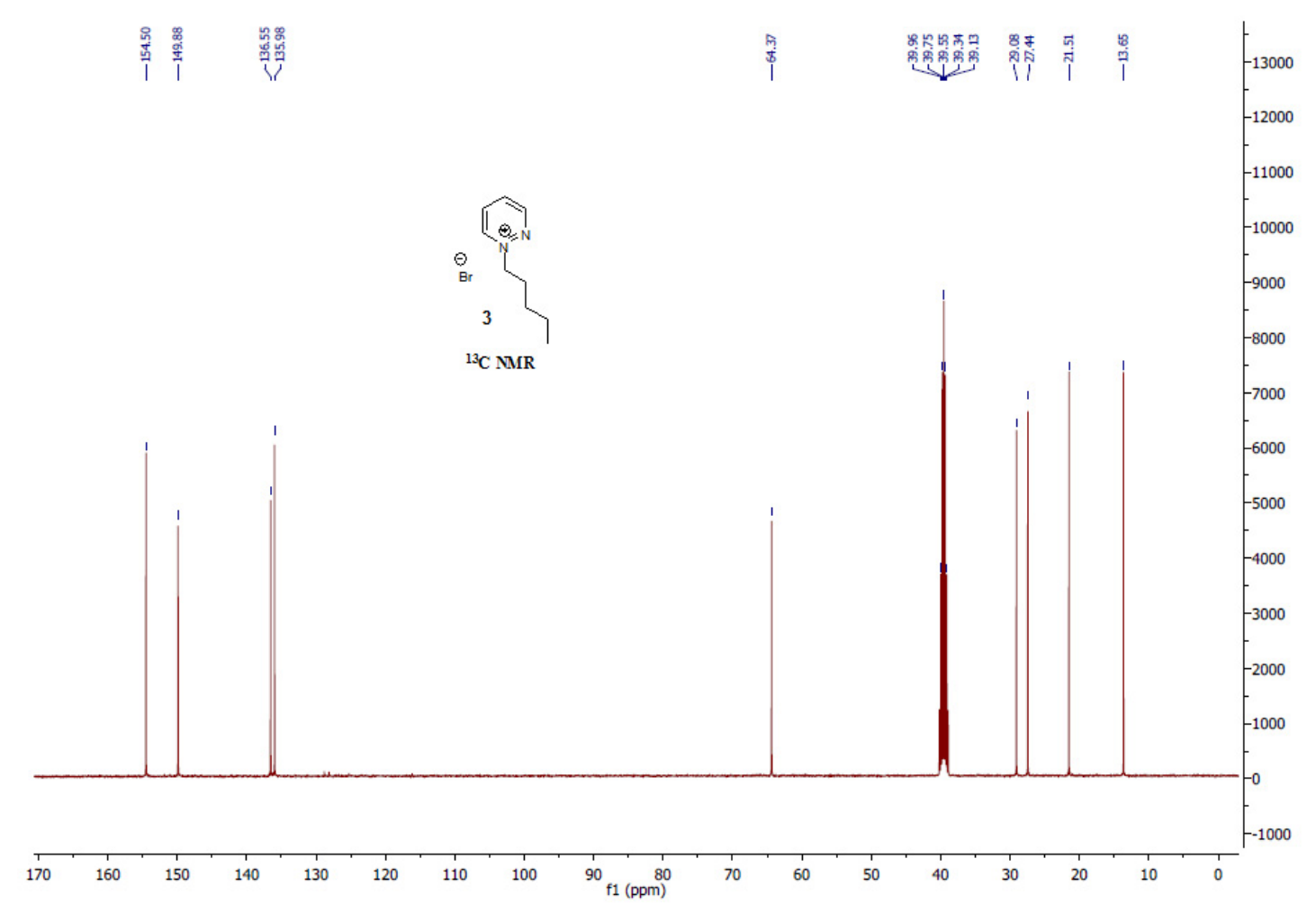

S3: ${ }^{13} \mathrm{C}$ NMR spectrum of IL 3 in DMSO (100 MHz) 


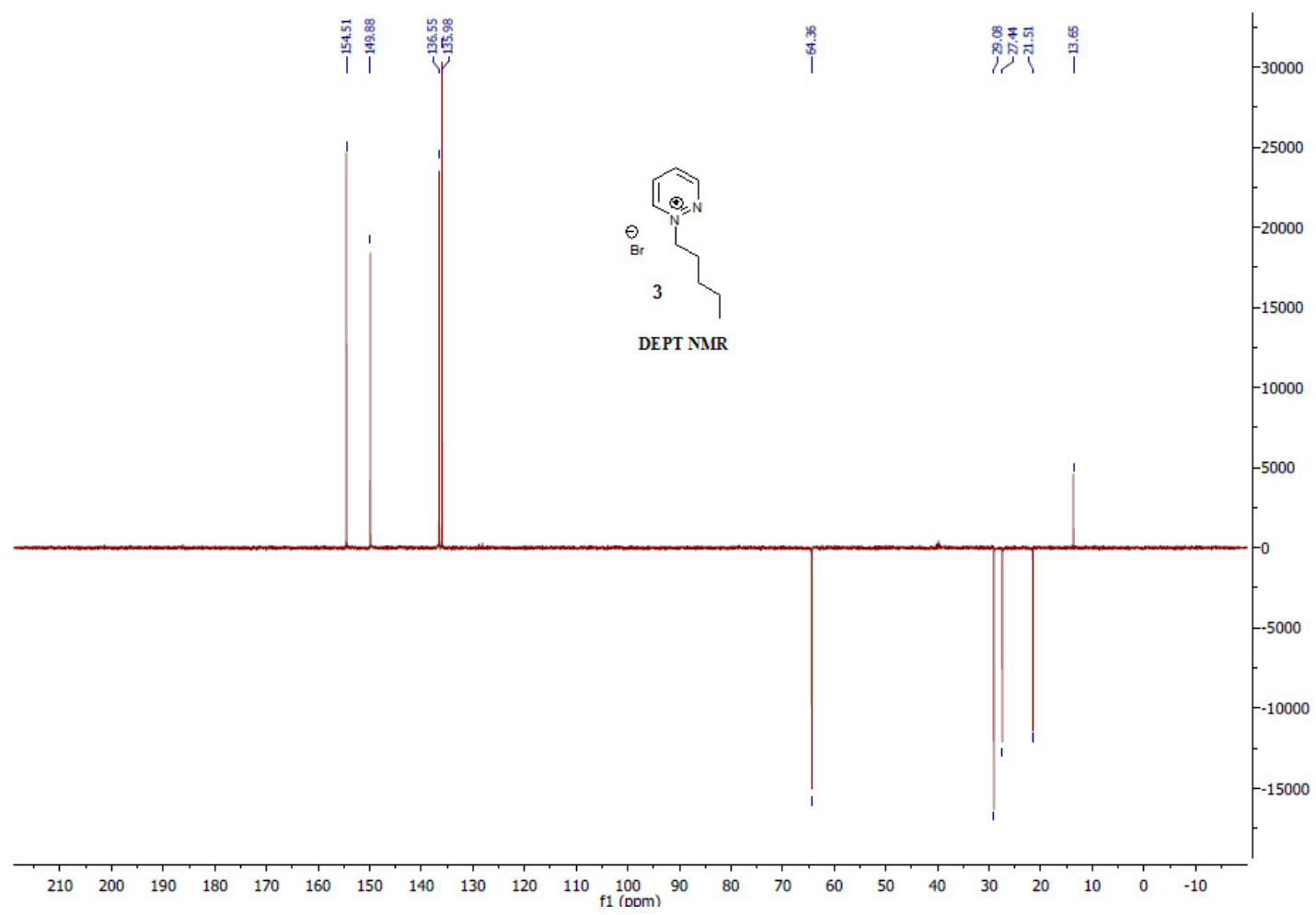

S3: DEPT- 135 NMR spectrum of IL 3 in DMSO (100 MHz)

Scan \#: : 153

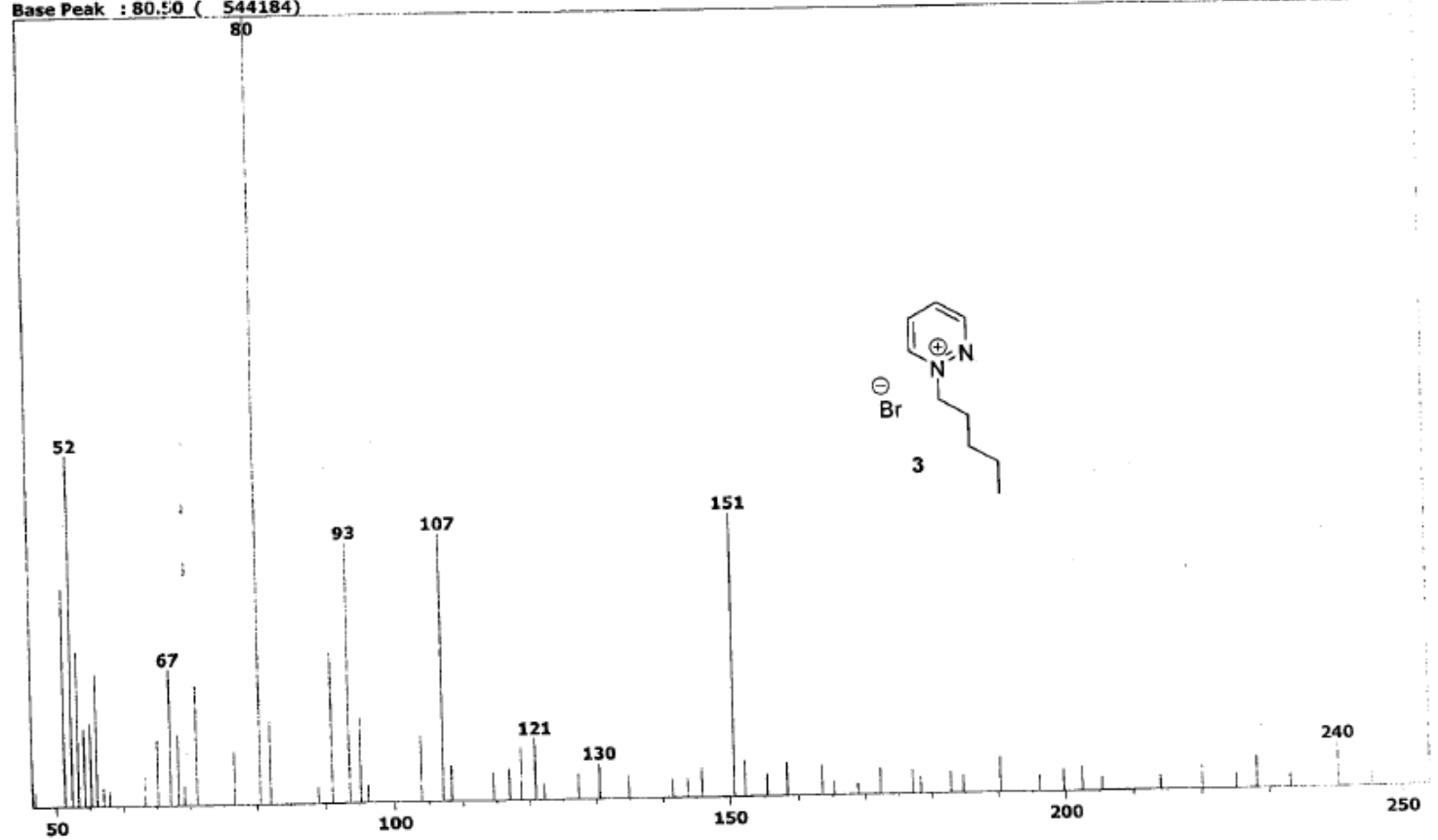

S3: (LCMS) Mass spectrum of IL 3 


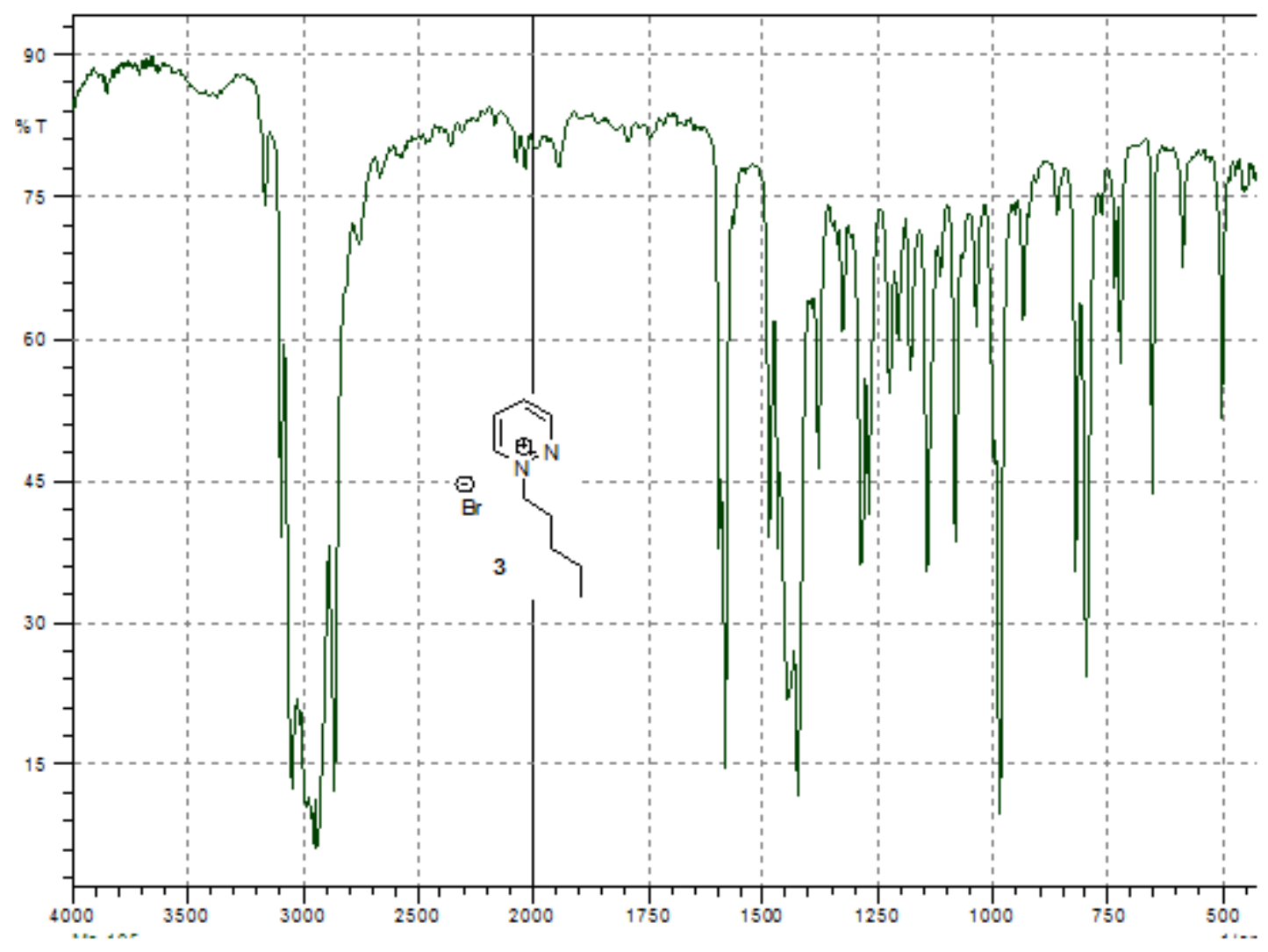

S3: IR spectrum of IL 3

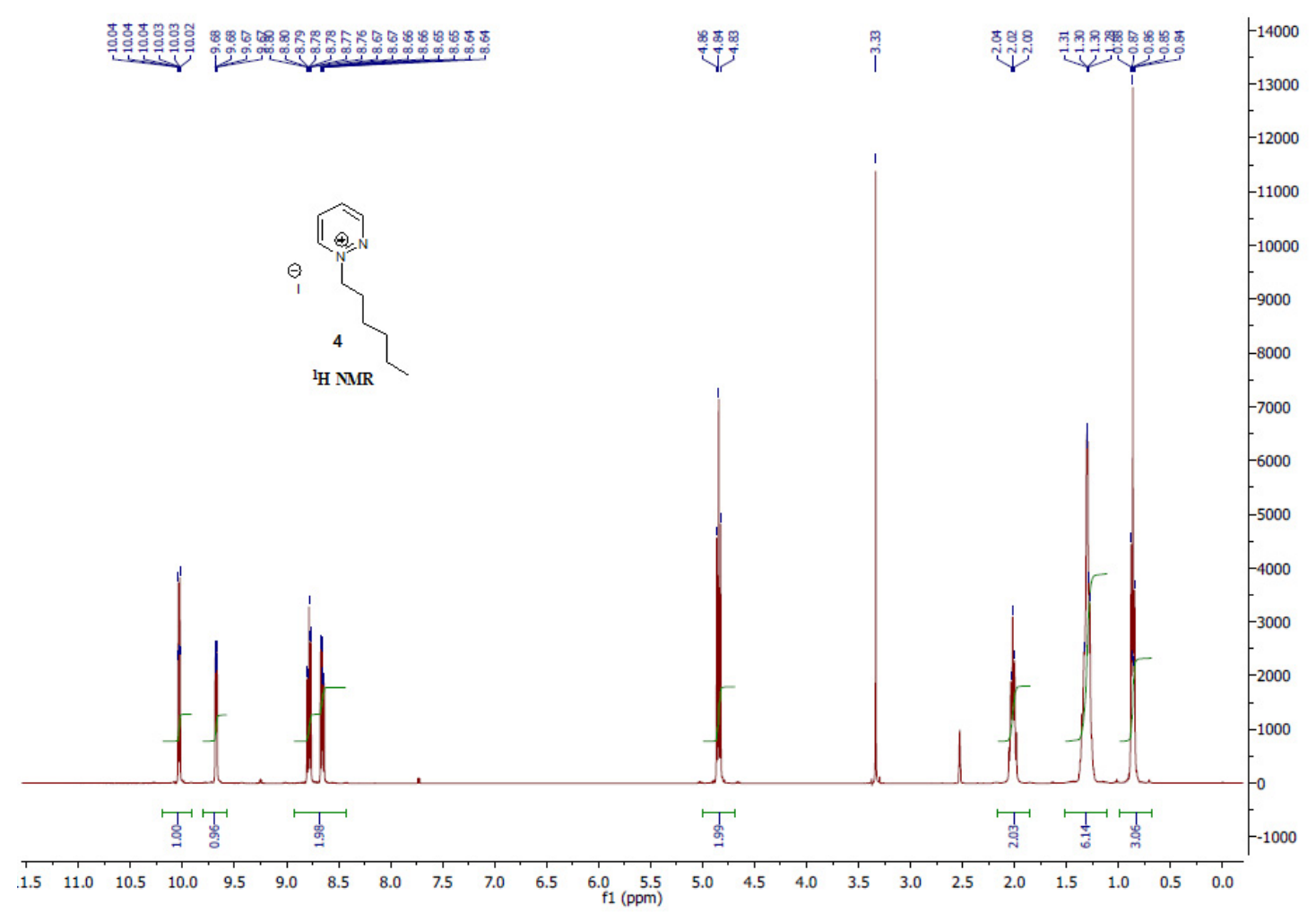


S4: ${ }^{1} \mathrm{H}$ NMR spectrum of IL 4 in DMSO (400 MHz)

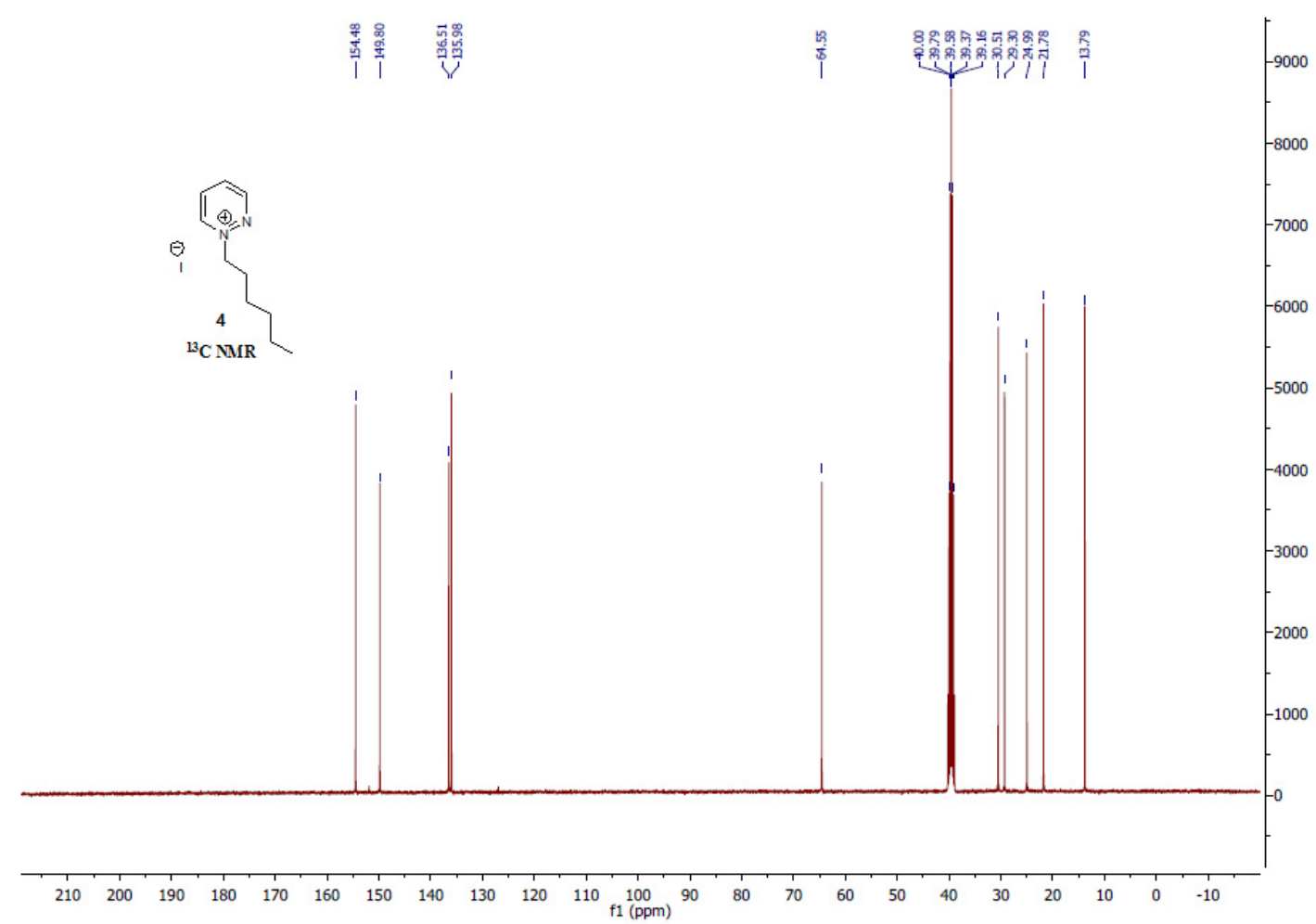

S4: ${ }^{13} \mathrm{C}$ NMR spectrum of IL 4 in DMSO (100 MHz)

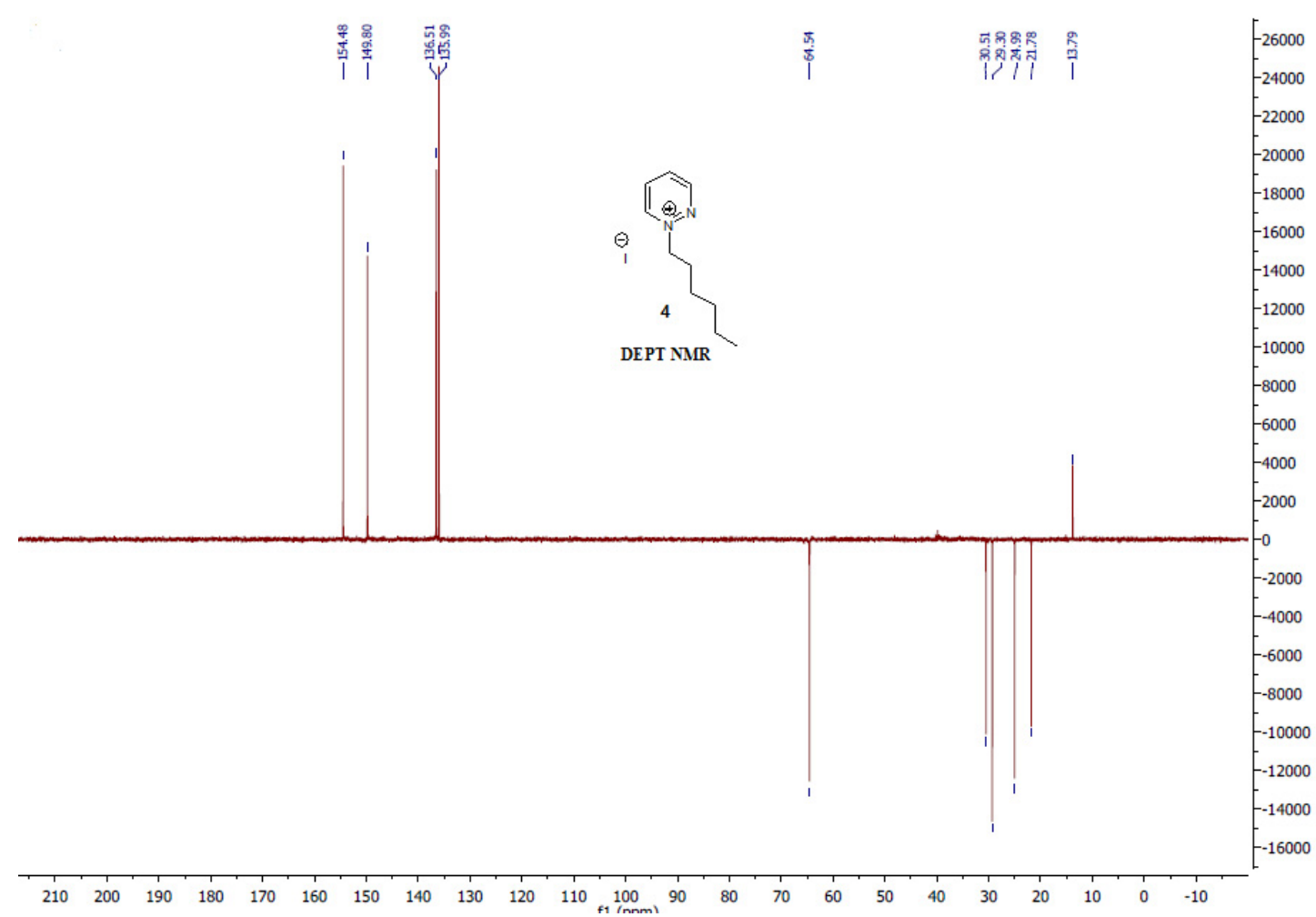


S4: DEPT- 135 NMR spectrum of IL 4 in DMSO (100 MHz)

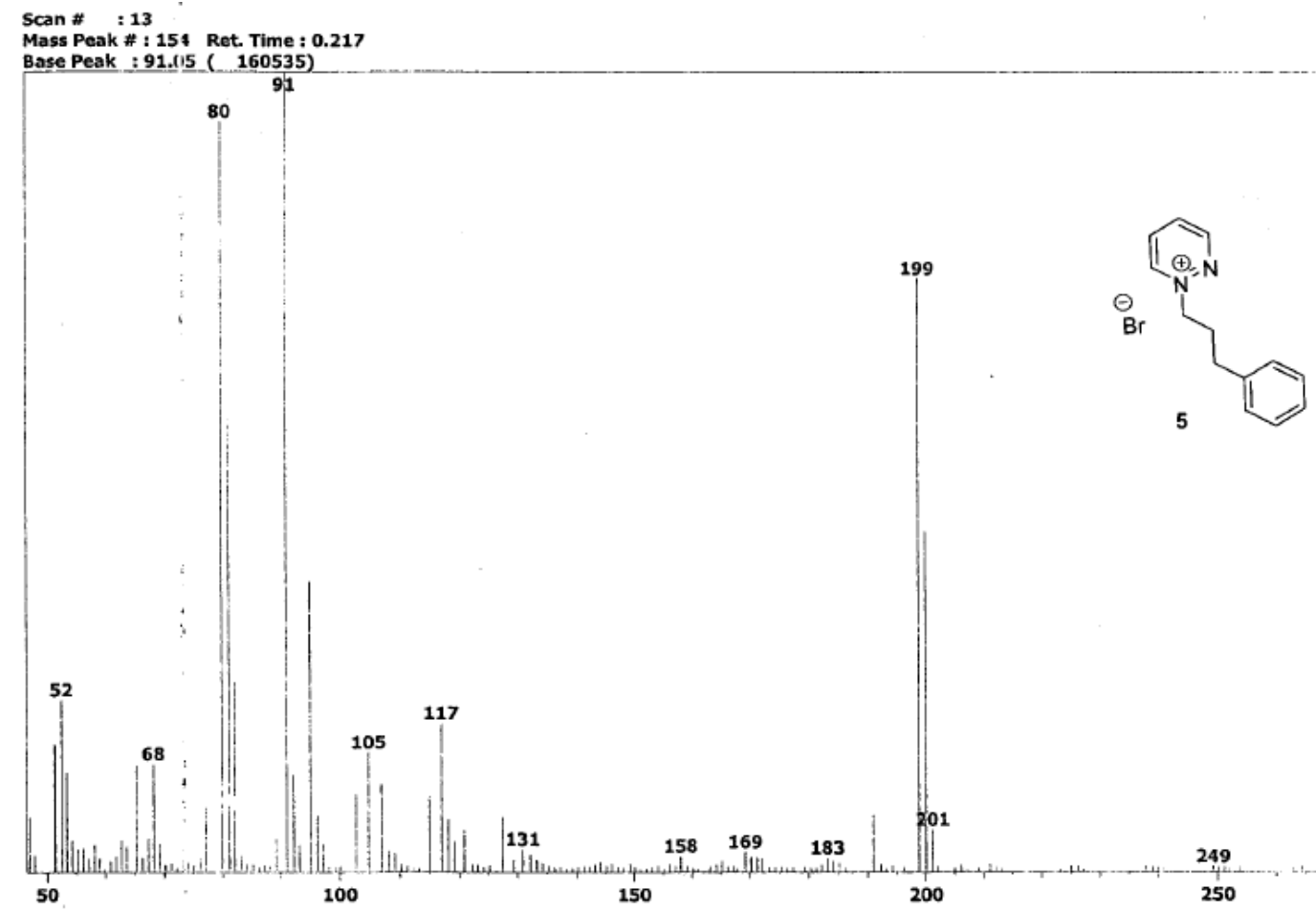

S4: (LCMS) Mass spectrum of IL 4

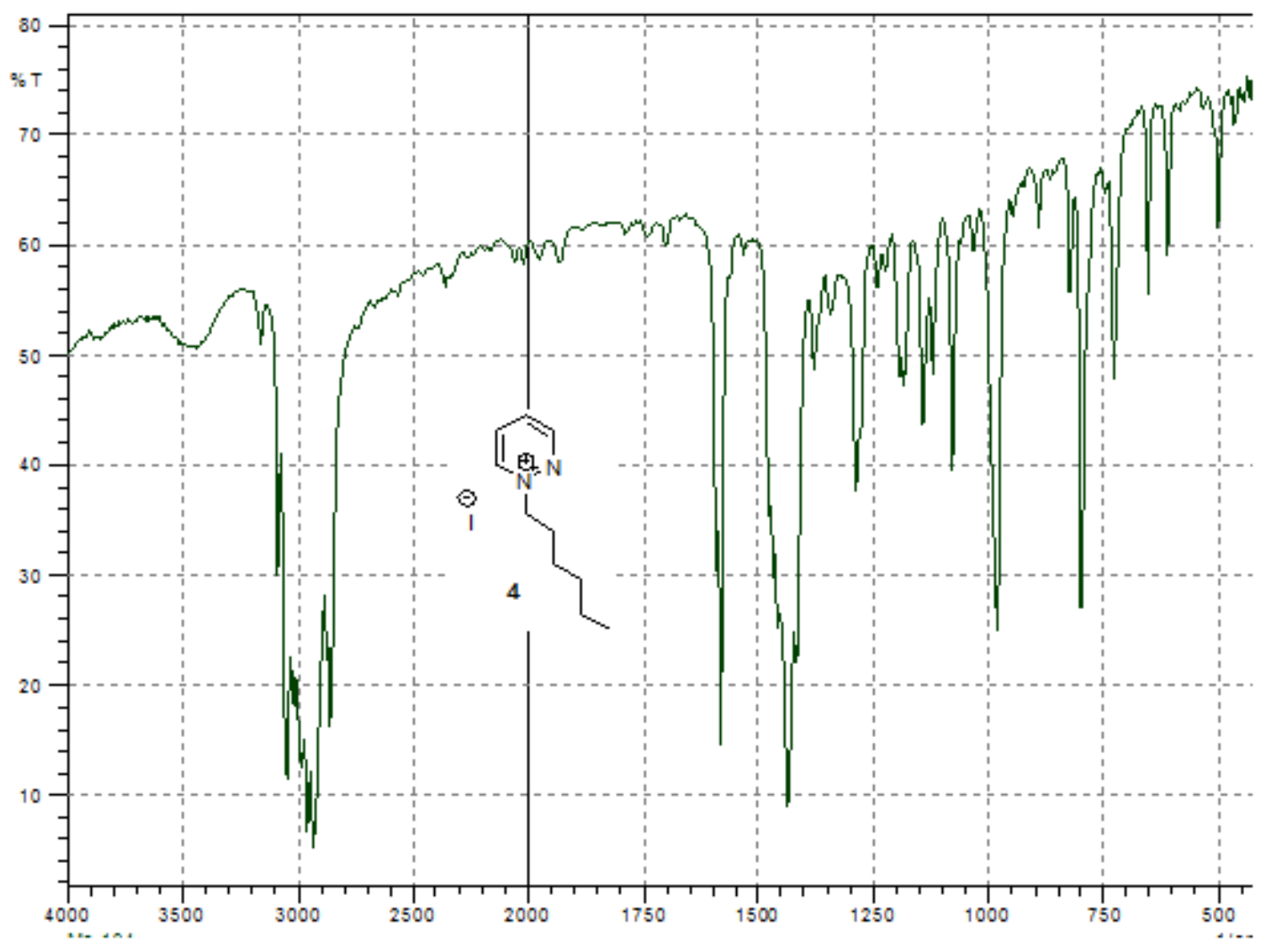

S4: IR spectrum of IL 4 


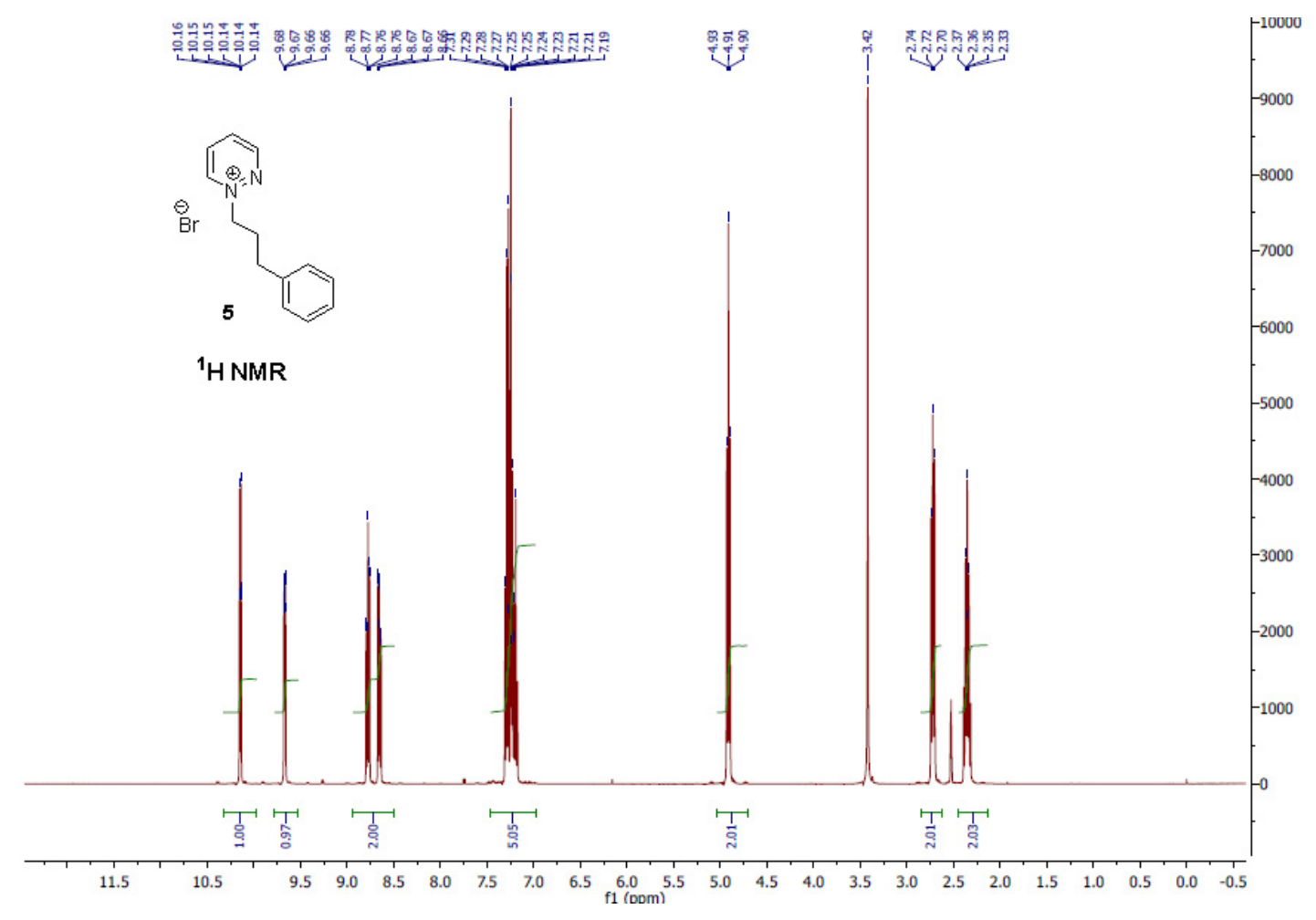

S5: ${ }^{1} \mathrm{H}$ NMR spectrum of IL 5 in DMSO (400 MHz)

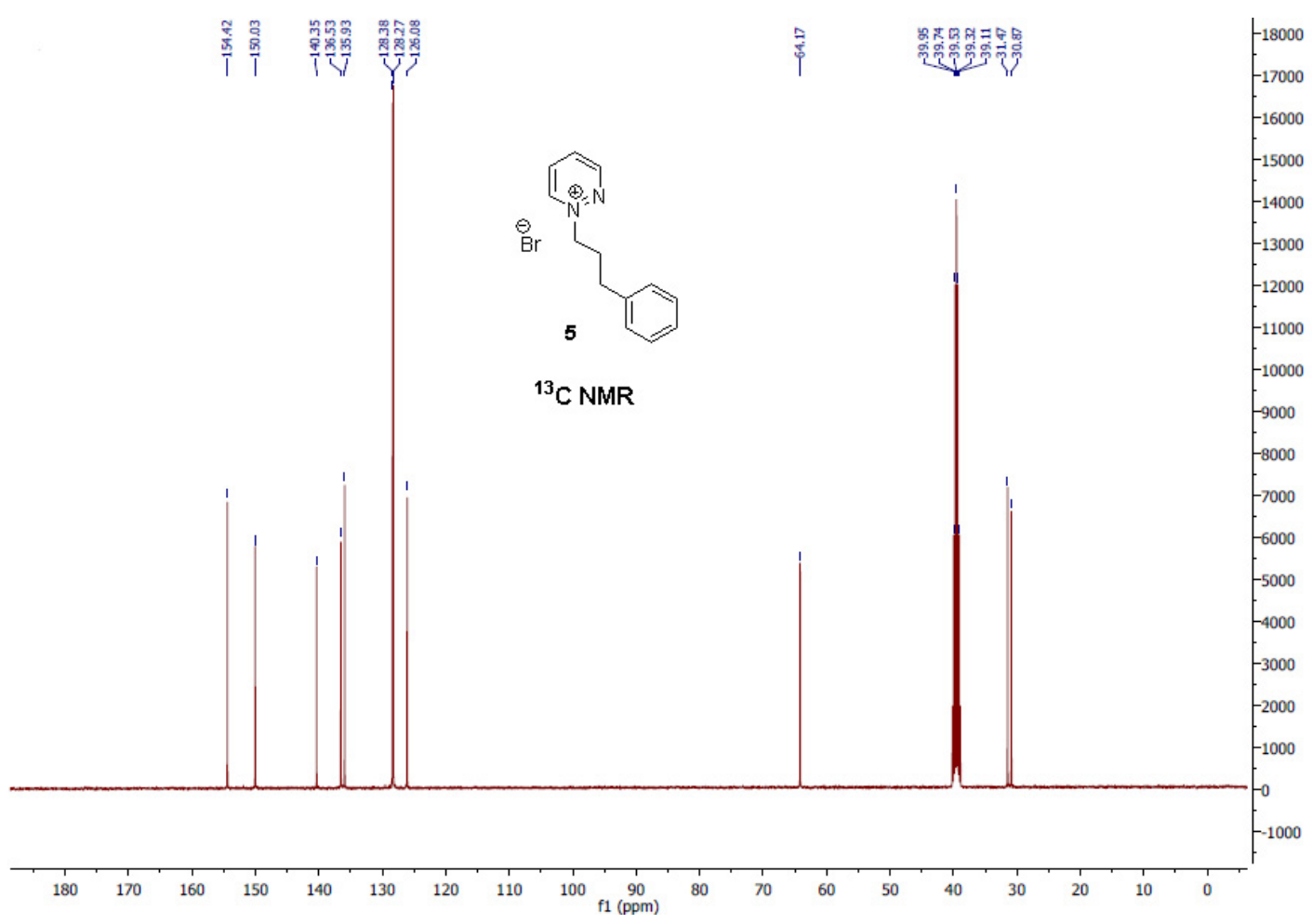

S5: ${ }^{13} \mathrm{C}$ NMR spectrum of IL 5 in DMSO (100 MHz) 


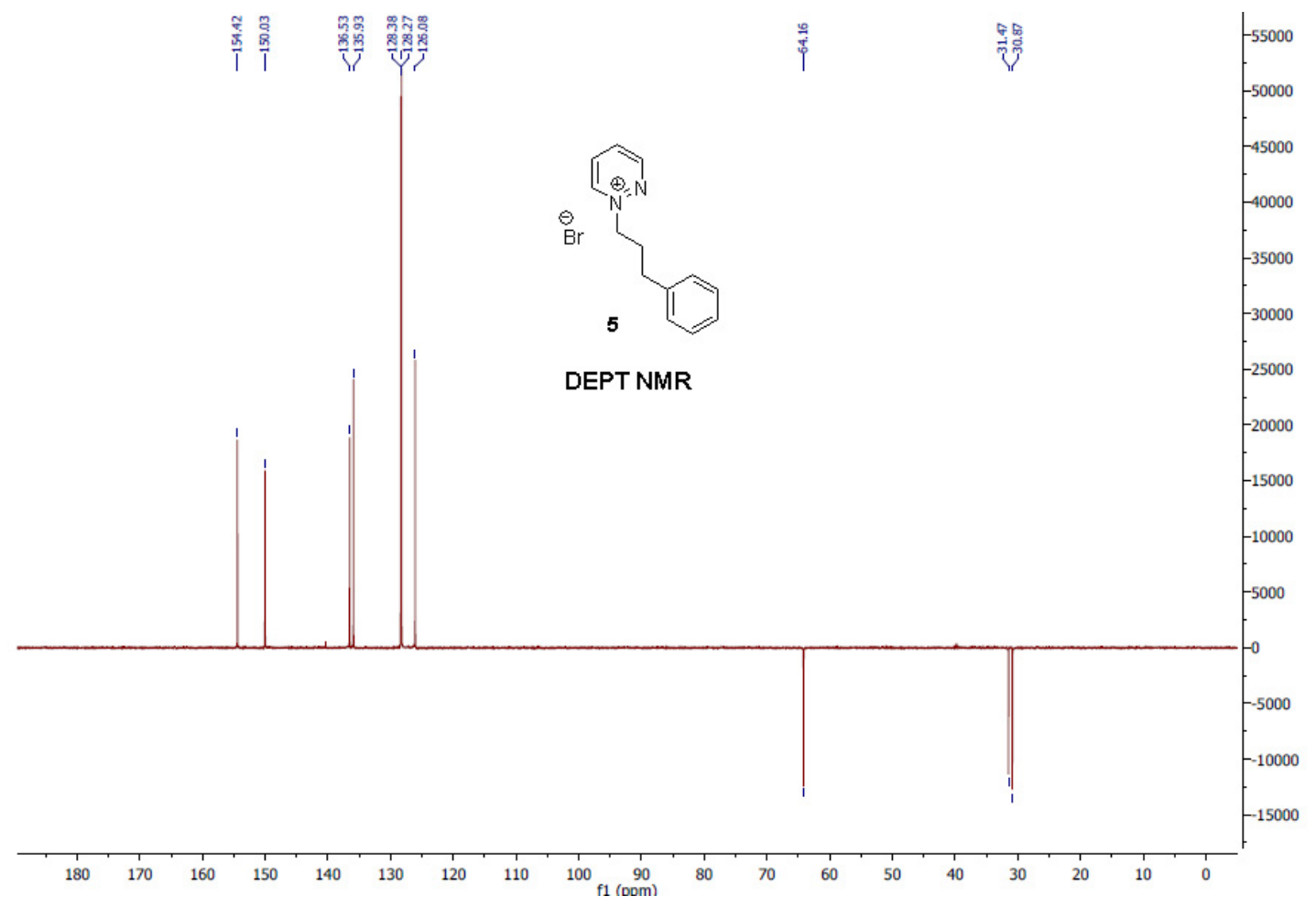

S5: DEPT- 135 NMR spectrum of IL 5 in DMSO (100 MHz)

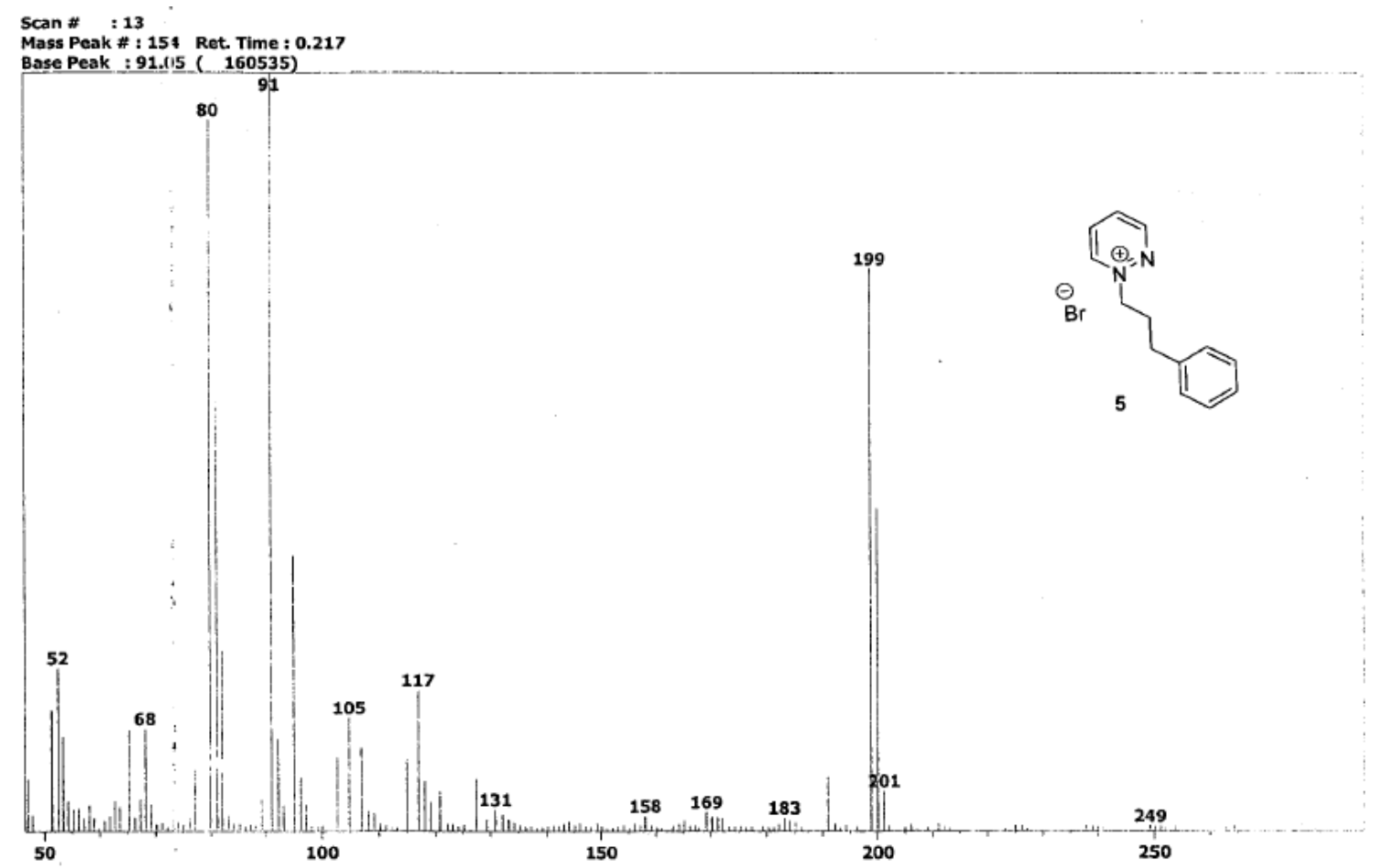

S5: (LCMS) Mass spectrum of IL 5 


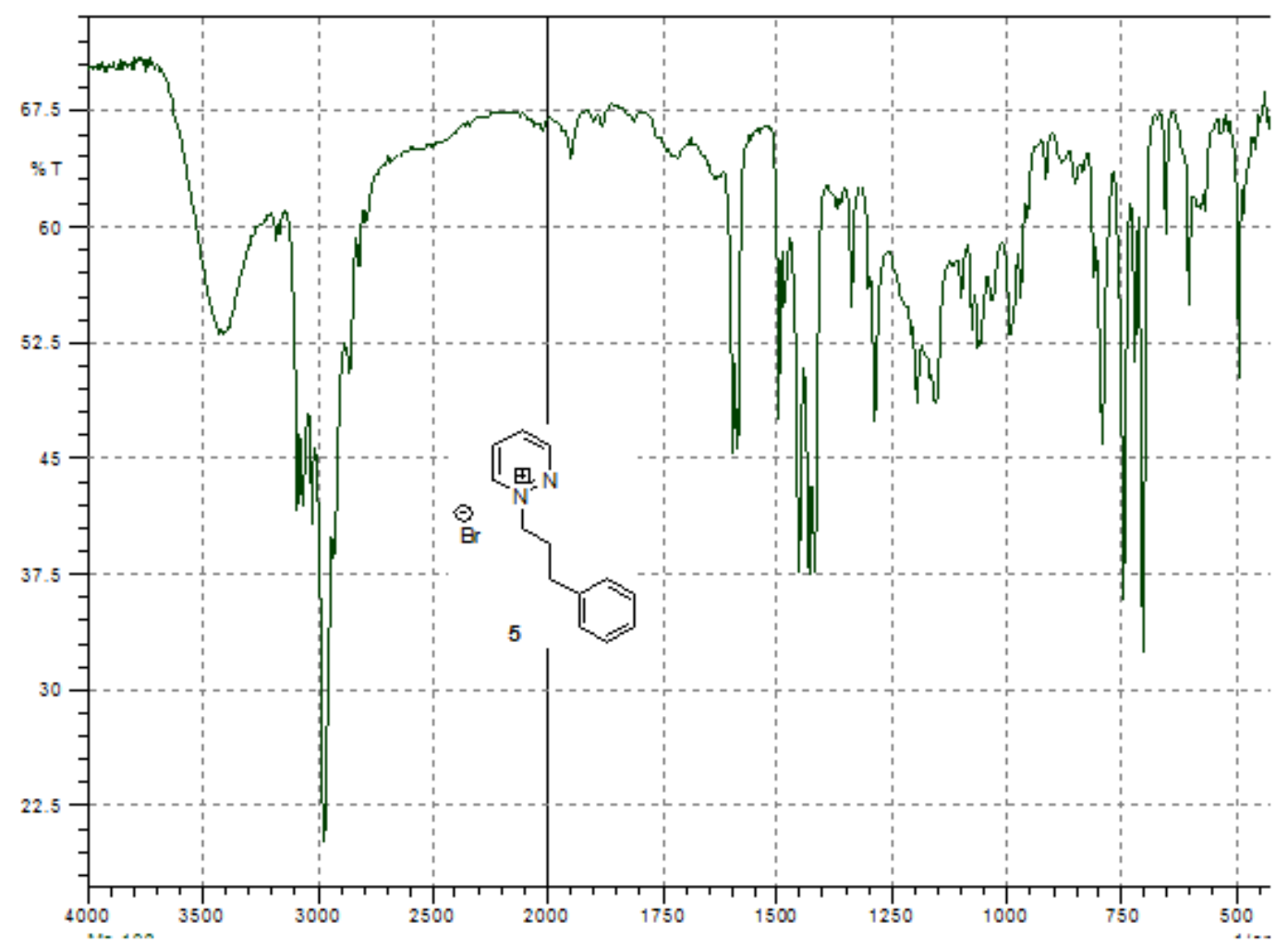

S5: IR spectrum of IL 5

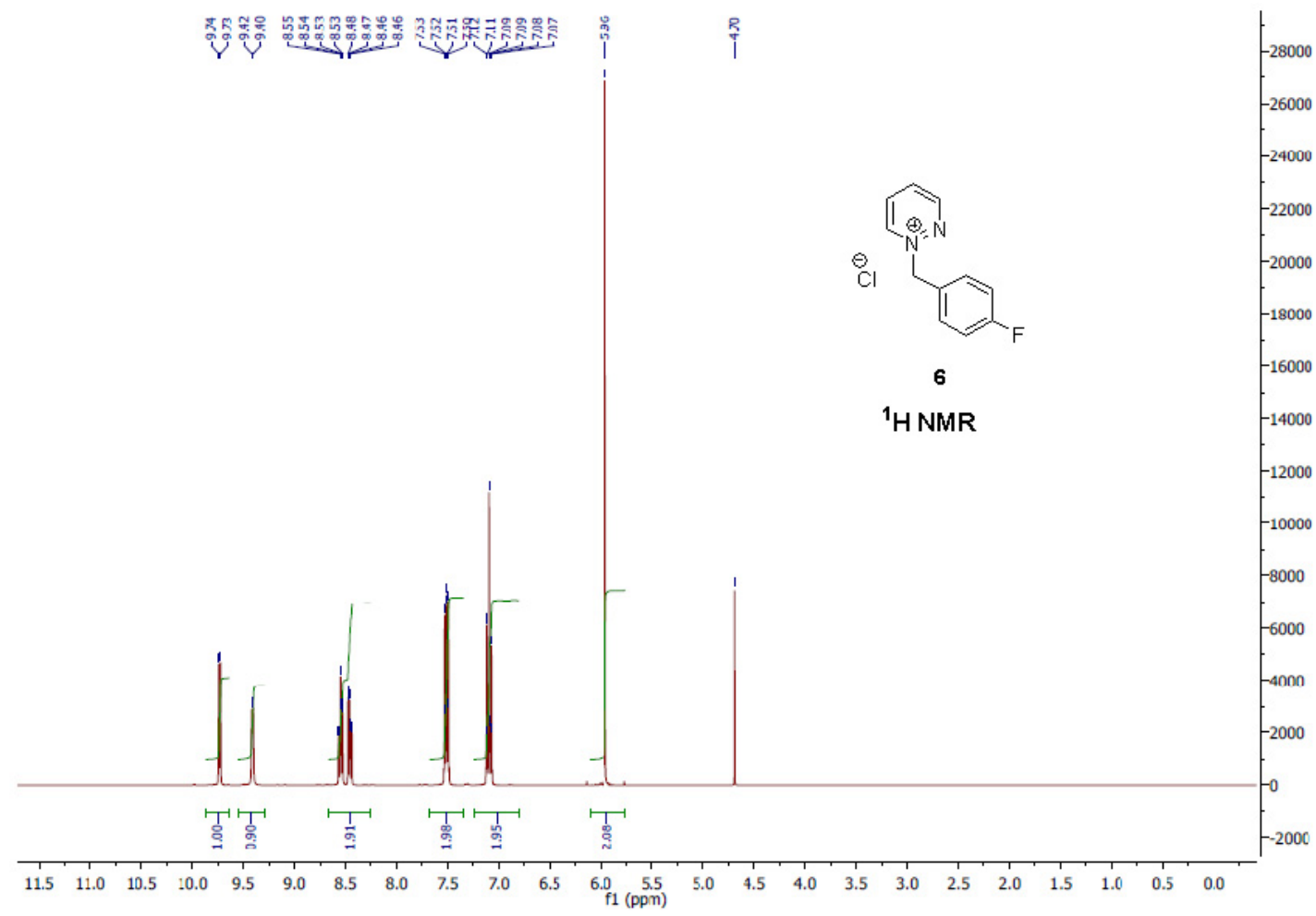

S6: ${ }^{1} \mathrm{H}$ NMR spectrum of IL 6 in $\mathrm{D}_{2} \mathrm{O}(400 \mathrm{MHz})$ 


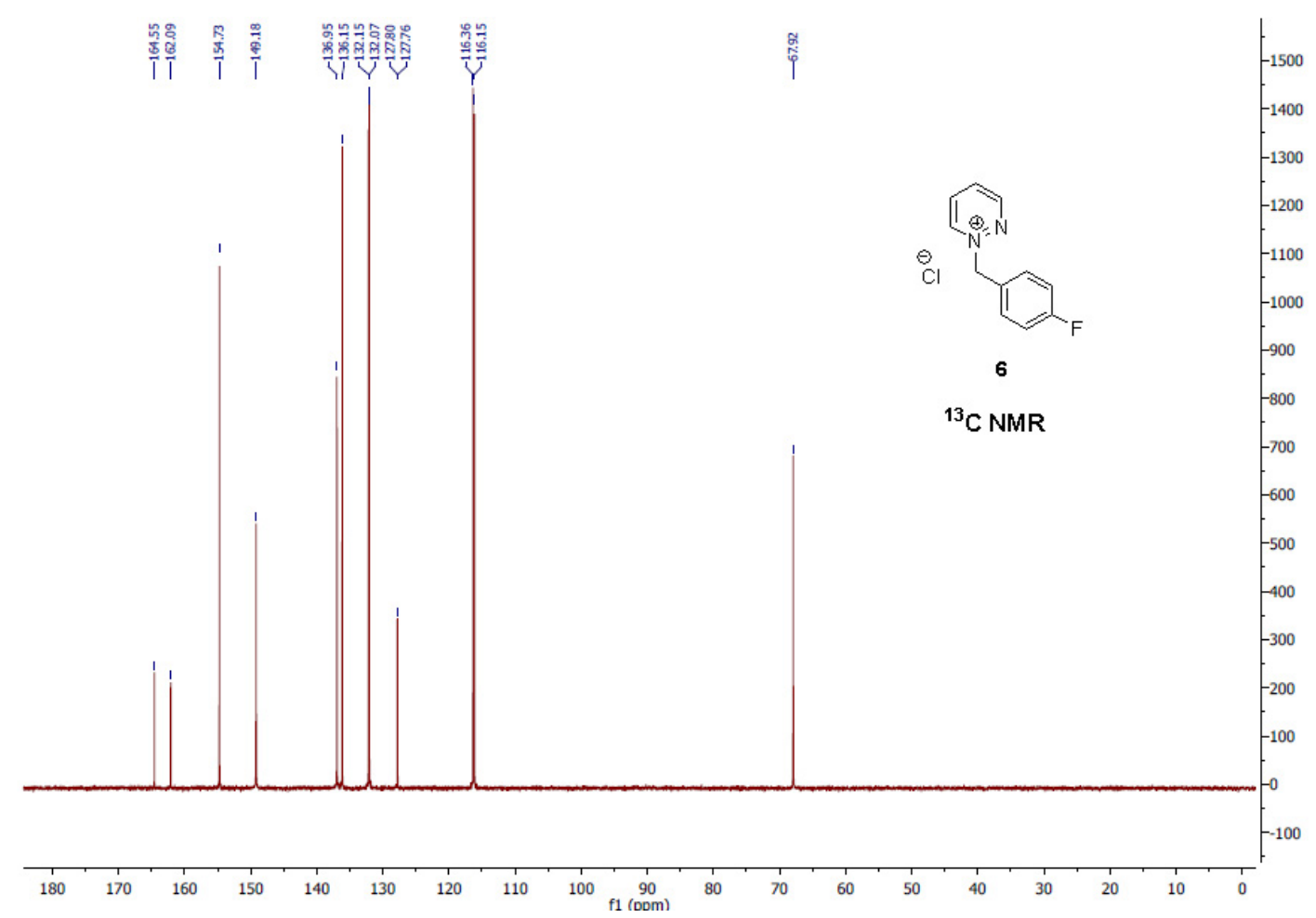

S6: ${ }^{13} \mathrm{C}$ NMR spectrum of IL 6 in $\mathrm{D}_{2} \mathrm{O}(100 \mathrm{MHz})$

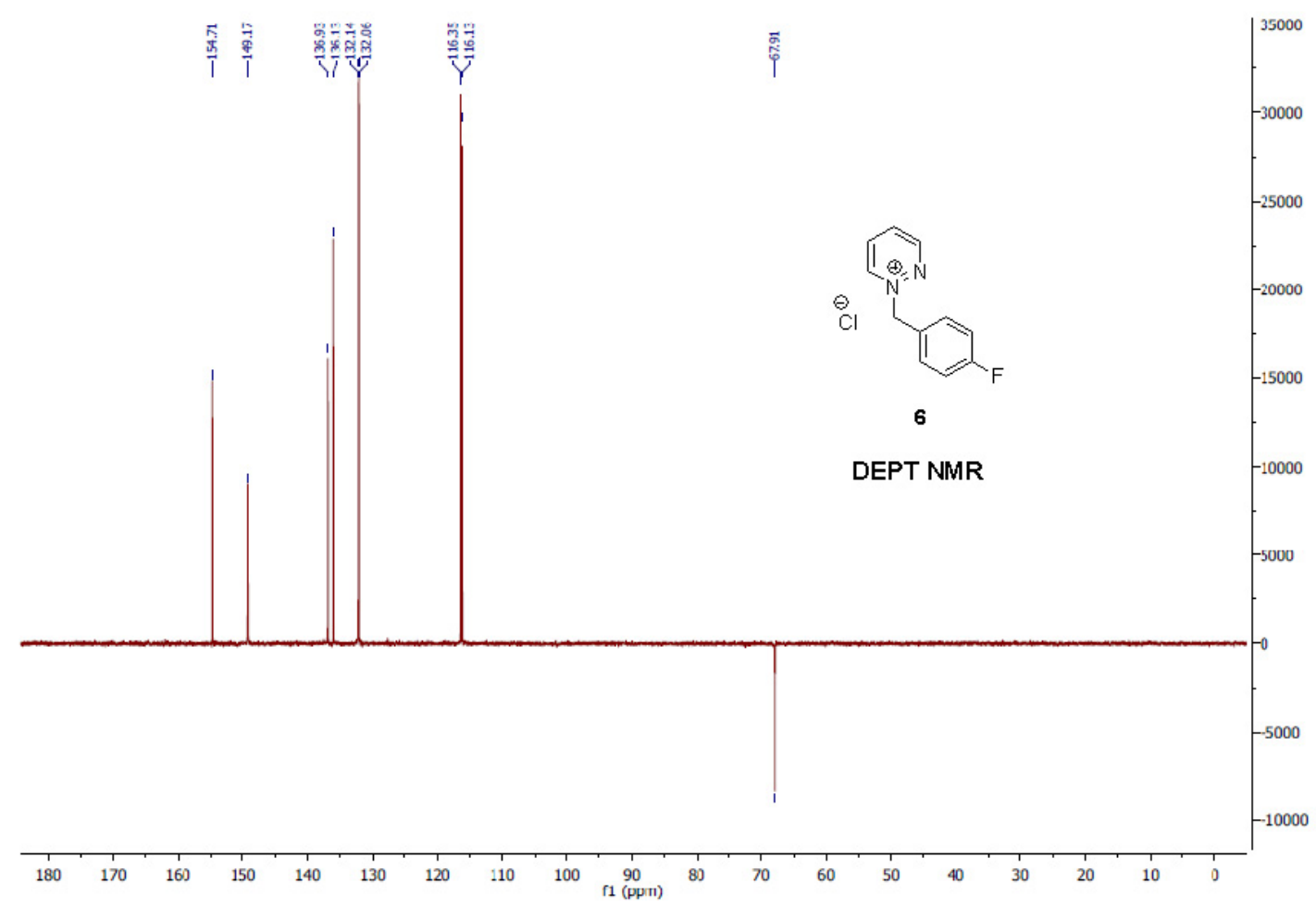

S6: DEPT- 135 NMR spectrum of IL 6 in $D_{2} O(100 \mathrm{MHz})$ 


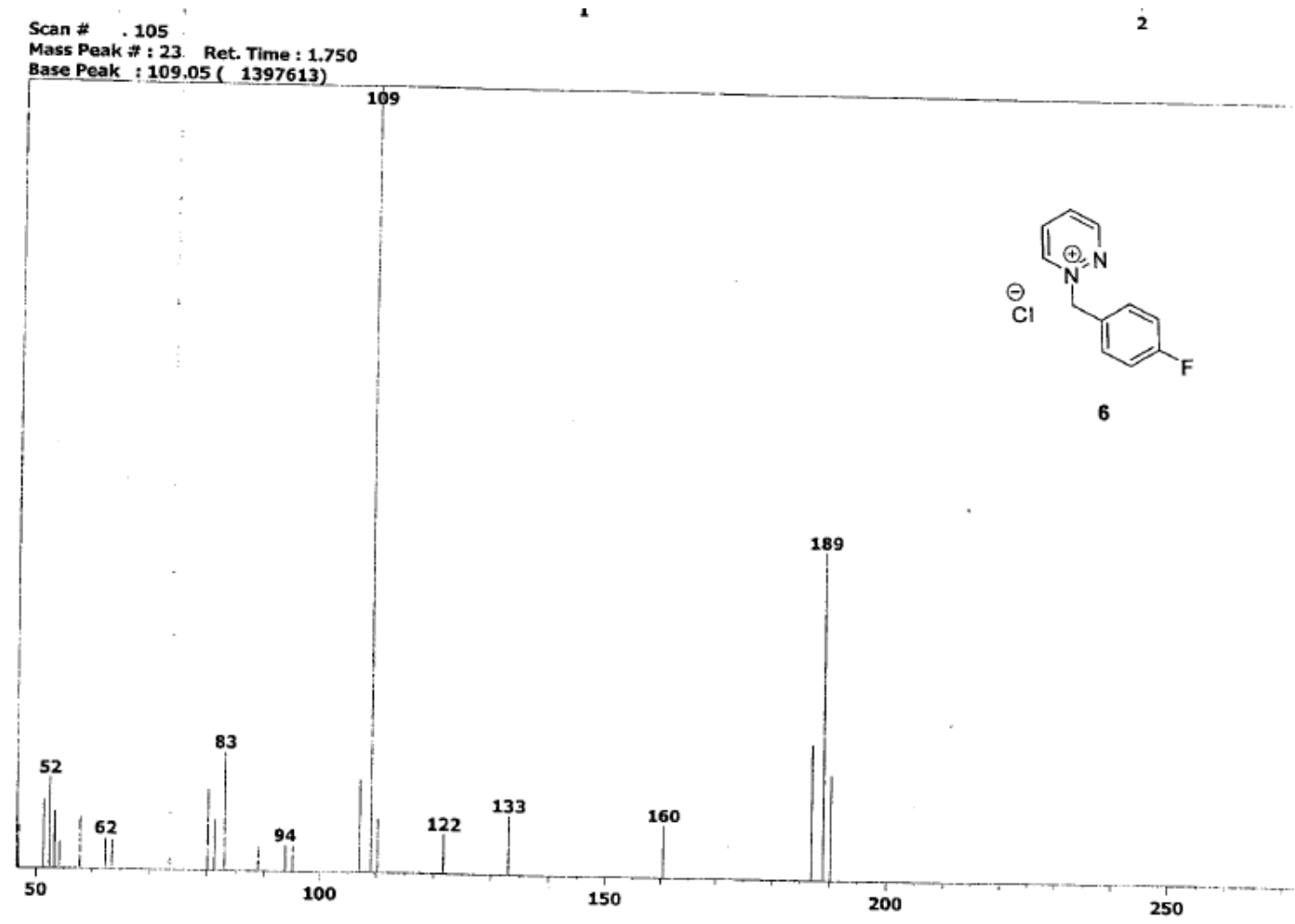

S6: (LCMS) Mass spectrum of IL 6

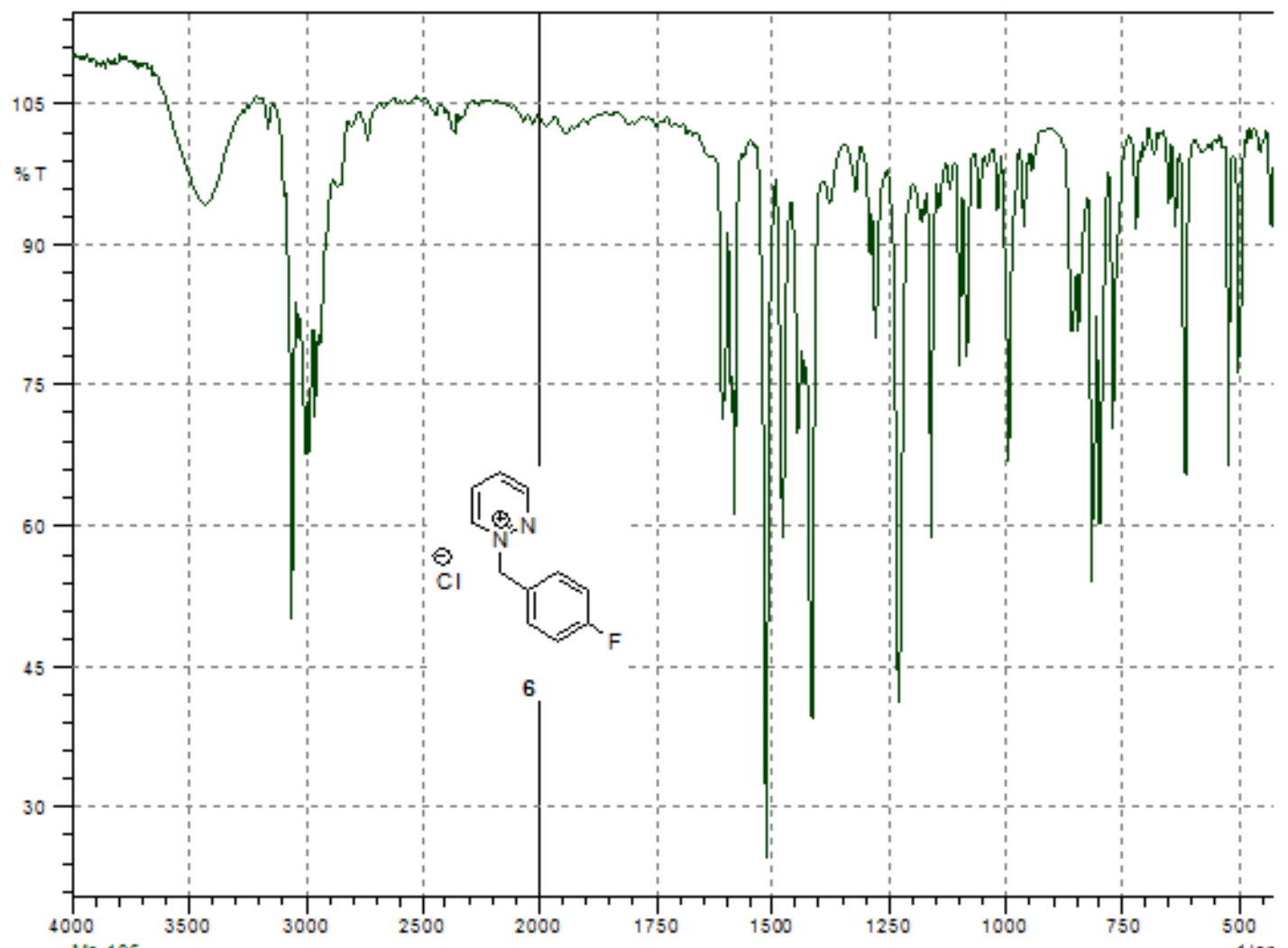

S6: IR spectrum of IL 6 


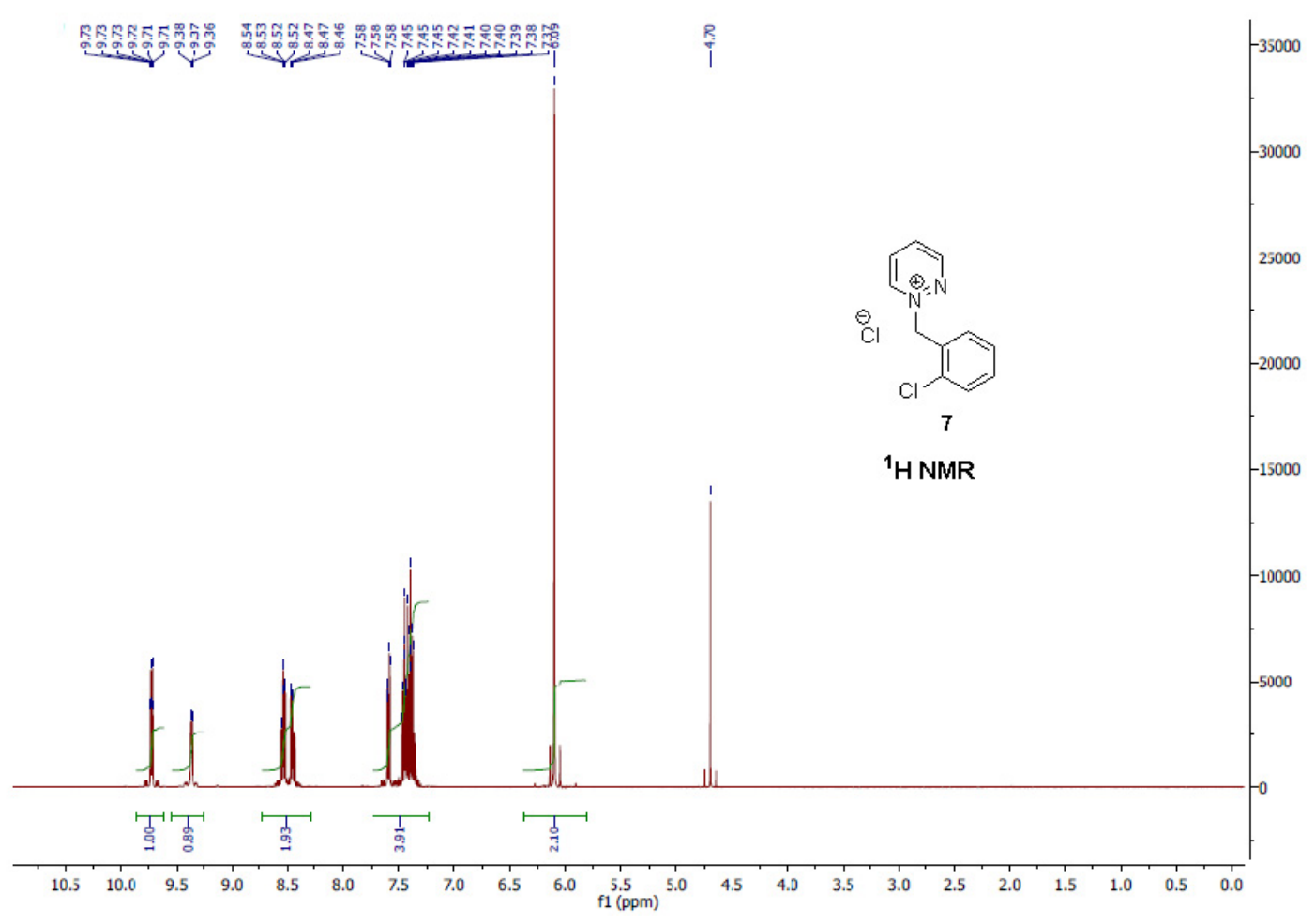

S7: ${ }^{1} \mathrm{H}$ NMR spectrum of IL 7 in $\mathrm{D}_{2} \mathrm{O}(400 \mathrm{MHz})$

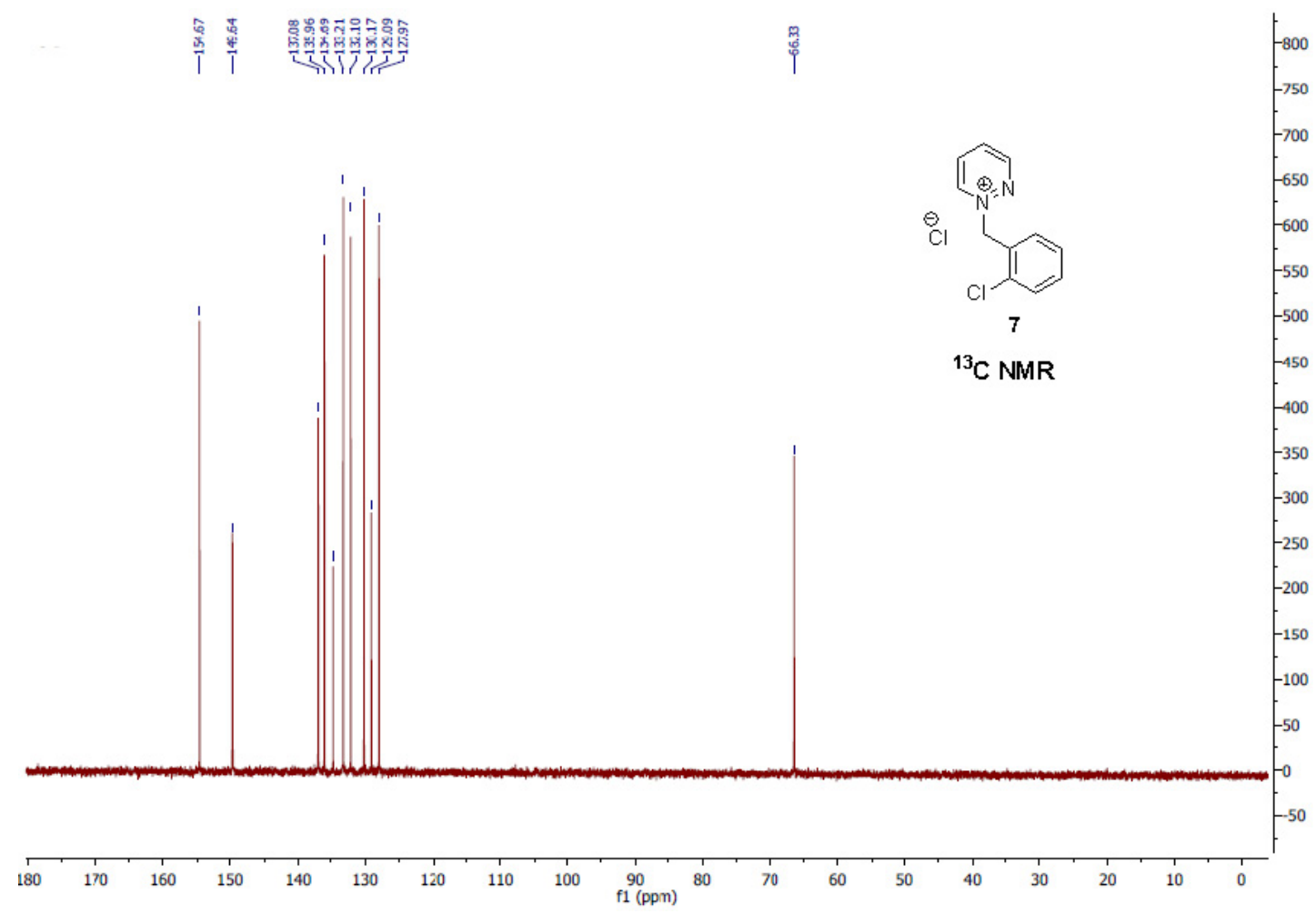

S7: ${ }^{13} \mathrm{C}$ NMR spectrum of IL 7 in $\mathrm{D}_{2} \mathrm{O}(100 \mathrm{MHz})$ 


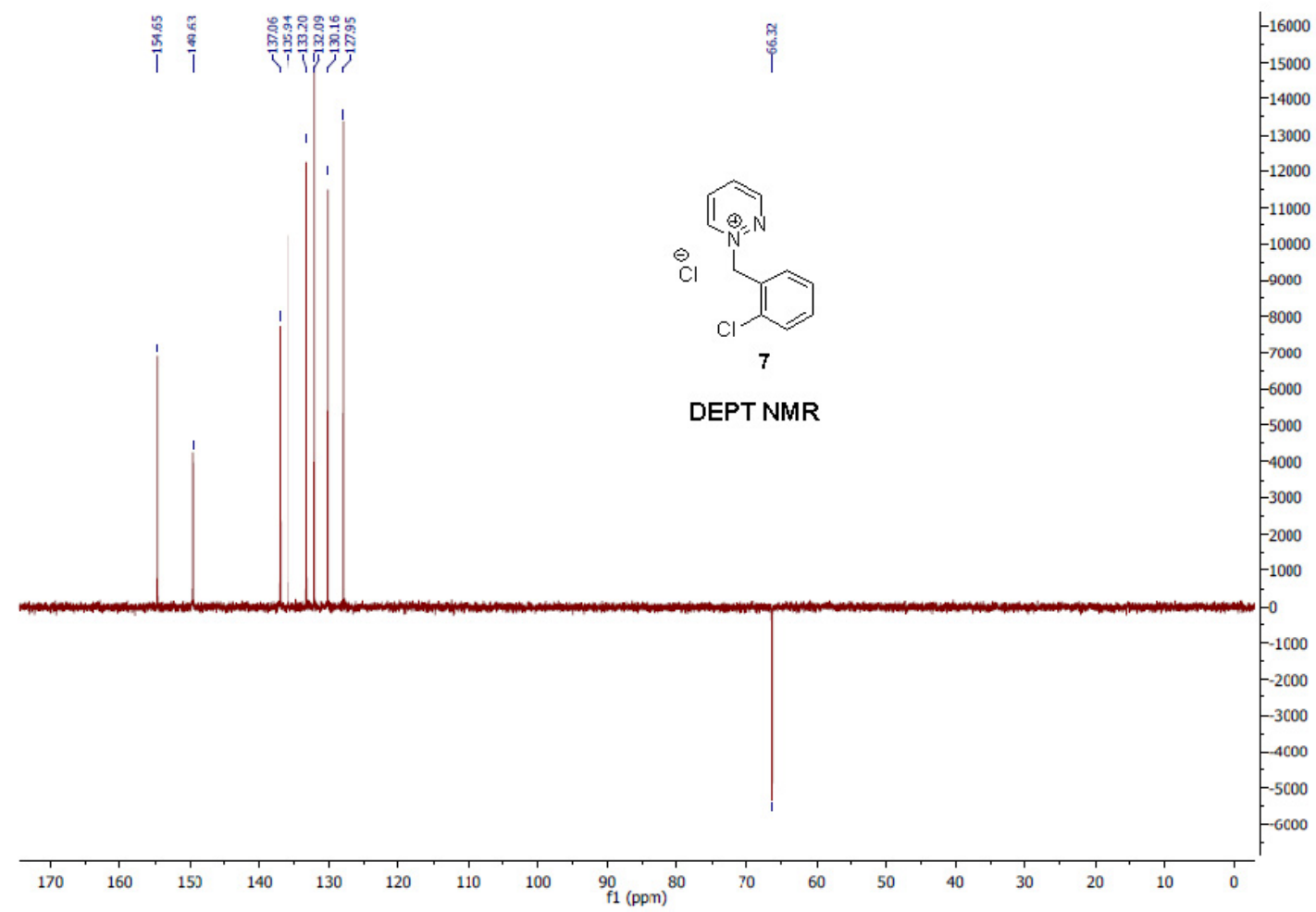

S7: DEPT- 135 NMR spectrum of IL 7 in $D_{2} O(100 \mathrm{MHz})$

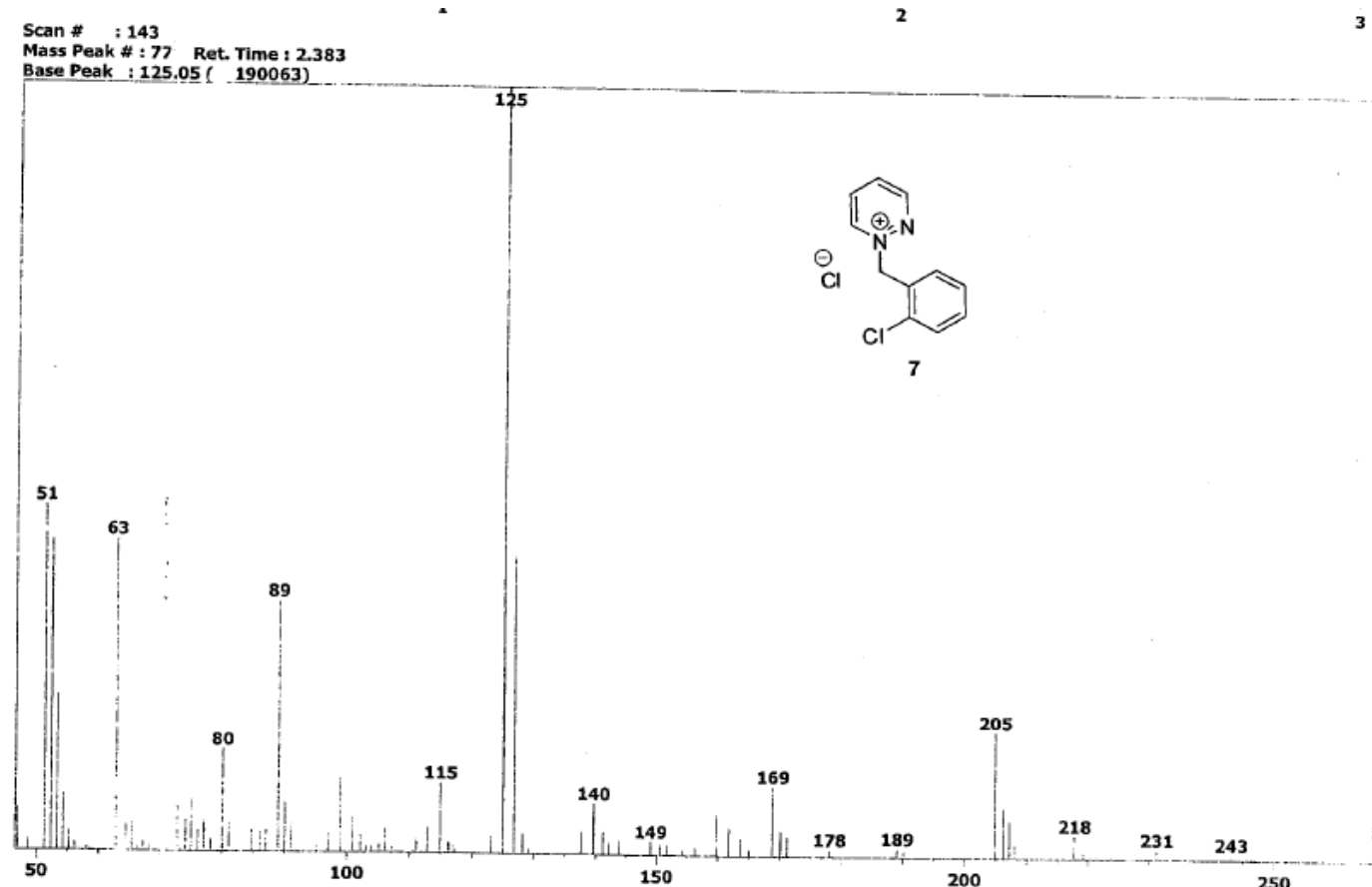

S7: (LCMS) Mass spectrum of IL 7 


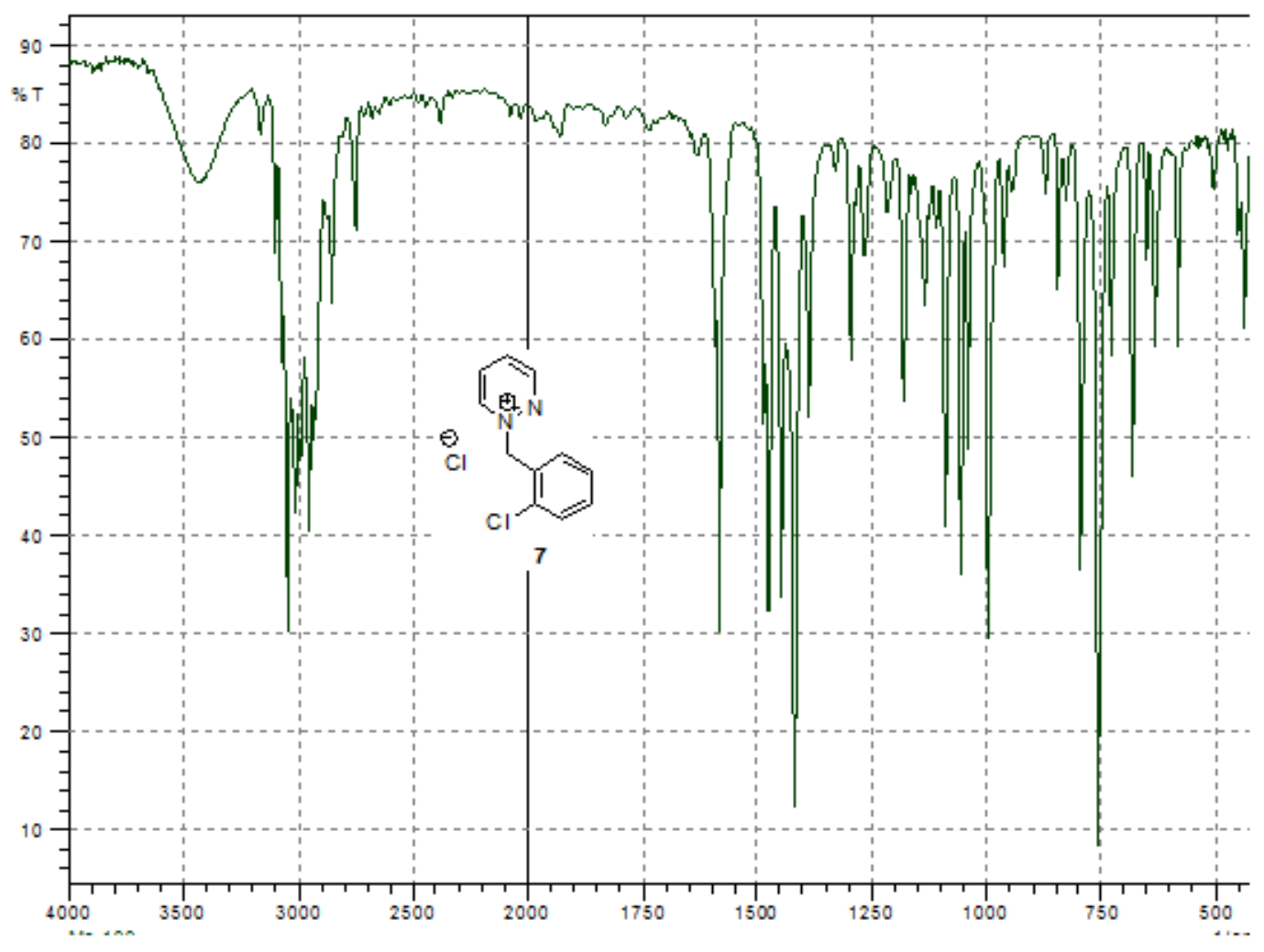

S7: IR spectrum of IL 7

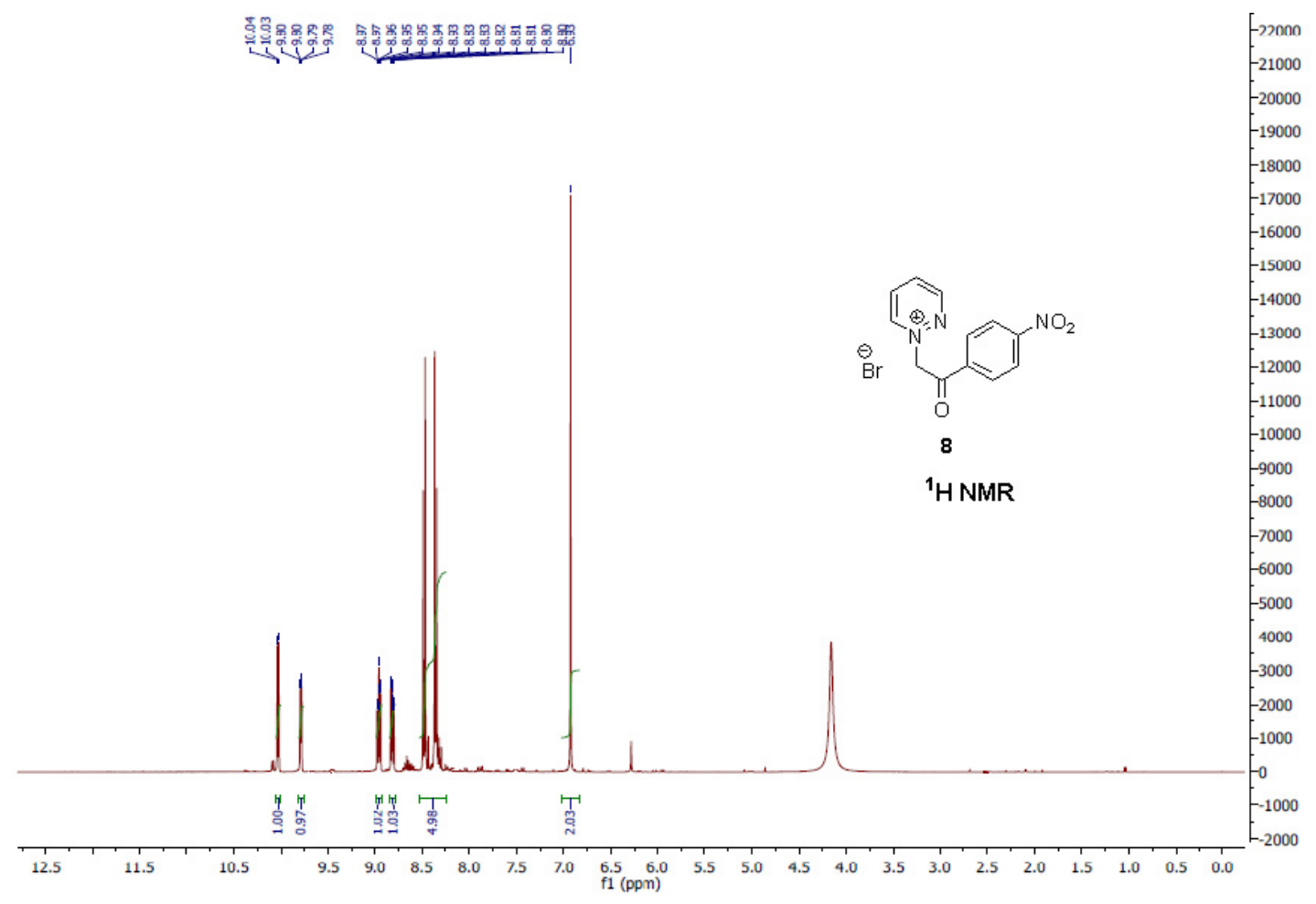

S8: ${ }^{1} \mathrm{H}$ NMR spectrum of IL 8 in DMSO (400 MHz) 


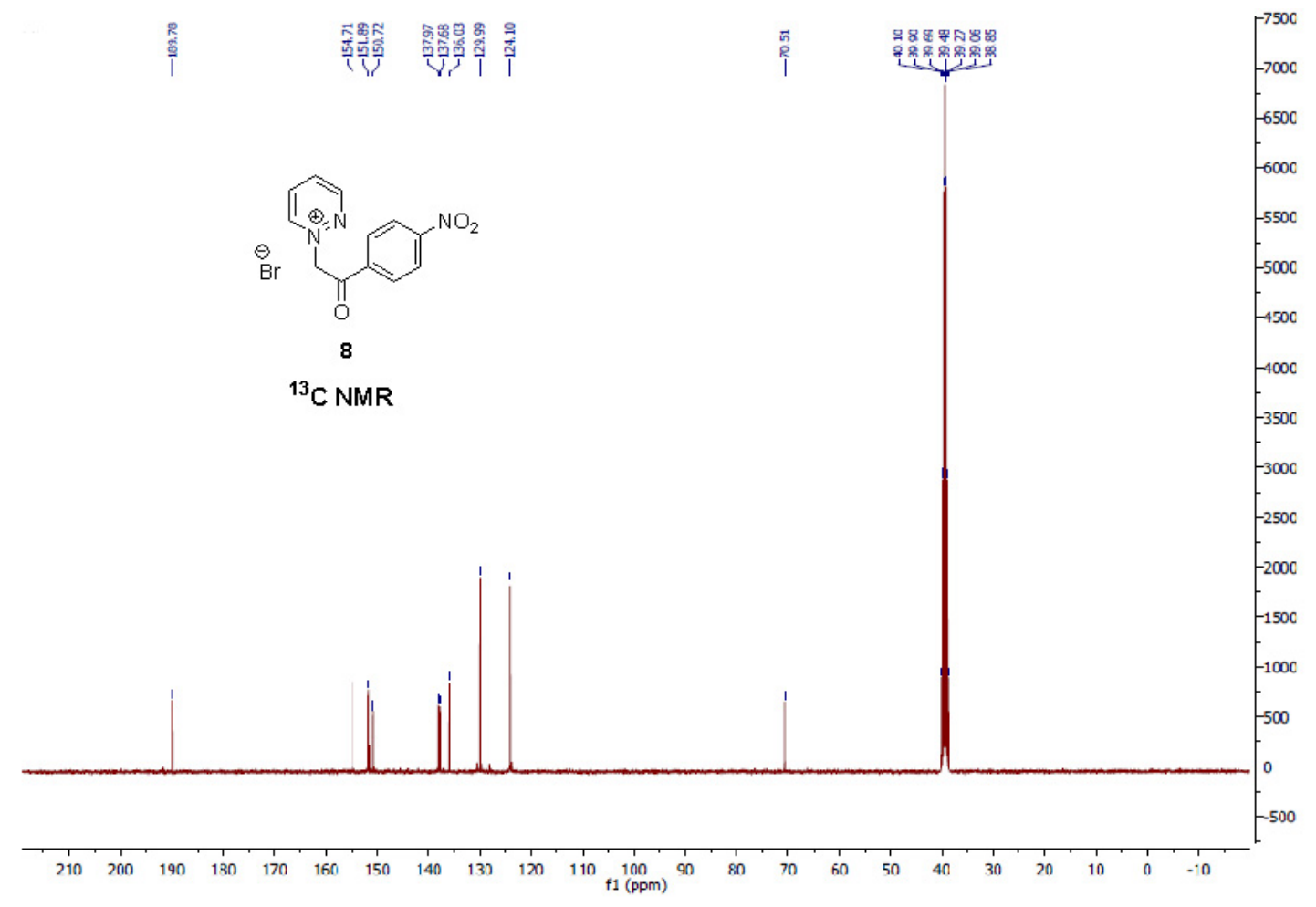

S8: ${ }^{13} \mathrm{C}$ NMR spectrum of IL 8 in DMSO (100 MHz)

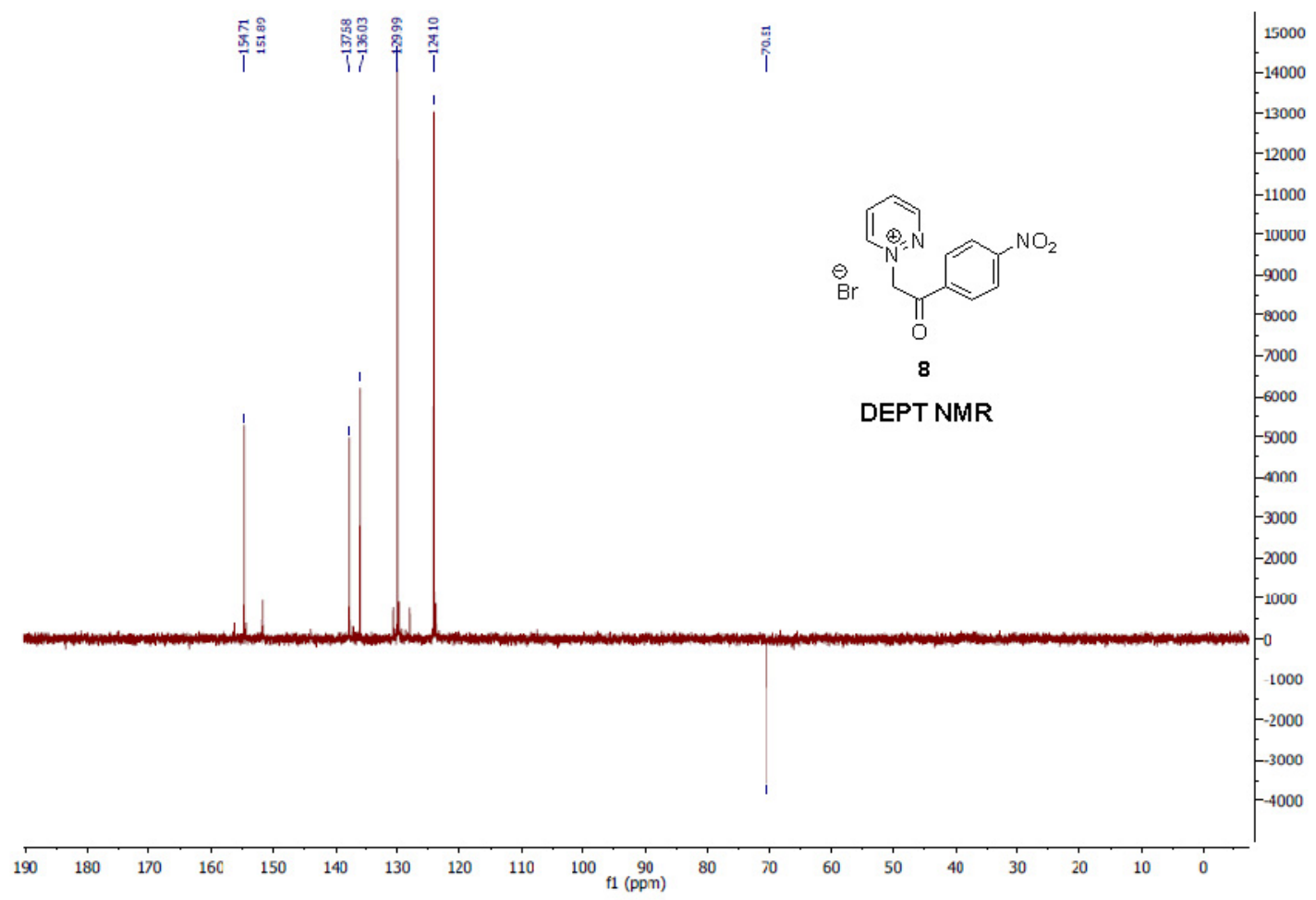

S8: DEPT- 135 NMR spectrum of IL 8 in DMSO (100 MHz) 
Mass Peak \# : 50 Ret. Time : 3.050

Base Peak : 92.90 (.912772)

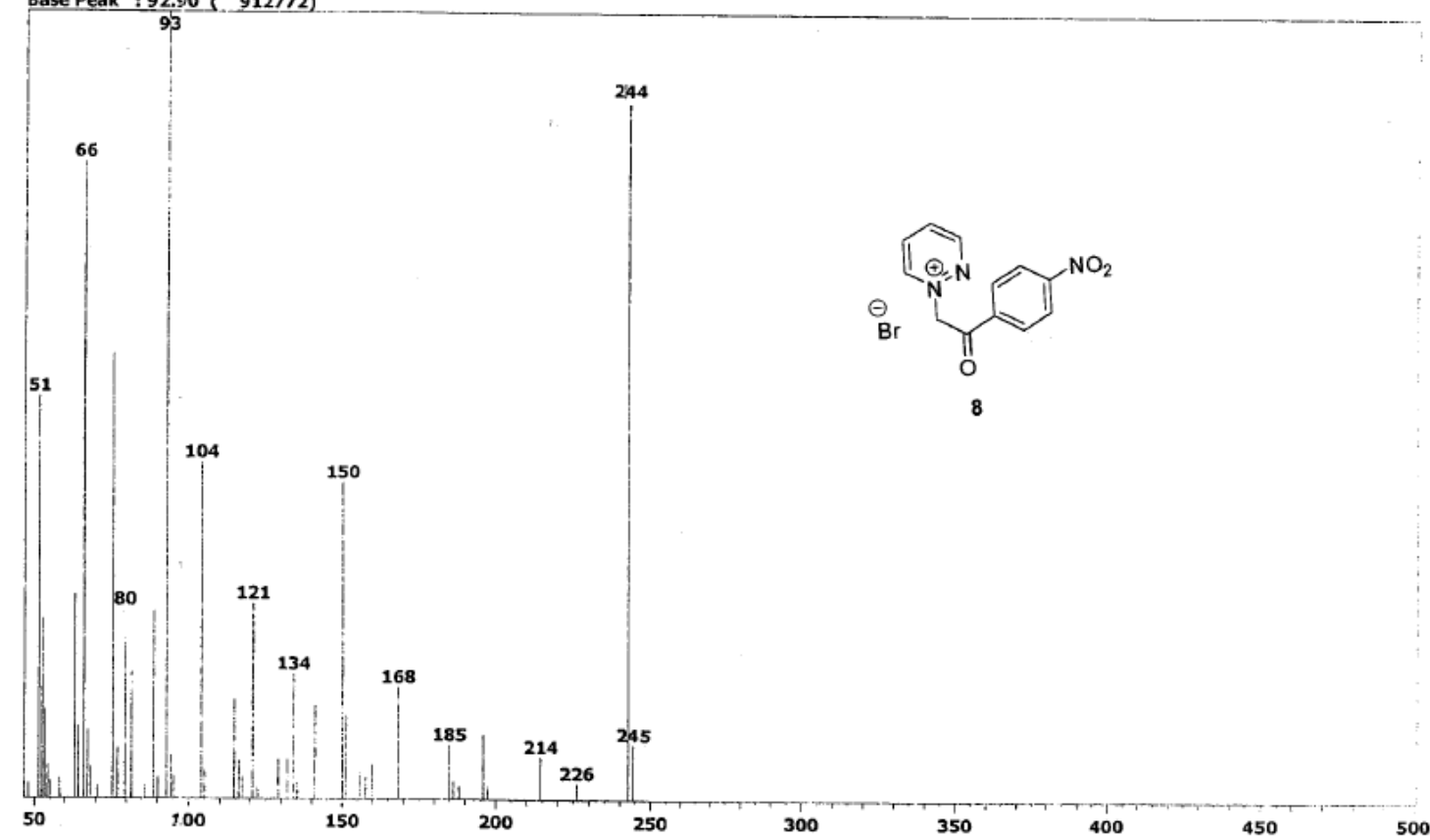

S8: (LCMS) Mass spectrum of IL 8

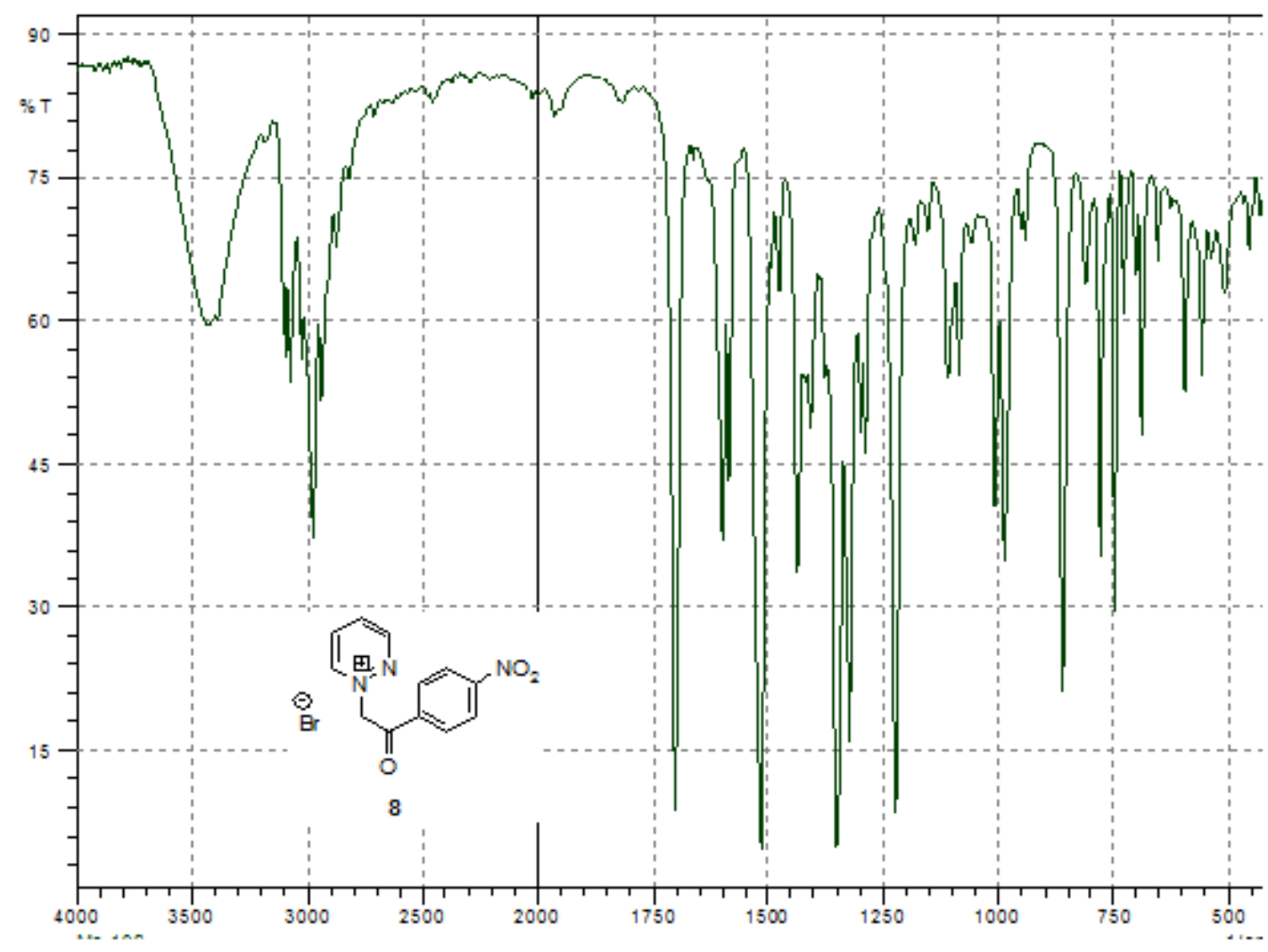

S8: IR spectrum of IL 8 